\title{
Advances in the Design of Heterogeneous Catalysts and Thermocatalytic Processes for $\mathrm{CO}_{2}$ Utilization
}

\author{
Sudipta De, Abhay Dokania, Adrian Ramirez and Jorge Gascon* \\ KAUST Catalysis Center (KCC), King Abdullah University of Science and Technology, Thuwal 23955, \\ Saudi Arabia \\ *Correspondence to: jorge.gascon@kaust.edu.sa
}

\begin{abstract}
Utilization of $\mathrm{CO}_{2}$ as feedstock to produce fine chemicals and renewable fuels is a highly promising field, which presents unique challenges in its implementation at scale. Heterogeneous catalysis with its simple operation and industrial compatibility can be an effective means of achieving this challenging task. This review summarizes the current developments in heterogeneous thermal catalysis for the production of carbon monoxide, alcohols and hydrocarbons from $\mathrm{CO}_{2}$. A detailed discussion is provided regarding structure-activity correlations between catalyst surface and intermediate species which can aid in rational design of future generation catalysts. Effects of active metal components, catalyst supports, and promoters are discussed in each section, which will guide researchers to synthesize new catalysts with improved selectivity and stability. Additionally, a brief overview regarding process design considerations has been provided. Future research directions are proposed with special emphasis on the application scope of new catalytic materials and possible approaches of increasing catalyst performance.
\end{abstract}

KEYWORDS: $\mathrm{CO}_{2}$ utilization, Heterogeneous catalysis, Methanol, Hydrocarbons, Multifunctional catalysts, Cascade reactions, Reactor engineering 


\section{INTRODUCTION}

The combined effect of increasing global population, economic development, and higher standards of living has raised the global energy demand rapidly. In this scenario, it is imperative that the dependence on fossil fuels is diminished not only because of their limited reserves but especially because of the fact that their use has led to an alarming increase in $\mathrm{CO}_{2}$ levels worldwide. The global $\mathrm{CO}_{2}$ emissions in 2018 were approximately $33.9 \mathrm{Gt}^{1}$

\subsection{Need for Catalyst Design - Impact on Climate Change}

It is now a well-established fact that the high atmospheric $\mathrm{CO}_{2}$ levels are irrevocably linked to climate change. In order to mitigate further carbon emissions, a transition to renewable, non-carbon based energy sources is essential. However, given the current state of the art, we are still at least a few decades away from such a transition and thus we would still be largely dependent on fossil fuels for that period. This dependence would lead to some unavoidable emissions that would need to be captured in order to ensure that we do not go beyond the point of no return (i.e. increase of the average global temperature above 2 ${ }^{\circ} \mathrm{C}$ as compared to pre-industrial levels also known as the " 2 degree scenario" or 2DS). However, an extensive debate is going on worldwide about what to do with the captured $\mathrm{CO}_{2}$ since the quantity captured would not be trivial (in the order of hundreds of Gt).

Currently, two schools of thought exist regarding the post-capture application of $\mathrm{CO}_{2}$. These consist of Carbon Capture and Storage (CCS) and Carbon Capture and Utilization (CCU). On a surface level, $\mathrm{CCU}$ presents itself as an elegant solution - mitigating $\mathrm{CO}_{2}$ emissions while making useful products out of it. However, Mac Dowell et al. point out that, even if $\mathrm{CO}_{2}$ were to be used as the sole feedstock for the production of the world's most demanded chemicals, the impact on overall emissions in terms of volume would still be minimal. ${ }^{2}$ In contrast, CCS has the potential to cause an appreciable impact on global emissions. This report does not however take into account the possibility of production of fuels from $\mathrm{CO}_{2}$ (resulting in $\mathrm{CO}_{2}$ neutral fuels). A term gaining rapid popularity in the discussion surrounding $\mathrm{CO}_{2}$ utilization is about the possibility to bring about a 'Circular Carbon Economy'. This term encompasses the concept of 'avoiding' new $\mathrm{CO}_{2}$ emissions from fossil sources by recycling the existing $\mathrm{CO}_{2}$ into chemicals and fuels. In this way, we can eschew a significant overhaul of the energy infrastructure while at the same time circumventing additional $\mathrm{CO}_{2}$ emissions. In order for this concept to be put to actual practice, either of two possible approaches (or most likely, a combination of them) would need to be employed concerning $\mathrm{CO}_{2}$ capture.

The first approach is 'Direct Air Capture' (DAC) where, as the name suggests, $\mathrm{CO}_{2}$ is directly captured from the atmosphere and either stored or put into use. This approach is attractive as it offers the possibility of putting a capture station wherever required and would not need the implementation of point sources of capture (i.e., capture systems at points of emission including vehicles, factories and power plants). A significant drawback to this approach is the very low concentration of $\mathrm{CO}_{2}(\sim 400 \mathrm{ppm})$ in the atmosphere which provides a severe impediment with respect to the thermodynamics of the capture process. ${ }^{3}$ Therefore, considerable advances in systems and engineering would be required before this process can be deployed at scale.

The second approach is to implement $\mathrm{CO}_{2}$ capture systems at point sources of emission. This is

more feasible to carry out as e.g. $\mathrm{CO}_{2}$ containing effluent streams from industry or power plants usually 
consist of $3-35 \%$ of $\mathrm{CO}_{2}$ making it possible to capture it with relative efficiency. ${ }^{4}$ A disadvantage to this approach is that while point sources of capture are possible at large scale installations like industrial plants or power generation facilities, it is much more difficult to implement at smaller sources of emission like vehicles. The road transportation sector accounts for approximately $16 \%$ of total $\mathrm{CO}_{2}$ emissions and thus it is important to implement a system to curb the emissions from this sector. ${ }^{5}$ Another possible drawback of this system could be the lack of available transport and storage infrastructure (e.g., underground reservoirs) close to a source of emission such as a power plant. In order to overcome this second drawback, a proper distributed network of $\mathrm{CO}_{2}$ pipelines would need to be established in order to ensure appropriate transport of the captured $\mathrm{CO}_{2}$ to adequate storage facilities.

Having defined the concept of a circular carbon economy and the requirements regarding $\mathrm{CO}_{2}$ capture for its implementation, we next try to quantify the potential $\mathrm{CO}_{2}$ that can be avoided if it is fully utilized for the production of chemicals and fuels (Table 1). Multiple works have been published which highlight the possibility of the production of liquid fuel from $\mathrm{CO}_{2}{ }^{6,7}$ Similarly, the production of methane (which is the majority component of natural gas) has also been demonstrated via $\mathrm{CO}_{2}{ }^{8}$ The fuel consumption (and the corresponding market size) is many times bigger than that of the chemical market in terms of volume. For instance, the global consumption in 2017 of oil and natural gas was approximately 4.6 and $3.1 \mathrm{Gt}$ of oil equivalent respectively. ${ }^{1}$ Approximately, 20 gallons of gasoline are produced per barrel of crude oil and thus, if the only liquid fuel to be produced from $\mathrm{CO}_{2}$ was to be gasoline, it would already account for a massive reduction of $\mathrm{CO}_{2}$ emissions. ${ }^{9}$ As stated earlier, chemical production from $\mathrm{CO}_{2}$ will have a relatively minor role to play in terms of volume for $\mathrm{CO}_{2}$ emission reduction but it cannot be discounted due to the potential economic benefits and especially since the demand for these chemicals keeps on increasing every year. The vast majority of carbon-based chemicals most used globally is derived from fossil fuel sources and are thus termed petrochemicals. The most demanded petrochemicals include ethylene, propylene, benzene, methanol, toluene and xylenes. ${ }^{10}$ Table 1 provides an overview of potential $\mathrm{CO}_{2}$ avoided if all the demand for these chemicals was fulfilled via production from $\mathrm{CO}_{2}$.

Table 1. Potential $\mathrm{CO}_{2}$ avoided in the circular carbon economy scenario

\begin{tabular}{|c|c|c|c|c|}
\hline Entry & Product & ton $_{\mathrm{CO} 2} /$ unit pdt. $^{a}$ & 2017 Global Demand & $\begin{array}{l}\text { Potential } \mathrm{CO}_{2} \\
\text { avoided }(\mathrm{mmt})\end{array}$ \\
\hline \multicolumn{5}{|l|}{ Fuels } \\
\hline 1 & Gasoline & $0.009^{\mathrm{b}}$ & $6.75 \times 10^{11}$ gallons $^{1}$ & $\sim 6000$ \\
\hline 2 & Natural Gas & $0.0549^{\mathrm{b}}$ & $1.27 \times 10^{11} \mathrm{mcf}^{d 1}$ & $\sim 7000$ \\
\hline \multicolumn{5}{|c|}{ Chemicals } \\
\hline 1 & Ethylene & $3.1 \times 10^{6 c}$ & $152 \mathrm{mmt}^{e} 11$ & 477 \\
\hline 2 & Propylene & $3.1 \times 10^{6 c}$ & $102 \mathrm{mmt}^{11}$ & 320 \\
\hline 3 & Methanol & $1.4 \times 10^{6 \mathrm{c}}$ & $135 \mathrm{mmt}^{11}$ & 185 \\
\hline 4 & Benzene & $3.4 \times 10^{6 c}$ & $46 \mathrm{mmt}^{11}$ & 155 \\
\hline \multirow[t]{2}{*}{6} & Paraxylene & $3.3 \times 10^{6 \mathrm{c}}$ & $41 \mathrm{mmt}^{11}$ & 136 \\
\hline & & & Total & 14273 \\
\hline \multicolumn{5}{|c|}{$\begin{array}{l}\text { Global Demand' column. }{ }^{b} \text { Value taken from ref }{ }^{12},{ }^{c} \text { based on carbon number equivalency } \\
\text { i.e. } 1 \text { mol of ethylene contains } 2 \text { moles of } \mathrm{C} \text { and thus } 2 \text { moles of } \mathrm{CO}_{2} \text { can be used to make } 1 \\
\text { mol of ethylene. }{ }^{d} \mathrm{mcf}=\text { thousand cubic feet, }{ }^{e} \mathrm{mmt}=\text { million metric tons. }\end{array}$} \\
\hline
\end{tabular}


From the values in Table 1, we see that it is possible to reuse around $14.2 \mathrm{Gt}$ of $\mathrm{CO}_{2}$ from the, for instance, $33.9 \mathrm{Gt}$ of $\mathrm{CO}_{2}$ emitted in 2018. This number is of course a very crude estimate as demands for these products can (and will) vary significantly at different points in time so this number can be significantly higher or lower depending on the degree of implementation of $\mathrm{CO}_{2}$ utilization worldwide. Another factor to consider is the relative climate benefits of different uses of $\mathrm{CO}_{2}$. For instance, $\mathrm{CO}_{2}$ can also be used in the production of building materials (not considered in this review) and this use is considered to have a high climate benefit as the $\mathrm{CO}_{2}$ thus used can be considered sequestered for the long term if not permanently. ${ }^{13}$ Figure 1 provides a relative estimate of climate benefits and potential level of $\mathrm{CO}_{2}$ utilization for various products. ${ }^{13}$

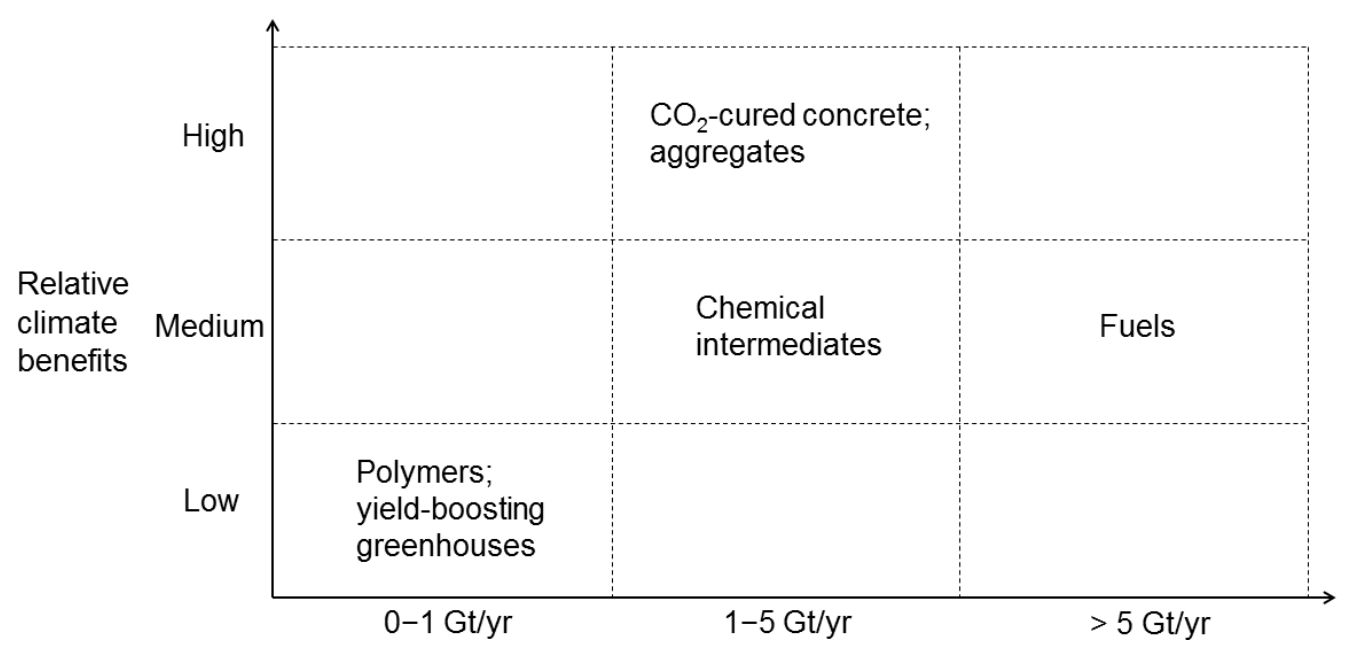

Figure 1. Relative climate benefits and potential for $\mathrm{CO}_{2}$ utilization of different products. Adapted from ref. 13.

Nevertheless, if $14.2 \mathrm{Gt}$ of $\mathrm{CO}_{2}$ can be potentially endlessly recycled to make certain chemicals and fuels, we still need to consider the disposal of the remaining $19.7 \mathrm{Gt}$ of $\mathrm{CO}_{2}$ (assuming $33.9 \mathrm{Gt}$ of annual emission in 2018 as mentioned above). This, inevitably, would need to be carried out via CCS. However, one factor that is often not taken into account when making these estimates is the natural role of land and/or sea acting as $\mathrm{CO}_{2}$ sinks. It has been estimated that approximately $25 \%$ of anthropogenic $\mathrm{CO}_{2}$ emissions is reabsorbed by the oceans and another $25 \%$ is reabsorbed by terrestrial land sinks. ${ }^{14,15}$ This would then imply that only half of the global $\mathrm{CO}_{2}$ emissions would need to be addressed (i.e. $\sim 17 \mathrm{Gt}$ ). If $14.2 \mathrm{Gt}$ can be reused, then it implies that only $2.8 \mathrm{Gt}$ of $\mathrm{CO}_{2}$ would need to be disposed of via man made CCS. However, there are a number of drawbacks of considering this approach. The first drawback that is immediately apparent is that while both aquatic and terrestrial sinks can absorb approximately half of the current $\mathrm{CO}_{2}$ emissions, this capacity would slowly deteriorate and thus, we cannot rely on it indefinitely. A second, more serious, drawback is that $\mathrm{CO}_{2}$ absorption by the oceans is leading to their acidification causing significant ecological damage. Thus, in effect, we would also have to account for the $25 \%$ of emissions that are absorbed by the oceans with manmade CCS installations.

In summary, considering $33.9 \mathrm{Gt}$ of $\mathrm{CO}_{2}$ emissions, about $14.2 \mathrm{Gt}$ of $\mathrm{CO}_{2}$ could be reused, about $8.5 \mathrm{Gt}$ can be accounted for by natural terrestrial carbon sinks and the remaining $11.2 \mathrm{Gt}$ of $\mathrm{CO}_{2}$ would have to be sequestered via CCS. As before, these numbers are very crude estimates and can vary significantly depending on a number of geographic, political and socioeconomic factors. Finally, it has to 
be mentioned that successful application of $\mathrm{CCU}$ is contingent upon the availability of cheap, renewable $\mathrm{H}_{2}$. The production of fuels and/or chemicals from $\mathrm{CO}_{2}$ is possible by carrying out $\mathrm{CO}_{2}$ hydrogenation. While $\mathrm{H}_{2}$ itself can act as a clean source of energy, it is of course quite difficult to empower a $\mathrm{H}_{2}$ supply chain and distribution system due to its high flammability and the fact that it is quite tricky and expensive to compress it to a sufficient degree in order to enable transport in pressurized containers. Currently, cheap $\mathrm{H}_{2}$ comes from fossil sources (e.g., steam reforming of methane) which is carbon intensive since $\mathrm{CO} / \mathrm{CO}_{2}$ are side products (unless it is coupled with CCS). A non-carbon intensive approach for $\mathrm{H}_{2}$ production is water electrolysis. However, this is a much more expensive endeavor as the $\mathrm{H}_{2}$ produced via this approach is 3-4 times more expensive than $\mathrm{H}_{2}$ produced from fossil sources. ${ }^{16}$ In the latter case, the source of energy used to carry out the electrolysis is also important. If the electricity used is generated from fossil sources, then the net process is once again carbon intensive. Thus, $\mathrm{H}_{2}$ would need to be produced in an economic manner via water electrolysis using clean and/or renewable energy (e.g., wind, solar, nuclear etc.) before it can be utilized towards CCU.

Based on the earlier discussion, it is evident that there is no single panacea for controlling $\mathrm{CO}_{2}$ emissions and an innovative integration of approaches needs to be adopted to ensure that we can meet the 2DS goals. One such innovative approach has been proposed by Dittmeyer et al. ${ }^{17}$ They recommend the retrofitting of air-conditioning units as devices capable of producing fuels that can enable energy democratization and reduce dependence on crude oil. It can thus be argued that if the production of renewable energy can be scaled enough to empower (i) DAC and (ii) water electrolysis, we can be well on our way to solve the climate crisis. This is because the huge problem of the intermittent nature of renewable energy (i.e. wind and/or solar) can be solved by storing this energy in the form of carbon fuels made from the captured $\mathrm{CO}_{2}$ and the $\mathrm{H}_{2}$ generated via electrolysis. Since the carbon emitted from these fuels could be recycled, we would arrive at a state of net zero emissions. An added incentive that would make this approach attractive is of course the fact that most of the existing energy infrastructure can remain in use thus avoiding the capital costs associated with developing new infrastructure.

In this frame, it is evident that CCU can make a significant contribution towards the mitigation of new carbon emissions and play an important role when used in conjunction with other approaches. One of the most important factors for effective implementation of CCU is proper catalyst design. Assuming that cheap, plentiful $\mathrm{H}_{2}$ is available, the correct catalyst would have to be employed in order to ensure an economically viable process. In fact, one of the aspects of CCU catalyst design would be to ensure efficient utilization of $\mathrm{H}_{2}$ in order to improve the process sustainability. Therefore, a careful, rational approach is required for designing such a catalyst as multiple challenges abound for $\mathrm{CO}_{2}$ conversion.

\subsection{Need for Catalyst Design - Challenges in $\mathrm{CO}_{2}$ Conversion}

Despite the high abundance of $\mathrm{CO}_{2}$ in nature, the main challenge in its catalytic conversion is associated with the inertness of this molecule. The crucial task is therefore to find active, selective and stable catalysts as well as to gain a proper understanding of the reactivity of $\mathrm{CO}_{2}$ in different catalytic environments. Along this line, homogeneous catalysts such as different transition metal complexes, $N$ heterocyclic carbenes (NHCs), and frustrated Lewis pairs have shown high activity for $\mathrm{CO}_{2}$ activation under milder reactions. ${ }^{18-23}$ However, the current industrial infrastructure is not suitable for the production of a large volume of chemicals and fuels over homogeneous catalysts due to complications regarding separation of catalyst from products and poor process economy. More importantly, the total production 
over homogeneous catalysts cannot fulfil the current worldwide demand of renewable products. Therefore, significant focus has been turned to using heterogeneous catalysts, which are expected to offer better process economy and meet the targeted production limit. ${ }^{24-28}$ A representative example is the "George Olah Renewable Methanol Plant" in Iceland, the first commercial $\mathrm{CO}_{2}$ to methanol recycling plant established in 2012, which started with an initial annual production capacity of $4500 \mathrm{~m}^{3}$ of methanol (10 ton per day) recycling $~ 5600$ tons of $\mathrm{CO}_{2}$ per annum. ${ }^{29}$ The plant is currently run by the Carbon Recycling International (CRI) company and the required $\mathrm{H}_{2}$ is produced by water electrolysis using cheap, geothermally produced electricity. The required energy for $\mathrm{CO}_{2}$ conversion is also obtained from the readily available local geothermal energy sources. Therefore, this project has been demonstrated as being quite successful in terms of economical utilization of $\mathrm{CO}_{2}$ captured from flue gases with minimum adverse effects on the environment.

Current efforts made in heterogeneous catalysis for $\mathrm{CO}_{2}$ conversion mainly focus on the electrochemical and thermal reduction of $\mathrm{CO}_{2}{ }^{30,} 31$ Apart from these two approaches, photochemical reduction is another alternative strategy for $\mathrm{CO}_{2}$ transformation, ${ }^{32-34}$ but the maximum efficiency achieved till date is much lower than the targeted production. So far, the electrochemical reduction approach has been operated on a small scale, which is more suitable for limited $\mathrm{CO}_{2}$ conversion and fine chemical production. The main advantage of electrocatalytic $\mathrm{CO}_{2}$ reduction is that the required $\mathrm{H}_{2}$ comes from water, which is beneficial compared to thermal reduction considering that pressurized molecular $\mathrm{H}_{2}$ is required in the latter case. However, the Faradic efficiency of the electrocatalytic $\mathrm{CO}_{2}$ reduction process is significantly lower as compared to the $\mathrm{H}_{2}$ evolution rate, and thus it limits its application in large scale production. A number of excellent reviews have recently been published on the efforts made in the field of electrocatalytic $\mathrm{CO}_{2}$ conversion process and catalyst development. ${ }^{35-37}$

In terms of substrate scope and application, catalytic conversion of $\mathrm{CO}_{2}$ can provide numerous useful products including building block intermediates (such as $\mathrm{CO}$, methane, formic acid, methanol, dimethyl ether, carbonates, lower olefins etc.) and readily usable chemicals/fuels (such as renewable polymers, hydrocarbons etc.). Extensive studies have been done on focusing the production of each chemical, but there seems to be a general consensus in literature that the production of syngas, alcohols and hydrocarbons is the most promising. Thus, this review will focus on the recent development of catalyst design targeting the production of these three products (Figure 2). Special emphasis will be given on rational approaches to identify structure-activity correlations between active sites and different reaction intermediates in order to guide towards the discovery of promising catalysts for specific reactions. 


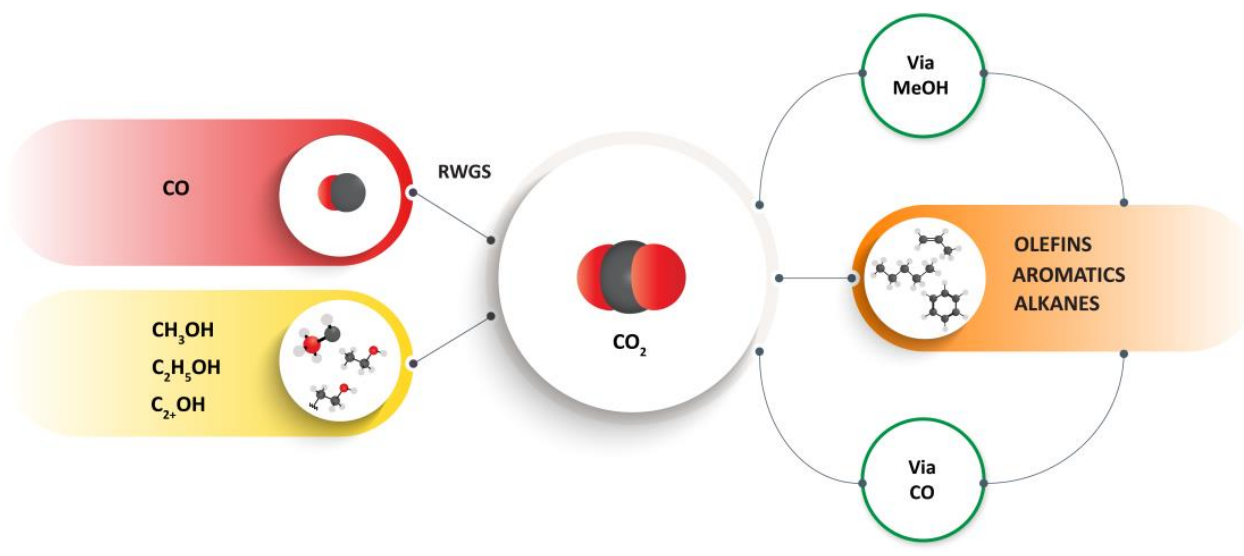

Figure 2. Schematic diagram showing the scope of this review.

\section{ACTIVATION OF CO2: THERMODYNAMIC CONSIDERATIONS}

The highest oxidation state of carbon makes $\mathrm{CO}_{2}$ comparatively inert thereby making its chemical transformations thermodynamically unfavorable. Therefore, using $\mathrm{CO}_{2}$ as a feedstock is challenging and one must consider the relative stability of the final products as compared to $\mathrm{CO}_{2}$. Figure 3 gives an overview of Gibbs free energy of formation $\left(\Delta \mathrm{G}_{\mathrm{f}}^{\mathrm{o}}\right)$ for different carbon-containing molecules, which directly reflects the comparative stability of $\mathrm{CO}_{2}$. Based on energy considerations, $\mathrm{C}-\mathrm{O}$ bonds are relatively stronger than $\mathrm{C}-\mathrm{H}$ bonds, and therefore oxygenated molecules possess higher thermodynamic stability compared to hydrocarbon molecules. As a result, substantial energy is required for carbon reduction in the former case. Another difficulty in the transformation of $\mathrm{CO}_{2}$ is that the final products derived from $\mathrm{CO}_{2}$ are mostly liquid in nature (e.g., formic acid, methanol, higher hydrocarbons). Since these reactions involve a phase change from gaseous reagent into liquid products, they are entropically unfavorable.

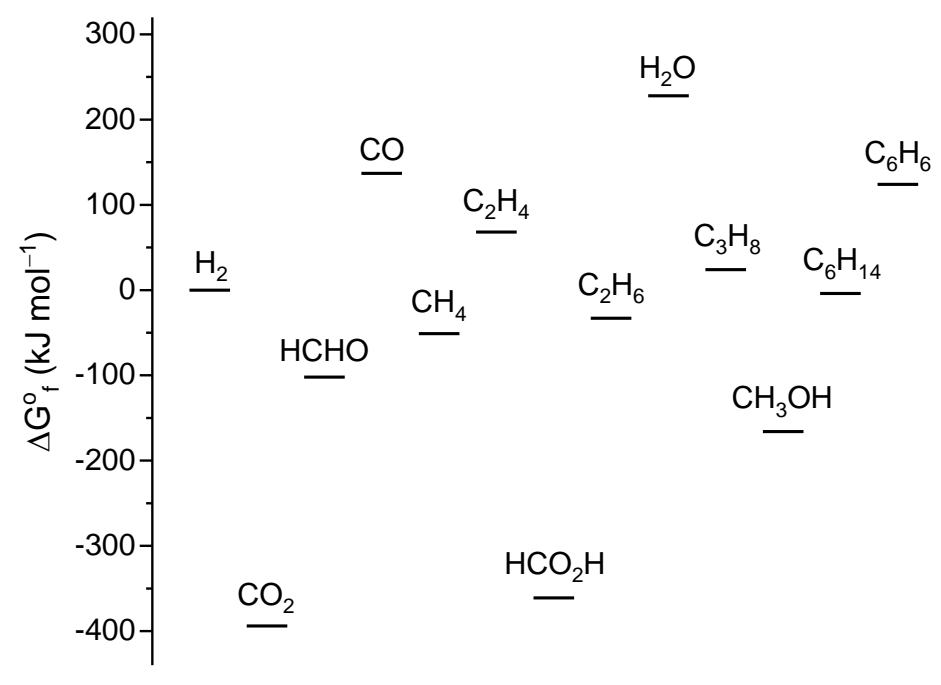

Figure 3. Gibbs free energy of formation $\left(\Delta \mathrm{G}_{\mathrm{f}}^{\mathrm{o}}\right)$ for some carbon compounds at different oxidation states of carbon. $\mathrm{H}_{2}$ and $\mathrm{H}_{2} \mathrm{O}$ are also included as they are frequently involved in the reactions. 
The chemical transformation of $\mathrm{CO}_{2}$ is thermodynamically more favorable when it is used as a co-reactant with another molecule that has a higher Gibbs free energy. For example, production of $\mathrm{CO}$ from $\mathrm{CO}_{2}$ requires much higher energy when $\mathrm{CO}_{2}$ is used as the single reactant, while the presence of $\mathrm{H}_{2}$ significantly reduces the enthalpies of reaction (Equations 1 and 2, Table 2). Therefore, most of its transformations use a second molecule, usually $\mathrm{H}_{2}$, to make useful chemicals and fuels. Another way to make the $\mathrm{CO}_{2}$ transformation more feasible is to use a solvent. For example, the transformation of $\mathrm{CO}_{2}$ into formic acid in gaseous phase is thermodynamically unfavorable (Eq. A), while addition of water makes the reaction slightly exergonic (Eq. B).

$\mathrm{CO}_{2}(\mathrm{~g})+\mathrm{H}_{2}(\mathrm{~g}) \leftrightarrow \mathrm{HCO}_{2} \mathrm{H}(\mathrm{l}) ; \quad \Delta G^{\mathrm{o}}{ }_{298 \mathrm{~K}}=32.9 \mathrm{~kJ} \mathrm{~mol}^{-1}$

$\mathrm{CO}_{2}(\mathrm{aq})+\mathrm{H}_{2}(\mathrm{aq}) \leftrightarrow \mathrm{HCO}_{2} \mathrm{H}(\mathrm{aq}) ; \quad \Delta G^{\mathrm{o}}{ }_{298 \mathrm{~K}}=-4 \mathrm{~kJ} \mathrm{~mol}^{-1}$

Based on the energy requirement, reactions involved in $\mathrm{CO}_{2}$ conversion can be classified into two major categories. Firstly, reactions where the second reactants (with higher Gibbs free energy) supply energy as is the case for addition of $\mathrm{CO}_{2}$ to other reactants. Production of carboxylates and lactones, carbamates, ureas, isocyanates, and carbonates fall in this category. These processes are energetically favorable and often run without any catalyst. Secondly, reactions where carbon is reduced and therefore a substantial amount of external energy is required. Reduction of $\mathrm{CO}_{2}$ into formates, oxalates, carbon monoxide, formaldehyde, methanol, and methane fall in this category. The external energy is generally provided in terms of heat energy, but the strong $\mathrm{C}=\mathrm{O}$ double bond in $\mathrm{CO}_{2}$ often requires a catalyst to overcome the high activation barrier.

The most important aspect of $\mathrm{CO}_{2}$ conversion is controlling the selectivity of different intermediates in the reaction, which requires a thorough understanding of the thermodynamics and kinetics of each step. Therefore, multiple parameters need to be considered for optimizing the desired process and most importantly, efficient and selective catalysts are a prerequisite to overcome the thermodynamic and kinetic barrier in $\mathrm{CO}_{2}$ conversion. For instance, the production of $\mathrm{CO}$ from $\mathrm{CO}_{2}$ is endothermic in nature (Eq. 2, Table 2) implying that the forward reaction is favoured by higher temperatures. Increasing the pressure, on the other hand, has no effect on the yield of $\mathrm{CO}$ since there is no change in the number of molecules during the reaction (Figure 4). The $\mathrm{CO}_{2}: \mathrm{H}_{2}$ ratio is an important factor influencing the $\mathrm{CO}$ yield and it has been observed that increasing the $\mathrm{H}_{2}$ content in the feed greatly increases the amount of $\mathrm{CO}$ obtained from $\mathrm{CO}_{2}{ }^{38}$ 
Table 2. Standard enthalpies $\left(\Delta H^{\mathrm{o}}{ }_{298 \mathrm{~K}}\right)$ and Gibbs free energies $\left(\Delta G^{\mathrm{o}}{ }_{298 \mathrm{~K}}\right)$ for different products formed via $\mathrm{CO}_{2}$. Values taken from ref 38 .

\begin{tabular}{|c|c|c|c|}
\hline $\begin{array}{l}\text { Equation } \\
\text { number }\end{array}$ & Reaction & $\begin{array}{c}\Delta H^{\mathrm{o}}{ }_{298 \mathrm{~K}} \\
\left(\mathrm{~kJ} \mathrm{~mol}^{-1}\right)\end{array}$ & $\begin{array}{c}\Delta G^{\mathrm{o}}{ }_{298 \mathrm{~K}} \\
\left(\mathrm{~kJ} \mathrm{~mol}^{-1}\right)\end{array}$ \\
\hline (1) & $\mathrm{CO}_{2} \rightarrow \mathrm{CO}+\frac{1}{2} \mathrm{O}_{2}$ & 293.0 & 257.2 \\
\hline (2) & $\mathrm{CO}_{2}+\mathrm{H}_{2} \rightarrow \mathrm{CO}+\mathrm{H}_{2} \mathrm{O}$ & 41.2 & 28.6 \\
\hline (3) & $\mathrm{CO}_{2}+3 \mathrm{H}_{2} \rightarrow \mathrm{CH}_{3} \mathrm{OH}+\mathrm{H}_{2} \mathrm{O}$ & -49.5 & 3.5 \\
\hline (4) & $\mathrm{CO}_{2}+3 \mathrm{H}_{2} \rightarrow \frac{1}{2} \mathrm{C}_{2} \mathrm{H}_{5} \mathrm{OH}+\frac{3}{2} \mathrm{H}_{2} \mathrm{O}$ & -86.7 & -32.4 \\
\hline (5) & $\mathrm{CO}_{2}+4 \mathrm{H}_{2} \rightarrow \mathrm{CH}_{4}+2 \mathrm{H}_{2} \mathrm{O}$ & -165.0 & -113.5 \\
\hline (6) & $\mathrm{CO}_{2}+\frac{7}{2} \mathrm{H}_{2} \rightarrow \frac{1}{2} \mathrm{C}_{2} \mathrm{H}_{6}+2 \mathrm{H}_{2} \mathrm{O}$ & -132.1 & -78.7 \\
\hline (7) & $\mathrm{CO}_{2}+\frac{10}{3} \mathrm{H}_{2} \rightarrow \frac{1}{3} \mathrm{C}_{3} \mathrm{H}_{8}+2 \mathrm{H}_{2} \mathrm{O}$ & -125.0 & -70.9 \\
\hline (8) & $\mathrm{CO}_{2}+\frac{13}{4} \mathrm{H}_{2} \rightarrow \frac{1}{4} \mathrm{n}^{-\mathrm{C}_{4} \mathrm{H}_{10}}+2 \mathrm{H}_{2} \mathrm{O}$ & -121.6 & -66.9 \\
\hline (9) & $\mathrm{CO}_{2}+3 \mathrm{H}_{2} \rightarrow \frac{1}{2} \mathrm{C}_{2} \mathrm{H}_{4}+2 \mathrm{H}_{2} \mathrm{O}$ & -64.0 & -28.7 \\
\hline (10) & $\mathrm{CO}_{2}+3 \mathrm{H}_{2} \rightarrow \frac{1}{3} \mathrm{C}_{3} \mathrm{H}_{6}+2 \mathrm{H}_{2} \mathrm{O}$ & -83.6 & -42.1 \\
\hline (11) & $\mathrm{CO}_{2}+3 \mathrm{H}_{2} \rightarrow \frac{1}{4} \mathrm{n}^{-\mathrm{C}_{4} \mathrm{H}_{8}}+2 \mathrm{H}_{2} \mathrm{O}$ & -90.3 & -45.2 \\
\hline
\end{tabular}

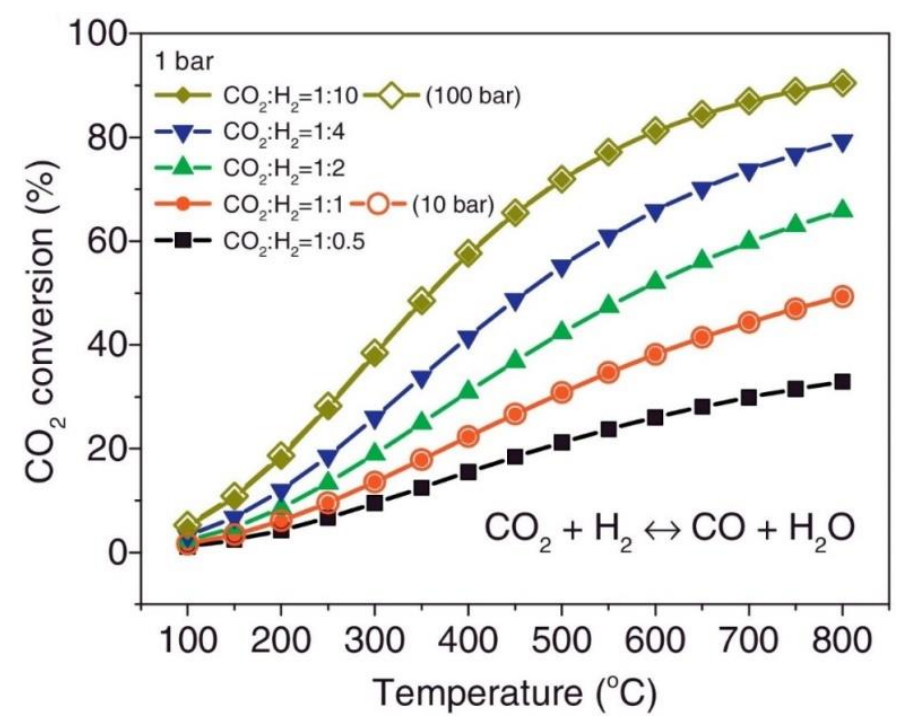

Figure 4. Equilibrium $\mathrm{CO}_{2}$ conversion for $\mathrm{CO}_{2}$ hydrogenation to $\mathrm{CO}$. Reproduced with permission from ref. 38. Copyright 2016 Elsevier. 
On the other hand, evaluating the thermodynamics of methanol production from $\mathrm{CO}_{2}$ we observe that it is exothermic in nature (Eq. 3, Table 2). This implies that lower temperatures are beneficial for methanol production. Furthermore, higher pressures favour both $\mathrm{CO}_{2}$ conversion and methanol selectivity during $\mathrm{CO}_{2}$ hydrogenation (Figure 5) due to the reduction in the number of molecules. Finally it is also seen that a higher $\mathrm{H}_{2}$ content in the feed (i.e. higher $\mathrm{H}_{2}: \mathrm{CO}_{2}$ ratio) promotes higher $\mathrm{CO}_{2}$ conversion and methanol selectivity. In contrast, ethanol production from $\mathrm{CO}_{2}$ is more exothermic and thermodynamically favoured as compared to methanol (Eq. 4, Table 2). Similar to methanol production, lower temperature and higher pressures facilitate ethanol production from $\mathrm{CO}_{2} \cdot{ }^{38}$
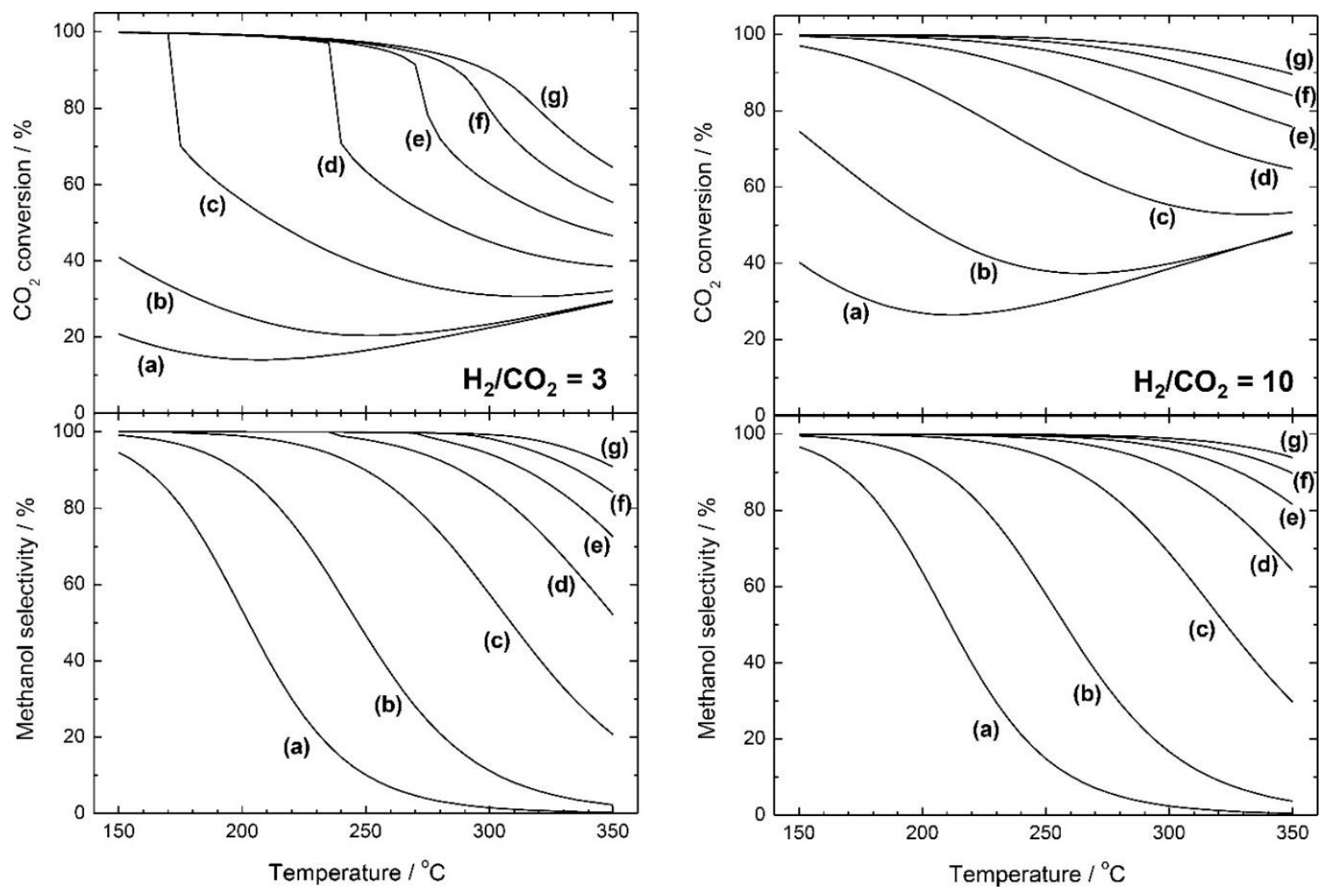

Figure 5. Equilibrium $\mathrm{CO}_{2}$ conversion and methanol selectivity for $\mathrm{CO}_{2}: \mathrm{H}_{2}$ ratio of 1:3 (left) and 1:10 (right) at pressures of (a) 10 bar (b) 30 bar (c) 100 bar (d) 200 bar (e) 300 bar (f) 400 bar (g) 500 bar. Reproduced from ref. 24.

Lastly, for the production of hydrocarbons from $\mathrm{CO}_{2}$, it is well known that olefins and paraffins follow opposing thermodynamic trends. The production of higher paraffins is less exothermic as compared to lower paraffins and is thermodynamically less favoured (Eqs. 5-8, Table 2). Conversely, the production of higher olefins is more exothermic and thermodynamically more favourable as compared to lower olefins (Eqs. 9-11, Table 2). As before, the exothermicity and volume reduction implies that the production of hydrocarbons from $\mathrm{CO}_{2}$ is promoted by lower temperatures and higher pressures (Figures 6 and 7). For olefins, it is also seen that higher pressures and higher $\mathrm{H}_{2}: \mathrm{CO}_{2}$ ratio favour the formation of longer chain olefins as compared to lighter olefins. 

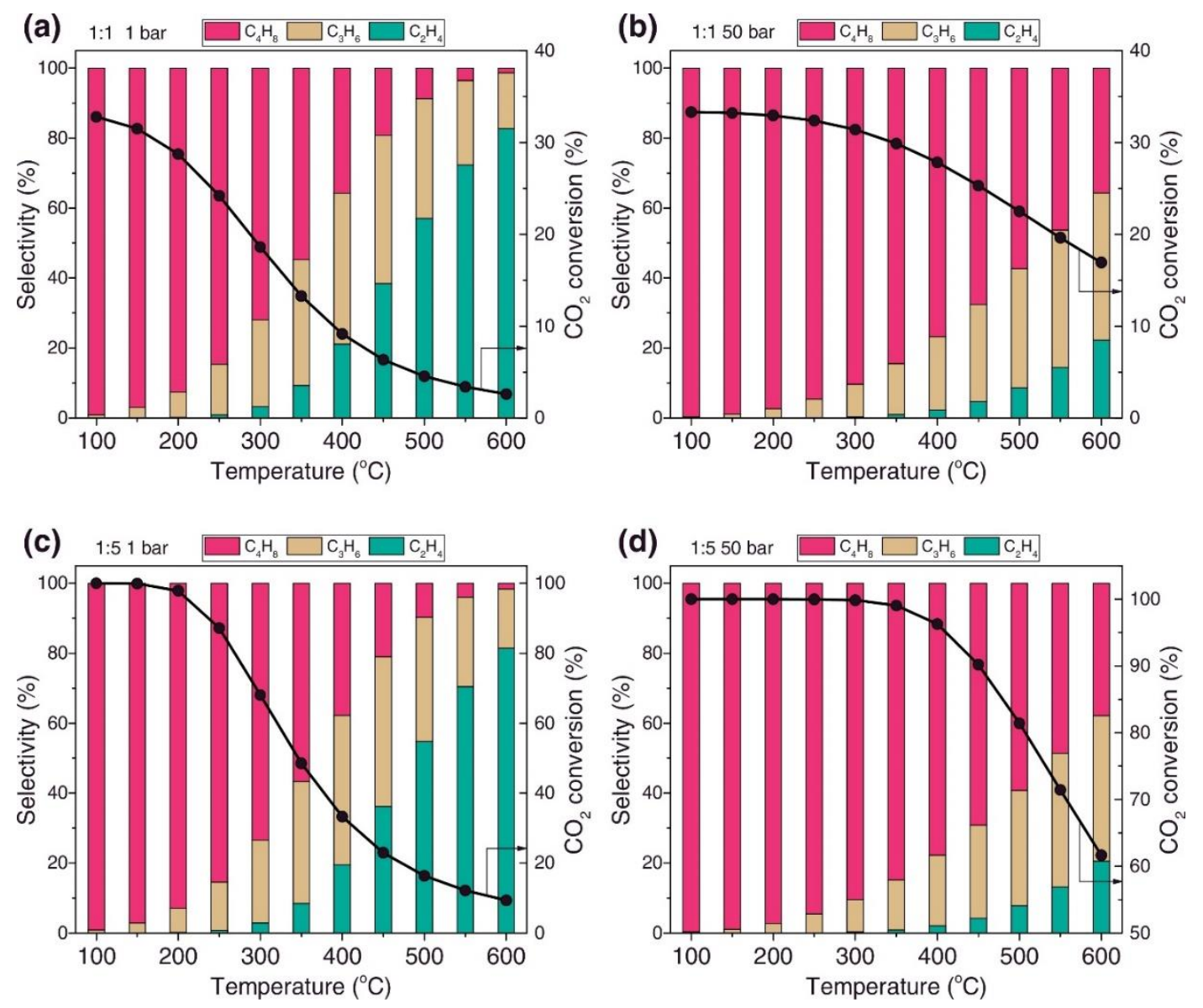

Figure 6. Equilibrium $\mathrm{CO}_{2}$ conversion for $\mathrm{CO}_{2}$ hydrogenation to light alkenes. (a) 1 bar and $\mathrm{CO}_{2}: \mathrm{H}_{2}$ ratio of 1:1, (b) 50 bar and $\mathrm{CO}_{2}: \mathrm{H}_{2}$ ratio of 1:1, (c) 1 bar and $\mathrm{CO}_{2}: \mathrm{H}_{2}$ ratio of 1:5, and (d) 50 bar and $\mathrm{CO}_{2}: \mathrm{H}_{2}$ ratio of 1:5. Reproduced with permission from ref. 38. Copyright 2016 Elsevier.
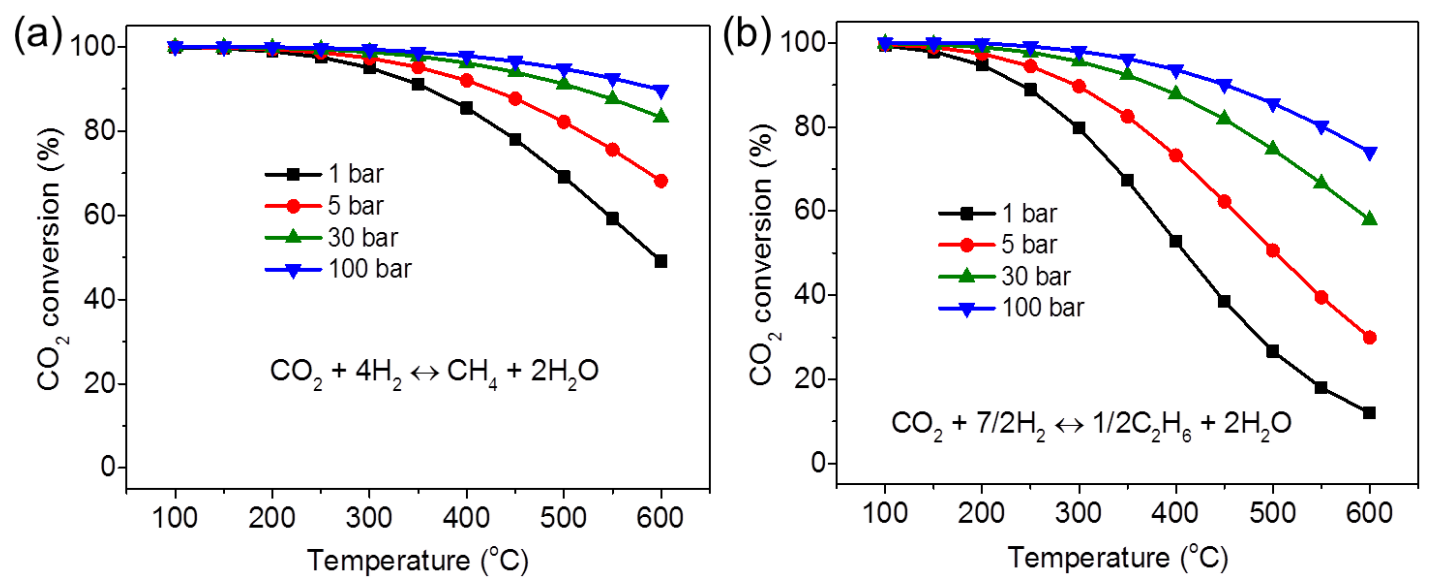

Figure 7. Equilibrium $\mathrm{CO}_{2}$ conversion for $\mathrm{CO}_{2}$ hydrogenation to light alkenes. (a) $\mathrm{CH}_{4}$ and (b) $\mathrm{C}_{2} \mathrm{H}_{6}$. Reproduced with permission from ref. 38. Copyright 2016 Elsevier. 


\section{CATALYTIC CONVERSION OF $\mathrm{CO}_{2}$}

In $\mathrm{CO}_{2}$ conversion, identifying the most crucial intermediate is always important to obtain the desired products. Stabilization of those intermediates is the key to achieve better selectivity and therefore the catalysts should be designed based on the interaction of intermediate species with the catalyst surface. For example, $\mathrm{CO}$ is found as the key intermediate in $\mathrm{MeOH}$ synthesis, which gives different $\mathrm{MeOH}$ selectivity based on CO-catalyst interaction. It was observed that stronger binding of $\mathrm{CO}$ over catalyst surface generally favors $\mathrm{MeOH}$ formation, while weaker binding favors RWGS. ${ }^{39}$ In this section, different catalytic systems will be discussed with their unique properties that are essential for particular reactions.

\subsection{Production of $\mathrm{CO}$}

Carbon monoxide (CO) is considered as the most important intermediate in $\mathrm{CO}_{2}$ conversion as it can be used as the starting material for multiple processes like Fischer-Tropsch synthesis and hydroformylation. Catalytic conversion of $\mathrm{CO}_{2}$ to $\mathrm{CO}$ is generally achieved via RWGS reaction (Eq. 2, Table 2). So far, various catalysts based on both noble metals and transition metals on different oxide supports have been studied with different reaction pathways reported depending on the catalyst surface..$^{31,40-42}$

\subsubsection{Noble metal-based catalysts}

According to the state of the art, the most extensively studied catalysts for $\mathrm{CO}$ production from $\mathrm{CO}_{2}$ were based on $\mathrm{Pt}$ or $\mathrm{Cu}^{41}$ Porosoff and Chen reported both monometallic and bimetallic Pt catalysts (such as PtNi and PtCo) on different oxide supports, where the activity and selectivity were found to be dependent on the nature of supports. ${ }^{43}$ For monometallic Pt catalysts, $\mathrm{CeO}_{2}$ showed higher activity than $\gamma$ $\mathrm{Al}_{2} \mathrm{O}_{3}$ support, while the $\mathrm{CO}$ selectivity followed the opposite trend. Among bimetallic combinations, $\mathrm{PtCo} / \mathrm{CeO}_{2}$ showed the best $\mathrm{CO} / \mathrm{CH}_{4}$ selectivity due to low interaction energy between the metallic interface and $\mathrm{CO}$. According to d-band center theory, the $\mathrm{CO}$ selectivity increases as the values of d-band center move towards more negative and the reported activity trend also followed the theoretical assumption. This study suggests that it is also possible to predict the activity of different bimetallic systems based on d-band energy.

While early studies on RWGS mainly used $\mathrm{Al}_{2} \mathrm{O}_{3}$ and $\mathrm{SiO}_{2}$ supported catalysts, the use of $\mathrm{CeO}_{2}$ as a support started to attract an increasing amount of attention after revealing its excellent reducible property. ${ }^{31,40,44-46}$ Apart from reducibility, $\mathrm{CeO}_{2}$ also shows high intrinsic activity toward $\mathrm{CO}_{2}$ adsorption. Although, $\mathrm{CeO}_{2}$ itself shows poor performance in the catalytic reaction, its reducibility and the ability to form oxygen vacancies can be improved by introducing other metals. ${ }^{47}$ Mechanistic studies have shown that direct dissociation of $\mathrm{CO}_{2}$ to $\mathrm{CO}$ is facilitated by the exchange of $\mathrm{O}$ from $\mathrm{CO}_{2}$ with pre-reduced $\mathrm{CeO}_{2}{ }^{48,49} \mathrm{In}$ addition to the advantage of oxygen vacancies, another advantage of using $\mathrm{CeO}_{2}$ as support is its ability to create strong metal-support interaction (SMSI) with other metals. In a report by Li et al., it was shown that the chemical state of Ir metal was a key factor responsible for CO selectivity and this chemical state could be tuned by altering the loading of the metal. ${ }^{44} \mathrm{In}$ the $\mathrm{Ir} / \mathrm{CeO}_{2}$ system, lower Ir loading (5 wt $\%$ ) resulted in high population of partially oxidized Ir species which adsorb CO very weakly as compared to metallic Ir at higher Ir loading (15 or $20 \mathrm{wt} \%$ ). As a result, the partially oxidized $\mathrm{Ir} / \mathrm{CeO}_{2}$ surface could effectively catalyze the dissociative chemisorption and further reaction of $\mathrm{CO}_{2}$, and fast desorption of resulting CO in order to give $\sim 100 \%$ CO selectivity (Figure $8 \mathrm{a}$ ). Both EXAFS and XPS data 
showed the evidence that the catalyst with lower Ir loading consisted of mainly Ir-O species as a result of SMSI (Figure 8b \& 8c). Furthermore, it was also noted that the isolated Ir species (e.g., at 0.7 wt $\%$ Ir loading) and the smaller Ir NPs displayed identical CO selectivity, indicating that the existence of isolated metal sites is not a prerequisite factor for the inhibition of methanation reaction. Rather, it is evident that a strong interaction between the support and the active species is the key factor on the catalytic performance at sub-nano scales.
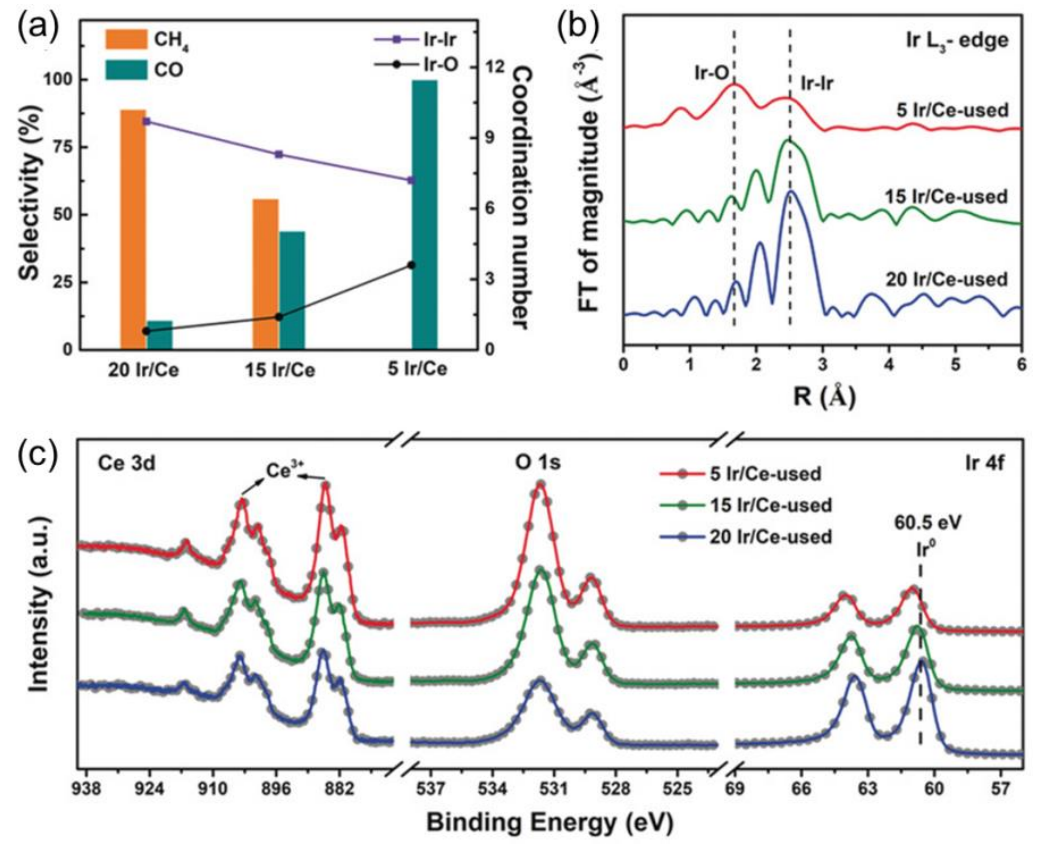

Figure 8. (a) Catalytic selectivity of $\mathrm{Ir} / \mathrm{CeO}_{2}$ catalysts (at different Ir loadings) against the coordination number of Ir-Ir and Ir-O shells. (b) $\mathrm{Ir} \mathrm{L}_{3}$-edge EXAFS of the $\mathrm{Ir} / \mathrm{CeO}_{2}$-used catalysts. (c) XPS analysis of the $\mathrm{Ir} / \mathrm{CeO}_{2}$-used catalysts. Reproduced with permission from ref. 44. Copyright $2019 \mathrm{Wiley-VCH}$.

Other redox active supports such as $\mathrm{TiO}_{2}$ and $\mathrm{ZrO}_{2}$ were also promising for $\mathrm{CO}_{2}$ adsorption by generating $\mathrm{O}$ vacancies. Chang Hong and coworkers reported $\mathrm{Pt} / \mathrm{TiO}_{2}$ catalyst in RWGS and showed that the catalyst had higher $\mathrm{CO}_{2}$ conversion rate than the Pt/Al ${ }_{2} \mathrm{O}_{3}$ catalyst. ${ }^{50} \mathrm{H}_{2}$ TPR and FT-IR studies confirmed the formation of high electron donating $\mathrm{Pt}-\mathrm{O}_{\mathrm{v}}-\mathrm{Ti}^{3+}\left(\mathrm{O}_{\mathrm{v}}\right.$ is $\mathrm{O}$ vacancy) sites due to the reducible nature of $\mathrm{TiO}_{2}$ support. These active sites were responsible for the formation of surface carbonate species, which was the key intermediate in the mechanism. On the other hand, since the $\mathrm{Pt} / \mathrm{Al}_{2} \mathrm{O}_{3}$ catalyst was irreducible in nature, the RWGS reaction could not proceed through carbonate species. Another study by Kattel et al. showed that the CO selectivity on bimetallic PtCo catalysts can be tuned by simply changing the support. ${ }^{51} \mathrm{TiO}_{2}$ supported PtCo catalysts preferentially formed $\mathrm{CO}$, whereas high selectivity towards $\mathrm{CH}_{4}$ was observed on $\mathrm{CeO}_{2}$ or $\mathrm{ZrO}_{2}$ supports. The main reason for difference in $\mathrm{CO}$ selectivity was associated with different reaction pathways over different catalysts. On $\mathrm{PtCo} / \mathrm{TiO}_{2}, * \mathrm{HCOO} / * \mathrm{HOCO}$ were formed as reaction intermediates, which further dissociated into $* \mathrm{CO}$ and $* \mathrm{OH}$. In contrast, both $* \mathrm{HCOO} / * \mathrm{HOCO}$ and $* \mathrm{CH}_{3} \mathrm{O}$ were observed on $\mathrm{PtCo} / \mathrm{CeO}_{2}$ and $\mathrm{PtCo} / \mathrm{ZrO}_{2}$, and ${ }^{*} \mathrm{CH}_{3} \mathrm{O}$ further formed $\mathrm{CH}_{4}$ through $* \mathrm{CH}_{3} \mathrm{OH}$ intermediate. Similar results were obtained with commercial Au-based catalysts supported on $\mathrm{Al}_{2} \mathrm{O}_{3}$ and $\mathrm{TiO}_{2}$, where $\mathrm{Au} / \mathrm{TiO}_{2}$ was better in terms of $\mathrm{CO}$ production rate. ${ }^{52}$ Transient and steady-state operando DRIFTS studies revealed that $\mathrm{Au} / \mathrm{Al}_{2} \mathrm{O}_{3}$ proceeds through the formate 
intermediates, while the $\mathrm{Au} / \mathrm{TiO}_{2}$ catalyst follows a redox mechanism due to the presence of both the surface hydroxyls and oxygen vacancies. Another interesting feature of $\mathrm{TiO}_{2}$ is its different crystal phases (anatase and rutile), which can be changed at different calcination temperature in order to tune the $\mathrm{CO} / \mathrm{CH}_{4}$ selectivity. One recent study revealed that $\mathrm{CO}$ is predominantly formed over anatase $\mathrm{TiO}_{2}$ supported Co catalyst, while $\mathrm{CH}_{4}$ was the main product on the $\mathrm{Co} /$ rutile- $\mathrm{TiO}_{2}$ catalyst. ${ }^{53}$

Additionally, to improve the intrinsic activity of irreducible supports (such as $\mathrm{Al}_{2} \mathrm{O}_{3}, \mathrm{SiO}_{2}$ etc.), another metal oxide phase with reducible property can be introduced. For example, the apparent activation energy of RWGS reaction on $\mathrm{Pt} / \mathrm{SiO}_{2}$ system could be decreased significantly by the addition of $\mathrm{Fe}_{2} \mathrm{O}_{3}$ and $\mathrm{MoO}_{\mathrm{x}}$ in order to increase the intrinsic activity by several times. ${ }^{54,} 55$ This type of promotional effect can be highly enhanced by introducing alkali metals, such as lithium or potassium. ${ }^{56-59}$ Liang et al. showed that the addition of potassium as promotor to $\mathrm{Pt} /$ mullite (mullite is a mixed oxide with a nominal composition of $3 \mathrm{Al}_{2} \mathrm{O}_{3} \cdot 2 \mathrm{SiO}_{2}$ ) catalyst can enhance the TOF of RWGS reaction by 7 times. ${ }^{58}$ The RWGS mechanism in Figure 9 shows that the dissociative adsorption of $\mathrm{H}_{2}$ molecules first occurs on the Pt NPs, while at the same time $\mathrm{CO}_{2}$ molecules mainly adsorb at the interface of $\mathrm{K}$-Pt species or $\mathrm{K}$ mullite support. K plays multiple roles, such as (i) stabilization of $\mathrm{Pt}$ in a higher oxidation state through the strong interaction between $\mathrm{KO}_{\mathrm{x}}$ and $\mathrm{Pt}$, (ii) creation of a new interface between $\mathrm{KO}_{\mathrm{x}}$ and $\mathrm{Pt}$ that can serve as the active site for formate decomposition to produce $\mathrm{CO}$, and (iii) weakening the strength of $\mathrm{CO}$ adsorption on $\mathrm{Pt}$ in order to hinder the subsequent hydrogenation of $\mathrm{CO}$ into $\mathrm{CH}_{4}$ through $\mathrm{C}-\mathrm{O}$ bond dissociation. Another study based on Pt/zeolite catalyst showed that the chemical state of Pt could be altered by the addition of $\mathrm{K}$ promoter, where the formation of $\mathrm{Pt}-\mathrm{O}(\mathrm{OH})-\mathrm{K}$ interfacial sites was evidenced by X-ray absorption near edge structure (XANES) and XPS studies. ${ }^{59}$ Due to the charge transfer from Pt surface to $\mathrm{K}, \mathrm{Pt}-\mathrm{O}(\mathrm{OH})-\mathrm{K}$ active interface could facilitate the formation of bridge-bonded formate intermediates and $\mathrm{CO}$ desorption.

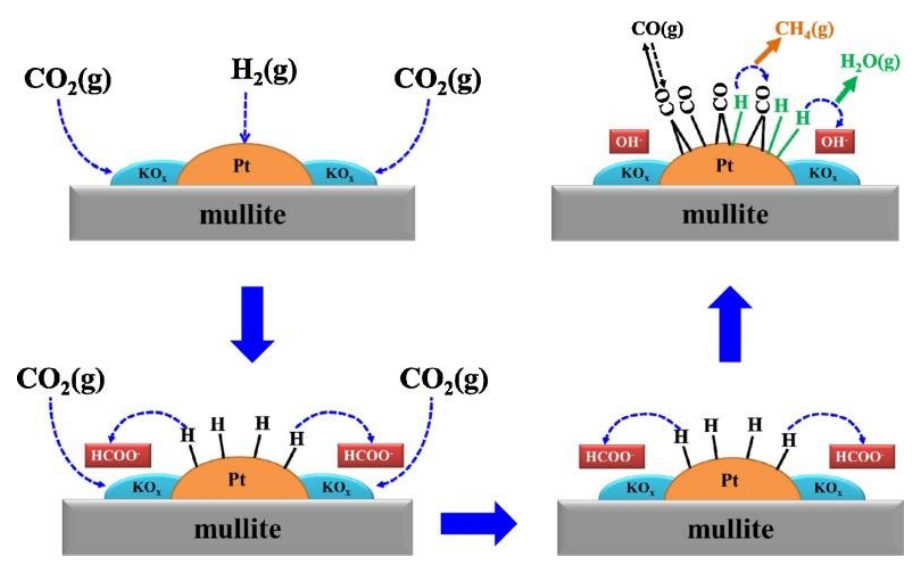

Figure 9. Effect of potassium as promoter in the RWGS reaction over K-Pt/mullite catalyst. Reproduced with permission from ref. 58. Copyright 2017 Elsevier.

\subsubsection{Non-noble metal-based catalysts}

Along with the above discussed Pt-based catalysts, other precious metals such as $\mathrm{Rh},{ }^{60} \mathrm{Ru},{ }^{61,62}$ $\mathrm{Ir},{ }^{44} \mathrm{Au}{ }^{63} \mathrm{Pd}^{64}$ were also reported to give high activity due to their good hydrogenation properties. However, the high cost restricts their real application in large scale production of $\mathrm{CO}$ and therefore the research in the field is increasingly shifting to non-noble metal systems. Among the non-noble metals, 
$\mathrm{Cu}, \mathrm{Fe}, \mathrm{Co}, \mathrm{Ni}$, and $\mathrm{Mn}$ were found to be active and therefore used as alternative catalysts for industrial RWGS process. ${ }^{65-74} \mathrm{~A}$ recent report explored different transition metal-based catalysts (M/ZIF-8-C; $\mathrm{M}=$ $\mathrm{Ni}, \mathrm{Fe}, \mathrm{Co}$ and $\mathrm{Cu}$ ) supported on zeolitic imidazolate framework-derived carbon support enriched with pyridinic $\mathrm{N}$ sites. ${ }^{66}$ The main advantage of using these materials was the dual functionalities, where metal/metal carbide phase performs $\mathrm{H}_{2}$ dissociation and pyridinic $\mathrm{N}$ adsorbs $\mathrm{CO}_{2}$. DFT calculations showed that the reaction mechanism followed direct cleavage of $* \mathrm{CO}_{2}$ into $* \mathrm{CO}$ and $* \mathrm{O}$ rather than decomposition of $* \mathrm{COOH}$. $\mathrm{Ni}$ and $\mathrm{Fe}$ were more selective toward $\mathrm{CO}$ due to the lower energy required for $* \mathrm{CO}$ desorption as compared to $\mathrm{Co}$ and $\mathrm{Cu}$. Zhao et al. reported lanthanum-iron-nickel perovskite catalysts, where the selectivity of $\mathrm{CO}_{2}$ hydrogenation was significantly tuned by controlling the valence state of $\mathrm{Ni}^{67} \mathrm{CH}_{4}$ was predominantly formed over $\mathrm{LaNiO}_{3}$, whereas $\mathrm{LaFe}_{0.5} \mathrm{Ni}_{0.5} \mathrm{O}_{3}$ preferentially formed CO. Combined studies by in situ XRD, XANES, and AP-XPS revealed that $\mathrm{LaNiO}_{3}$ formed metallic Ni under reaction conditions, while the higher valent $\mathrm{Ni}$ species were formed in $\mathrm{LaFe}_{0.5} \mathrm{Ni}_{0.5} \mathrm{O}_{3}$. According to DFT calculations, $\mathrm{CO}$ binds weakly on $\mathrm{NiO}(111)$ surface resulting in easy desorption of ${ }^{*} \mathrm{CO}$ which leads to higher $\mathrm{CO}$ selectivity. In addition to the effect of oxidation state, structural changes of metals can also affect product selectivity. For example, low loading of $\mathrm{Ni}(0.5 \mathrm{wt} \%)$ in $\mathrm{Ni} / \mathrm{CeO}_{2}$ catalyst showed high selectivity to $\mathrm{CO}$ over $\mathrm{CH}_{4}$ as compared to the catalyst with higher $\mathrm{Ni}$ loading (1.5 wt\%), although both catalysts contained $\mathrm{Ni}$ in the metallic state. ${ }^{68}$ The results suggest that metal-support interactions and distributions of metal sizes also account for the different selectivities.

A recent study revealed that $\mathrm{Cu}$ catalyst supported on $\mathrm{CeO}_{2}$ outperformed other $\mathrm{Cu}$ catalysts supported on nonredox oxides like $\mathrm{SiO}_{2}$ irrespective of loading, particle size, and dispersion of $\mathrm{Cu}^{45} \mathrm{The}$ $\mathrm{Cu} / \mathrm{CeO}_{2}$ catalyst showed $100 \% \mathrm{CO}$ selectivity and approximately 4 times higher activity than the corresponding $\mathrm{Cu} / \mathrm{SiO}_{2}$ catalyst at low temperature $\left(300{ }^{\circ} \mathrm{C}\right)$ and ambient pressure. The improved activity was attributed to the facile hydrogen spillover over the interfaces formed between well-dispersed Cu NPs and $\mathrm{Ce}^{3+}$ species. In situ XRD and XAS studies also revealed that the presence of $\mathrm{Cu}$ NPs on the $\mathrm{CeO}_{2}$ lowered the reduction temperature of $\mathrm{CeO}_{2}$ to create oxygen vacancies at $<300{ }^{\circ} \mathrm{C}$. A detailed analysis on the effect of $\mathrm{CeO}_{2}$ morphology was done over $\mathrm{Cu}$ catalysts supported on two types of ceria structures, nanorods $\left(\mathrm{CeO}_{2}-\mathrm{NR}\right)$ and nanospheres $\left(\mathrm{CeO}_{2}-\mathrm{NS}\right) .{ }^{75} \mathrm{Cu} / \mathrm{CeO}_{2}-\mathrm{NR}$ catalyst showed stronger affinity to $\mathrm{CO}_{2}$ at high temperature and thus preferentially formed active bidentate oxo-species, such as carbonate and formate. The main reason was probably the presence of $\mathrm{CeO}_{2}(110)$ termination in $\mathrm{CeO}_{2}-\mathrm{NR}$ structure, which binds bidentate formate stronger than on $\mathrm{CeO}_{2}(111)$ (mostly present in $\mathrm{CeO}_{2}-\mathrm{NS}$ structure).

Being the cheapest metal among all transition elements, iron can be a potential replacement of existing RWGS catalysts due to its high oxygen mobility and thermal stability. ${ }^{76}$ Although there are only a few examples of iron-based RWGS catalysts reported to date, the potential of some recently reported catalysts was remarkable in terms of both activity and stability ${ }^{66,76-79}$ An early report by Weatherbee et al. showed that $\mathrm{CO}$ can be produced over $\mathrm{Fe} / \mathrm{SiO}_{2}$ catalyst in $\mathrm{CO}_{2}$ hydrogenation, but the formation rate was much lower when compared to other transition metals of the same group. ${ }^{80}$ Fishman et al. obtained $28 \%$ $\mathrm{CO}_{2}$ conversion over hematite nanosheets at $510{ }^{\circ} \mathrm{C}$, and $50 \% \mathrm{CO}_{2}$ conversion over hematite nanowires at a very high temperature of $750{ }^{\circ} \mathrm{C} .{ }^{77}$ To achieve a decent conversion at low temperature, different promoters were recently used by some groups. Loiland et al. observed that the addition of potassium to the $\mathrm{Fe} / \mathrm{Al}_{2} \mathrm{O}_{3}$ catalyst $(\mathrm{Fe} / \mathrm{K}$ mass ratio $=1.24)$ led to a threefold increase in $\mathrm{CO}_{2}$ hydrogenation rate. ${ }^{78}$ DRIFTS studies confirmed an associative mechanism on $\mathrm{Fe}-\mathrm{K} / \mathrm{Al}_{2} \mathrm{O}_{3}$, which was not observed in the case of $\mathrm{Fe} / \mathrm{Al}_{2} \mathrm{O}_{3}$. Transition metal promoters such as $\mathrm{Cu}, \mathrm{Ni}$ and $\mathrm{Mo}$ were also reported to enhance the activity 
of iron-based catalysts, where $\mathrm{Cu}$ was proven to be the best candidate to provide high $\mathrm{CO}$ selectivity and long term stability. ${ }^{76}$

\subsubsection{Single atom catalysts (SACs)}

As we have seen that the reactivity and selectivity in $\mathrm{CO}_{2}$ hydrogenation depend on the metal particle sizes of the catalysts, single atom catalysts (SACs) could be an excellent choice in order to achieve high productivity and study the mechanism at the atomic level. Based on fundamental understanding, single atom-based catalysts are promising in RWGS reaction as they are only able to perform the $2 \mathrm{e}^{-}$redox cycle. On the other hand, to produce over-hydrogenated products (e.g., $\left.\mathrm{CH}_{4}\right)$, one requires clusters or particles that can perform full hydrogenation of $\mathrm{CO}_{2}$ (the $8 \mathrm{e}^{-}$redox cycle) ${ }^{81}$ In recent years, some SACs have been studied for the conversion of $\mathrm{CO}_{2}$ into $\mathrm{CO}$ and it was observed that the selectivities over SACs were very different from metal nanoparticle-based catalysts. ${ }^{82-89}$ For example, Kwak et al. studied a series of $\mathrm{Ru} / \mathrm{Al}_{2} \mathrm{O}_{3}$ catalysts with different $\mathrm{Ru}$ loading in the reduction of $\mathrm{CO}_{2}$ with $\mathrm{H}_{2} \cdot{ }^{83} \mathrm{CO}$ was selectively formed over the catalysts with low Ru loadings $(\leq 0.5 \%)$ where the active metal phase was mostly atomically dispersed. With increasing $\mathrm{Ru}$ loading, population of clusters and nanoparticles increased and therefore the selectivity toward $\mathrm{CH}_{4}$ formation increased. From the slopes of Arrhenius plots, apparent activation energies for the two competitive processes (i.e., $\mathrm{CO}$ and $\mathrm{CH}_{4}$ formation) were calculated as 82 and $62 \mathrm{~kJ} / \mathrm{mol}$ irrespective of Ru loading. The higher activation energy for $\mathrm{CO}$ formation suggests that $\mathrm{CO}$ is not an intermediate in the formation of $\mathrm{CH}_{4}$, and the formation of $\mathrm{CO}$ and $\mathrm{CH}_{4}$ follow different reaction pathways or proceed on different active sites. This was also supported by the results of activity measurements over a $0.1 \% \mathrm{Ru} / \mathrm{Al}_{2} \mathrm{O}_{3}$ catalyst, which showed $\sim 125^{\circ} \mathrm{C}$ onset temperature difference between the $\mathrm{CO}_{2}\left(\sim 325^{\circ} \mathrm{C}\right)$ and $\mathrm{CO}\left(\sim 450{ }^{\circ} \mathrm{C}\right)$ reduction. One drawback of this system was that the catalysts with low metal loading were unstable under reaction conditions and formed large metal clusters, thereby reducing the $\mathrm{CO}$ selectivity. Christopher and coworkers reported single atom and nanoparticle-based $\mathrm{Rh}$ catalysts on $\mathrm{TiO}_{2}$ support for $\mathrm{CO}_{2}$ reduction and observed a strong correlation between the RWGS TOF and the fraction of isolated Rh sites. ${ }^{84}$ It was also observed that Rh NPs were disintegrating under the reaction conditions to form isolated $\mathrm{Rh}$ species, which changed the reactivity with time on stream. Another example with $\mathrm{Ru} / \mathrm{CeO}_{2}$ showed that $\mathrm{Ru} \mathrm{NPs}$ on $\mathrm{CeO}_{2}$ support can be transformed into single atomic $\mathrm{RuO}_{x}$ species after oxidative pretreatment in $\mathrm{O}_{2}$ at low temperatures $\left(210{ }^{\circ} \mathrm{C}\right)$ to become a suitable RWGS catalyst, preferentially forming $\mathrm{CO}$ with selectivity above $90 \%{ }^{88} \mathrm{In}$ contrast, after reductive pretreatment of the catalyst in $\mathrm{H}_{2}$, the Ru NPs remain metallic, thereby increasing the selectivity for $\mathrm{CH}_{4}$.

To understand the difference in the catalytic behavior of single-atoms and nanoparticles in $\mathrm{CO}_{2}$ reduction, a clear understanding on an atomic-level is required. A recent study based on $\mathrm{Pt} / \mathrm{CeO}_{2}$ bifunctional catalyst system showed that the isolated Pt atom binds $\mathrm{CO}$ weakly, and therefore restricts further hydrogenation and prevents $\mathrm{CO}$ poisoning. ${ }^{86}$ Although in situ spectroscopic studies demonstrated that $\mathrm{CO}_{2}$ activation primarily occurs on the oxide support, product selectivity $\left(\mathrm{CO}\right.$ or $\left.\mathrm{CH}_{4}\right)$ depends on the single-atom or nanoclustered nature of active metal (here $\mathrm{Pt}$ for example). Based on different characterization techniques (in situ DRIFT, XPS, and EPR) and activity results, a reaction mechanism was proposed showing different pathways of $\mathrm{CO}_{2}$ reduction over Pt single-atoms and nanoclusters (Figure 10). Activation and adsorption of $\mathrm{CO}_{2}$ (steps 1-3) occur in the same way for both systems as the surface oxygen defects of $\mathrm{CeO}_{2}$ are found to play the key role. On the other hand, Pt helps to dissociate molecular $\mathrm{H}_{2}$ to form adatoms $\left(\mathrm{H}_{\mathrm{ad}}\right)$. Compared to a Pt (111) surface, isolated Pt sites possess lower activation 
energy for $\mathrm{H}_{2}$ dissociation and much weaker binding of $\mathrm{H}$ atoms, thereby facilitating better $\mathrm{H}$ diffusion. ${ }^{90}$ In case of a nanocluster catalyst, interaction of bicarbonate intermediate with $\mathrm{H}_{\mathrm{ad}}$ on the Pt nanoclusters is believed to happen in two ways: (i) generating formate (HCOO) species by reacting with $\mathrm{H}_{\mathrm{ad}}$ and/or (ii) carbon directly bonding with the Pt cluster to form a $\mathrm{C} \equiv \mathrm{O}$ triple bond. These two steps may occur either simultaneously or at different temperatures. $\mathrm{H}_{\mathrm{ad}}$ then subsequently attacks strongly bound $\mathrm{C}-\mathrm{O}, \mathrm{C}=\mathrm{O}$, and $\mathrm{C} \equiv \mathrm{O}$ species (in formate and/or $\mathrm{CO}$ ) to generate $\mathrm{CH}_{4}$ as the final product. A different mechanism is followed over isolated $\mathrm{Pt}$ sites. The $-\mathrm{OH}$ group of bicarbonate is replaced by $\mathrm{H}_{\mathrm{ad}}$ to generate an aldehyde group that further undergoes cleavage of $\mathrm{C}-\mathrm{H}$ bond to form $\mathrm{C} \equiv \mathrm{O}$ attached on a $\mathrm{Pt}$ single atom. Weak interaction of $\mathrm{CO}$ with $\mathrm{Pt}$ single-atom causes easy desorption of $\mathrm{CO}$ into the gas phase as a product.

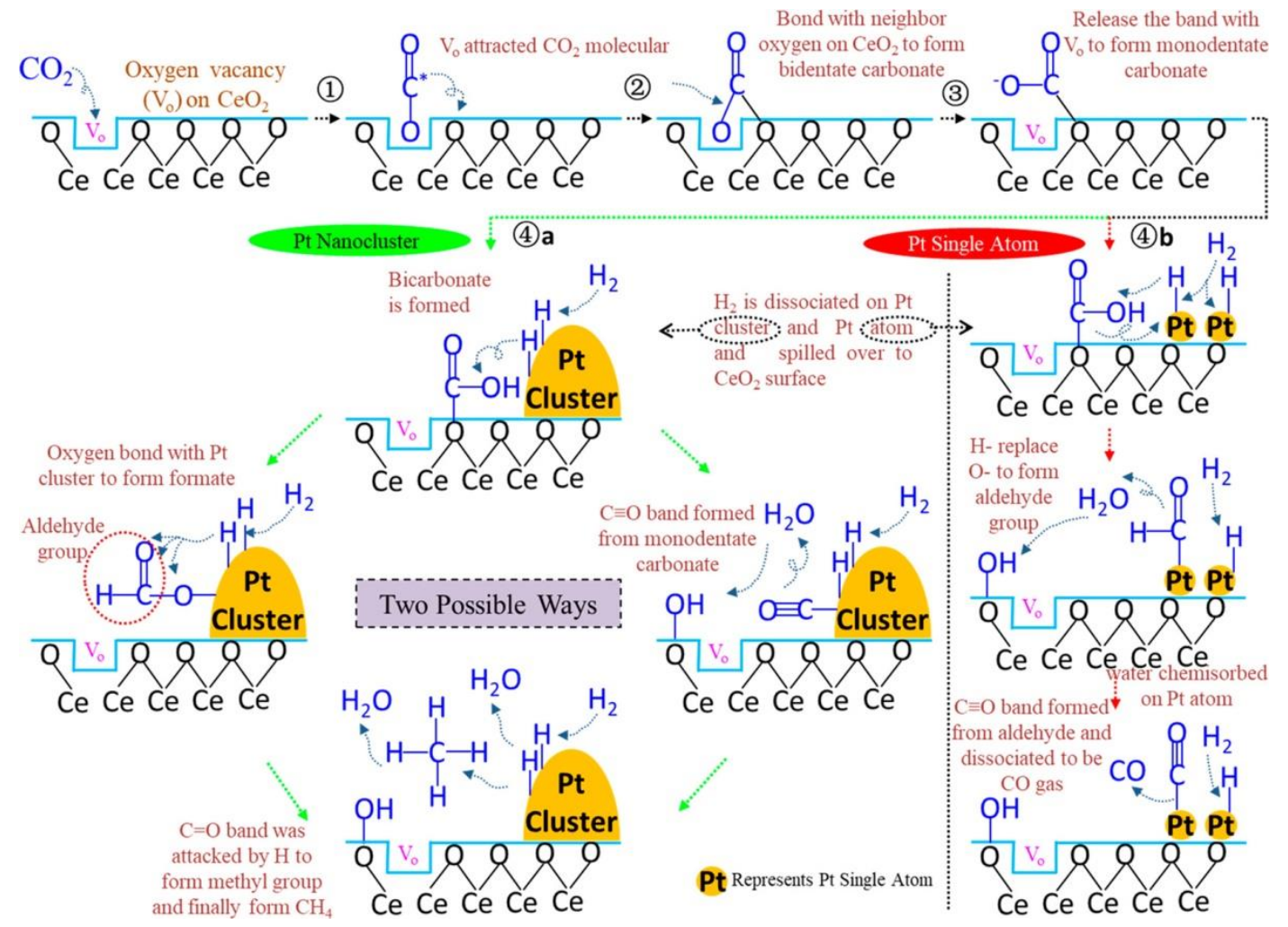

Figure 10. Proposed mechanism of $\mathrm{CO}_{2}$ reduction over $\mathrm{Pt} / \mathrm{CeO}_{2}$ catalysts containing $\mathrm{Pt}$ single-atoms and Pt nanoclusters. Reproduced with permission from ref. 86. Copyright 2018 American Chemical Society.

Although there are only a few examples of SACs reported in $\mathrm{CO}_{2}$ hydrogenation till date, there is a clear indication that SACs have promising future application due to their completely different reactivity. However, one of the main issues of using SACs for RWGS reaction is their poor thermal stability. Since RWGS usually requires high temperature, most of the SACs might agglomerate under such reaction conditions. ${ }^{83}$ To overcome this issue, Zhang and coworkers recently designed a thermally stable $\operatorname{Ir}_{1} / \mathrm{TiO}_{2}$ catalyst based on the lattice-match principle. Due to the same crystal structure (with similar lattice parameters) of the active $\mathrm{IrO}_{2}$ and pure rutile phase $\mathrm{TiO}_{2}\left(\mathrm{r}-\mathrm{TiO}_{2}\right)$, Ir species were lattice-matched and epitaxially bonded to the surface of $\mathrm{r}-\mathrm{TiO}_{2}$ to achieve extreme stability at high reaction temperature. ${ }^{91} \mathrm{~A}$ solid solution approach was reported to synthesize single atom $\mathrm{Ni}$ catalyst on $\mathrm{MgO}$, which was stable over $100 \mathrm{~h}$ on stream without forming any cluster or particle. ${ }^{81}$ 


\subsubsection{Reaction mechanism}

As mention above, two different pathways were reported for the conversion of $\mathrm{CO}_{2}$ to $\mathrm{CO}$ (Figure 11). According to path $\mathrm{A}$, activation of $\mathrm{CO}$ is followed by the direct cleavage of $\mathrm{C}-\mathrm{O}$ bond in reactive $* \mathrm{CO}_{2}$ to give $* \mathrm{CO}$ and $* \mathrm{O}$, and then $* \mathrm{CO}$ is desorbed from the catalyst surface to form gaseous $\mathrm{CO}$ as product. This is also termed as redox mechanism, which is mainly observed on $\mathrm{Cu}$-based catalysts due to easy conversion between two oxidation states of $\mathrm{Cu}\left(\mathrm{Cu}^{0}\right.$ and $\left.\mathrm{Cu}^{+1}\right){ }^{92}$ Detailed investigation was done by density functional theory (DFT) calculations, where it was shown that $\mathrm{C}$ atom of ${ }^{*} \mathrm{CO}_{2}$ is attached to the metal center and one of the $\mathrm{O}$ atoms is attached to the cationic metal center of the oxide supports. ${ }^{93,94}$ On the other side, molecular $\mathrm{H}_{2}$ is dissociated on the metal center and the active $\mathrm{H}$ atom is transferred through the spillover mechanism. Path $\mathrm{B}$ is the formate mechanism, where $\mathrm{CO}_{2}$ is hydrogenated to formate and then cleavage of the $\mathrm{C}=\mathrm{O}$ bond occurs. Essentially, the catalysts should consist of two functional groups that can perform both hydrogenation and $\mathrm{C}=\mathrm{O}$ bond cleavage. ${ }^{40}$ Several metal $/ \mathrm{metal}$ oxide catalysts have been reported for this process. ${ }^{41,42}$

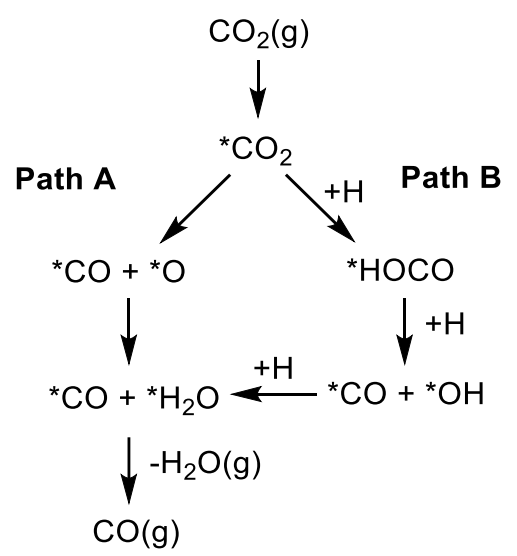

Figure 11. Possible pathways for $\mathrm{CO}_{2}$ hydrogenation to form $\mathrm{CO}$. $*(\mathrm{X})$ indicates reactive species adsorbed on catalyst surface.

The activity of a RWGS catalyst is determined by various factors, including hydrogenation capability of active metals, reducibility and oxygen vacancy of metal oxide supports, metal-support interaction, degree of metal dispersion, etc. However, the CO selectivity is mainly dependent on the binding capability of the metal/support interface for $\mathrm{CO}$. Weak binding of $\mathrm{CO}$ on metal/support interface is selective toward $\mathrm{CO}$ formation simply due to facile desorption of active * $\mathrm{CO}$. On the other hand, stronger binding of $\mathrm{CO}$ on metal/support interface assists further hydrogenation of $\mathrm{CO}$ to give $\mathrm{CH}_{4}$. To elaborate this point, some in situ studies on mechanistic investigations are discussed here. According to the in situ FTIR studies over $\mathrm{Pd} / \mathrm{Al}_{2} \mathrm{O}_{3}$ system by Arunajatesan et al., some carbonates and trace amount of formates were mainly observed when a bare $\mathrm{Al}_{2} \mathrm{O}_{3}$ support was exposed to a supercritical mixture of $\mathrm{CO}_{2}$ and $\mathrm{H}_{2}\left(\mathrm{P}=138\right.$ bar; $\left.\mathrm{T}=342 \mathrm{~K} ; \mathrm{CO}_{2} / \mathrm{H}_{2}=19\right) .{ }^{95}$ On the other hand, carbonates, formates, and $\mathrm{CO}$ were observed on $\mathrm{Pd} / \mathrm{Al}_{2} \mathrm{O}_{3}$, which confirmed that a formate mechanism is followed over Pd. One of the most important findings of this work was the appearance of a peak at $1900-1920 \mathrm{~cm}^{-1}$ after $20 \mathrm{~min}$ of reaction, which corresponds to bridged $\mathrm{CO}$ on $\mathrm{Pd}$. After $5 \mathrm{~h}$, the peak became significant and thus caused the catalyst deactivation by $\mathrm{CO}$, however there was no evidence of forming methane in this case. This study clearly suggests that a short-residence time continuous reactor would be preferred over batch 
reactors to maximize the catalyst lifetime. Furthermore, the $\mathrm{CO}$ peak was not observed on other $\mathrm{Al}_{2} \mathrm{O}_{3}$ supported metal catalysts, such as $\mathrm{Ru} / \mathrm{Al}_{2} \mathrm{O}_{3}$ or $\mathrm{Ni} / \mathrm{Al}_{2} \mathrm{O}_{3}$, suggesting that the choice of metal is important in RWGS reaction. In addition to the metal type (i.e., strength of metal-CO bond), the degree of metal dispersion is a crucial factor in determining the conversion and product selectivity. For instance, 5\% $\mathrm{Pd}$ loading over $\gamma-\mathrm{Al}_{2} \mathrm{O}_{3}\left(\sim 11 \%\right.$ metal dispersion) gave higher $\mathrm{CO}_{2}$ conversion as compared to the catalyst with $0.5 \%$ Pd loading ( 100\% metal dispersion). ${ }^{96}$ However, the $\mathrm{CH}_{4}$ selectivity on $5 \% \mathrm{Pd} / \mathrm{Al}_{2} \mathrm{O}_{3}$ also increased by a factor of $2-3$ than that on $0.5 \% \mathrm{Pd} / \mathrm{Al}_{2} \mathrm{O}_{3}$. Based on the observation of different rate expressions and apparent energies of activation for $\mathrm{CO}$ and $\mathrm{CH}_{4}$ formation, authors pointed out that RWGS and $\mathrm{CO}_{2}$ methanation pathways are probably catalyzed at different surface sites of the catalysts. Combined in situ DRIFTS and mass spectroscopic results demonstrated that for both catalysts $\mathrm{CO}_{2}$ first reacted with surface $-\mathrm{OH}$ groups on the oxide support to form bicarbonates, which further reacted with dissociatively adsorbed $\mathrm{H}$ on $\mathrm{Pd}$ particles to produce adsorbed formate species, confirming the formate mechanism again (Figure 12a). The remarkable difference between the two catalysts was the rate of change in the concentration of surface bicarbonate species under reaction conditions $\left(\mathrm{CO}_{2}+\mathrm{H}_{2}\right.$ at $\left.513 \mathrm{~K}\right)$ as observed by in situ IR studies (Figures $12 \mathrm{~b} \& 12 \mathrm{c}$ ). Since the formation rate of bicarbonate depends on the partial pressure of $\mathrm{CO}_{2}$, which should be identical for both catalysts, the higher consumption of bicarbonate on $5 \% \mathrm{Pd} / \mathrm{Al}_{2} \mathrm{O}_{3}$ than that on $0.5 \% \mathrm{Pd} / \mathrm{Al}_{2} \mathrm{O}_{3}$ must be caused by the higher concentration of active $\mathrm{H}$ species on the former catalyst, which contains larger Pd particles. The as-formed formates near metal/oxide interface reacted rapidly with adsorbed $\mathrm{H}$ to produce $\mathrm{CO}$, which then adsorbed on the metallic Pd particles. Since 5\% $\mathrm{Pd} / \mathrm{Al}_{2} \mathrm{O}_{3}$ contains larger Pd particles and therefore a larger fraction of active terrace sites are available for forming multiple $\mathrm{Pd}-\mathrm{CO}$ bonds, it eventually produced $\mathrm{CH}_{4}$ after subsequent hydrogenation.

(a)
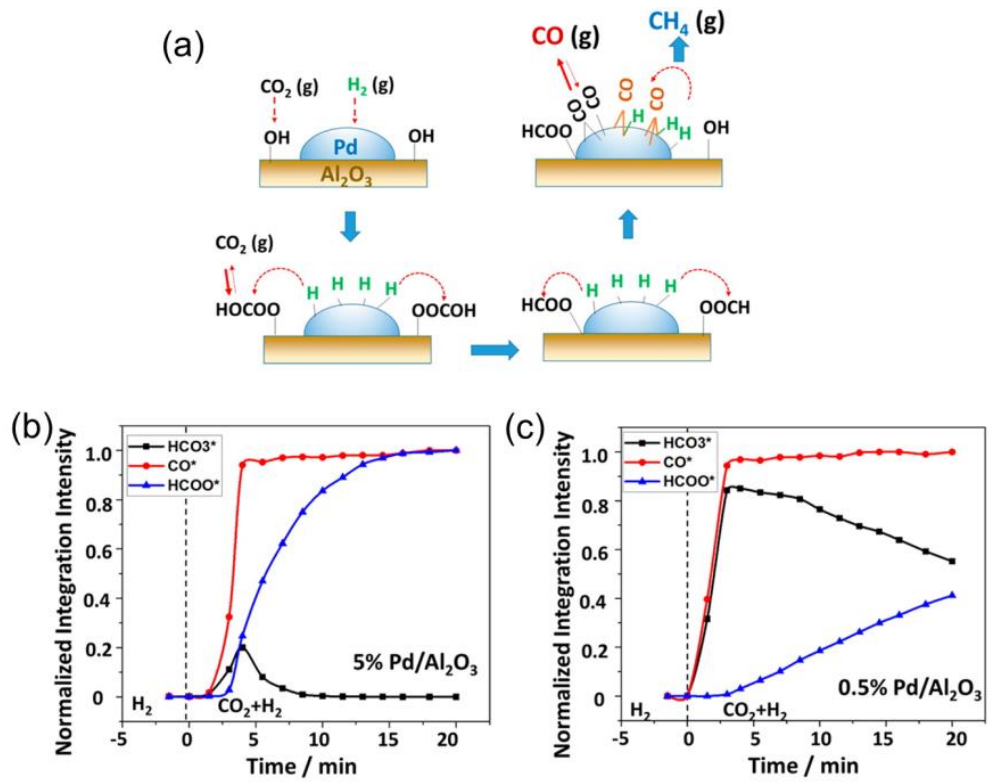

Figure 12. (a) Mechanism of $\mathrm{CO}_{2}$ hydrogenation on $\mathrm{Pd} / \mathrm{Al}_{2} \mathrm{O}_{3}$ with different Pd loading. Normalized integrated IR intensity of different adsorbed species as functions of time when the feed gas was switched from $\mathrm{H}_{2}$ to $\mathrm{CO}_{2}+\mathrm{H}_{2}$ on (b) $5 \% \mathrm{Pd} / \mathrm{Al}_{2} \mathrm{O}_{3}$ and (c) $0.5 \% \mathrm{Pd} / \mathrm{Al}_{2} \mathrm{O}_{3}$ at $513 \mathrm{~K}$. Reproduced with permission from ref. 96. Copyright 2018 American Chemical Society. 
Although the reports discussed above proposed the plausible pathways for both RWGS and $\mathrm{CO}_{2}$ methanation, the factors governing $\mathrm{CO} / \mathrm{CH}_{4}$ selectivity under steady-state $\mathrm{CO}_{2}$ reduction conditions were not completely clear. To shed light on this, an interesting and powerful technique called "steady-state isotopic transient kinetic analysis" (SSITKA) was applied by Wang et al. ${ }^{97}$ This technique allowed measurements at steady state in order to determine the abundances and mean surface lifetimes of intermediates leading to products. In addition, operando transmission FTIR was coupled with SSITKA to identify the chemical nature of the surface species. In the controlled experiment with $\mathrm{Pd} / \mathrm{Al}_{2} \mathrm{O}_{3}$ system, the decaying signals of ${ }^{12} \mathrm{CH}_{4}$ and ${ }^{12} \mathrm{CO}$ and the rising signals of ${ }^{13} \mathrm{CH}_{4}$ and ${ }^{13} \mathrm{CO}$ crossed at $\mathrm{y}=0.5$ when the feed gas was switched from ${ }^{12} \mathrm{CO}_{2} / \mathrm{H}_{2} / \mathrm{Ar}$ to ${ }^{13} \mathrm{CO}_{2} / \mathrm{H}_{2}$ at $533 \mathrm{~K}$ (Figures $13 \mathrm{a} \& 13 \mathrm{~b}$ ). The results indicated that the rates for $\mathrm{CH}_{4}$ and $\mathrm{CO}$ formation were constant regardless of isotopic substitution and the steady state of the catalyst surface was not perturbed during the switch. Another important observation was that the concentrations of products $\left({ }^{12} \mathrm{CH}_{4}\right.$ and $\left.{ }^{12} \mathrm{CO}\right)$ decreased more slowly than that of ${ }^{12} \mathrm{CO}_{2}$, indicating the large mean residence times for $\mathrm{C}$-containing surface intermediates leading to the products, and the intermediates which equilibrate with $\mathrm{CO}_{2}$ were not involved in the rate-determining steps for $\mathrm{CO}_{2}$ methanation and RWGS. Based on detailed operando FTIR studies and SSITKA theory, the authors provided a scheme showing the key factors governing the product selectivities in $\mathrm{CO}_{2}$ reduction (Figure 13c), according to which the reduction of formate produces * $\mathrm{CO}$ that first occupies strong adsorption sites on the Pd particles (to form ${ }^{*} \mathrm{CO}_{\mathrm{s}}$ pool). Once the strong adsorption sites of Pd particles are saturated, the excess $* \mathrm{CO}$ can only occupy the weak adsorption sites of $\mathrm{Pd}$ particles (to form $* \mathrm{CO}_{\mathrm{w}}$ ). The $* \mathrm{CO}_{\mathrm{s}}$ gets further hydrogenated to $\mathrm{CH}_{4}$ while the ${ }^{*} \mathrm{CO}_{\mathrm{w}}$ is desorbed. The rate of $\mathrm{CO}$ formation $\left(r_{\mathrm{CO}}\right)$ is calculated as the rate of $\mathrm{HCOO}^{*}$ conversion $\left(r_{\mathrm{HCOO}} *\right)$ subtracted by the rate of $\mathrm{CH}_{4}$ formation $\left(\mathrm{r}_{\mathrm{CH}}\right)$, i.e., $r_{\mathrm{CO}}=r_{\mathrm{HCOO}} *$ $r_{\mathrm{CH} 4}$. Since $* \mathrm{CO}_{\mathrm{s}}$ and $\mathrm{HCOO}^{*}$ do not share and compete for active sites, as they are located on Pd metal and $\mathrm{Al}_{2} \mathrm{O}_{3}$ support, respectively, ${ }^{96}$ rate of $\mathrm{CO}$ formation can be tuned by changing [ ${ }^{*} \mathrm{CO}_{\mathrm{s}}$ ] and $\left[\mathrm{HCOO}^{*}\right]$. For example, higher $\mathrm{CH}_{4}$ selectivity can be achieved either by increasing [ ${ }^{*} \mathrm{CO}_{\mathrm{s}}$ ] or by decreasing [HCOO*]. From the perspective of catalyst design, higher metal loading should result in increased number of metal sites for forming ${ }^{*} \mathrm{CO}_{\mathrm{s}}$ and decreased number of support sites to accommodate HCOO*. This hypothesis was tested on $\mathrm{Pd} / \mathrm{Al}_{2} \mathrm{O}_{3}$ catalysts with different $\mathrm{Pd}$ loadings but similar $\mathrm{Pd}$ particle size distributions, and it was observed that $\mathrm{CH}_{4}$ selectivity increased with increasing Pd loading (Figure 13d). Similar trends were observed on $\mathrm{Ru} / \mathrm{Al}_{2} \mathrm{O}_{3}$ and $\mathrm{Ni} / \mathrm{SiO}_{2}$ systems in previous studies. ${ }^{83,}{ }^{98},{ }^{99}$ Hence, all these systematic studies indicate that lower metal loading and high surface area of support are essential when targeting high $\mathrm{CO}$ selectivity. 
(a)

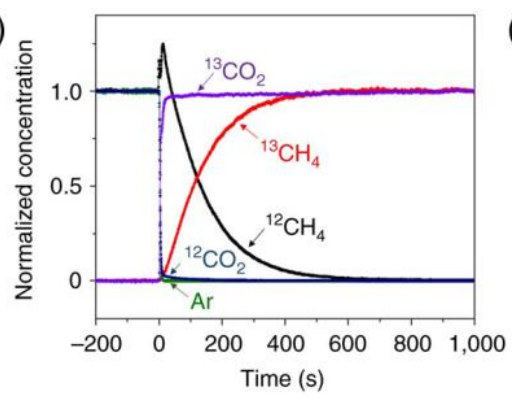

(b)
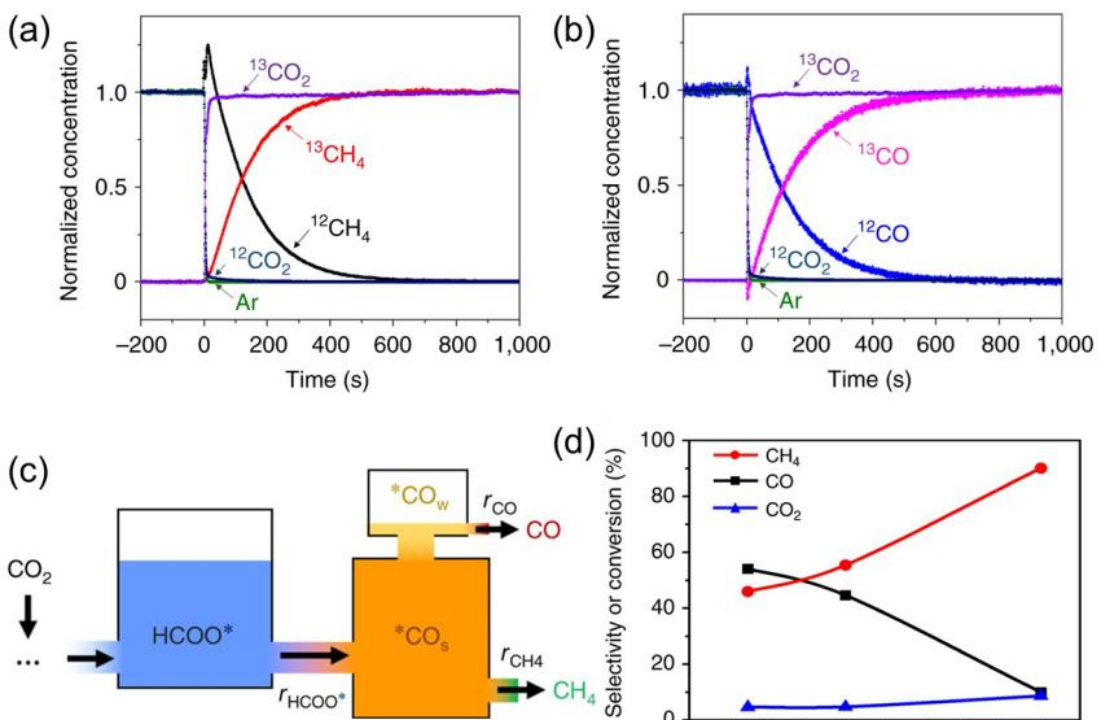

Figure 13. (a \& b) Normalized mass spectrometry signals of gases in the effluent during the switch of feed gas from ${ }^{12} \mathrm{CO}_{2} / \mathrm{H}_{2} / \mathrm{Ar}$ to ${ }^{13} \mathrm{CO}_{2} / \mathrm{H}_{2}$ over $\mathrm{Pd} / \mathrm{Al}_{2} \mathrm{O}_{3}$ catalysts at $533 \mathrm{~K}$. (c) Scheme showing the pathways from formate to products in $\mathrm{CO}_{2}$ methanation and RWGS. (d) $\mathrm{CH}_{4}$ and $\mathrm{CO}$ selectivities and $\mathrm{CO}_{2}$ conversion as a function of $\mathrm{Pd}$ loading at $573 \mathrm{~K}$. Reproduced with permission from ref. 97. Copyright 2017 Springer Nature.

\subsubsection{Summary and challenges}

In summary, in situ spectroscopic and kinetic studies have proven that RWGS and $\mathrm{CO}_{2}$ methanation are not two parallel reactions even if they share the initial steps and intermediates starting from bicarbonate to formate until after the decomposition of the latter. The rate of $\mathrm{CO}$ formation depends on decomposition of adsorbed formate, whereas the rate of $\mathrm{CH}_{4}$ formation is proportional to the hydrogenation rate of adsorbed carbonyl. The balance of the hydrogenation kinetics between adsorbed formates and carbonyls governs the selectivities between $\mathrm{CO}$ and $\mathrm{CH}_{4}$. All the examples discussed in this section provide guidance on design and synthesis of selective RWGS catalysts, which should have the following features: (i) weaker $\mathrm{CO}$ adsorption than $\mathrm{H}$ adsorption on active metal, (ii) presence of oxygen vacancies and reducible character of the support, (iii) strong metal-support interaction, and (iv) addition of promoters. Table 3 summarizes the catalytic performance of selected promising catalysts in $\mathrm{CO}_{2}$ hydrogenation to $\mathrm{CO}$. 
Table 3. Catalytic performance of different catalysts in $\mathrm{CO}_{2}$ hydrogenation to $\mathrm{CO}$

\begin{tabular}{|c|c|c|c|c|c|c|c|}
\hline \multirow[t]{2}{*}{ Catalyst } & \multicolumn{4}{|c|}{ Reaction conditions } & \multicolumn{2}{|c|}{ Catalytic performance } & \multirow[t]{2}{*}{ Ref. } \\
\hline & $T\left({ }^{\circ} \mathrm{C}\right)$ & $\mathrm{P}$ (bar) & $\mathrm{H}_{2} / \mathrm{CO}_{2}$ & $\begin{array}{l}\text { GHSV (mL } \\
\left.\mathrm{g}_{\text {cat }}{ }^{-1} \mathrm{~h}^{-1}\right)\end{array}$ & $X_{\mathrm{CO} 2}(\%)$ & $\mathrm{S}_{\mathrm{CO}}(\%)$ & \\
\hline $0.1 \mathrm{Ru} / \mathrm{Al}_{2} \mathrm{O}_{3}$ & 480 & 1 & 3 & 72000 & $\sim 44$ & $\sim 51$ & 83 \\
\hline $9 \mathrm{Cu} / \mathrm{CeO}_{2}$ & 300 & 1 & 3 & 550 & $\sim 18$ & $\sim 100$ & 45 \\
\hline $2 \mathrm{Ru}_{45} \mathrm{Fe}_{55} / \mathrm{SDC}\left(\mathrm{CeO}_{2}\right)$ & 500 & 1 & 1 & 120000 & $\sim 23$ & $\sim 100$ & 46 \\
\hline $2 \mathrm{Ru}_{45} \mathrm{Fe}_{55} / \mathrm{SDC}\left(\mathrm{CeO}_{2}\right)$ & 500 & 1 & 4 & 120000 & $\sim 46$ & $\sim 99.5$ & 46 \\
\hline $5 \mathrm{Cu} / \mathrm{CeO}_{2}$-nanorod & 450 & 1 & 5 & 150000 & $\sim 50$ & $\sim 100$ & 75 \\
\hline 0.3Pt/zeolite & 500 & 1 & 1 & 30000 & 13.1 & $\sim 97$ & 59 \\
\hline 24K-0.3Pt/zeolite & 500 & 1 & 1 & 30000 & 27.4 & 100 & 59 \\
\hline $1.6 \% \mathrm{Ru} @ \mathrm{mSiO}_{2}-\mathrm{N}_{2}$ & 400 & 1 & 4 & 15000 & 23.0 & 83.5 & 61 \\
\hline $1.7 \% \mathrm{Ru} @ \mathrm{mSiO}_{2}$-Air & 400 & 1 & 4 & 15000 & 19.9 & 4.8 & 61 \\
\hline $5 \mathrm{Pd} / \mathrm{BCNT}$ alginate & 600 & 1 & 4 & 15000 & 48.0 & 99.0 & 64 \\
\hline 7.6Fe/ZIF-8-C & 420 & 1 & 4 & 15000 & 43.8 & 97.3 & 66 \\
\hline 7.4Ni/ZIF-8-C & 420 & 1 & 4 & 15000 & 43.8 & 97.5 & 66 \\
\hline $\mathrm{LaFe}_{0.5} \mathrm{Ni}_{0.5} \mathrm{O}_{3}$ & 400 & 1 & 2 & 24000 & 16.3 & 96.6 & 67 \\
\hline $1.3 \mathrm{Cu} / \beta-\mathrm{Mo}_{2} \mathrm{C}$ & 400 & 1 & 2 & 300000 & 24.3 & 97.6 & 70 \\
\hline $1.3 \mathrm{Cu} / \beta-\mathrm{Mo}_{2} \mathrm{C}$ & 600 & 1 & 2 & 300000 & 47.7 & 99.2 & 70 \\
\hline Octapods- $\mathrm{Fe}_{1.5} \mathrm{Ni}_{1} \mathrm{Zn} \mathrm{MOF}$ & 400 & 1 & 4 & - & 29.9 & 81.0 & 73 \\
\hline $\mathrm{Fe}_{16.2} / \mathrm{CeAl}$ & 500 & 1 & 4 & 30000 & $\sim 39$ & $\sim 98$ & 76 \\
\hline $\mathrm{Fe}_{15.4} \mathrm{Ni}_{10} / \mathrm{CeAl}$ & 500 & 1 & 4 & 30000 & $\sim 55$ & $\sim 53$ & 76 \\
\hline $\mathrm{Fe}_{15.3} \mathrm{Cu}_{9.4} / \mathrm{CeAl}$ & 500 & 1 & 4 & 30000 & $\sim 46$ & $\sim 99.5$ & 76 \\
\hline $0.5 \% \mathrm{Pd} / \mathrm{Al}_{2} \mathrm{O}_{3}$ & 400 & 1 & 3 & 72000 & $\sim 20$ & $\sim 65$ & 82 \\
\hline $0.05 \mathrm{Pt} / \mathrm{CeO}_{2}$ & 300 & 1 & 12.5 & 48000 & $\sim 67$ & 100 & 86 \\
\hline $2 \mathrm{Pt} / \mathrm{CeO}_{2}$ & 300 & 1 & 12.5 & 48000 & $\sim 35$ & 100 & 86 \\
\hline $0.05 \mathrm{Pt} / \mathrm{CeO}_{2}$ & 400 & 1 & 12.5 & 48000 & 100 & 100 & 86 \\
\hline $2 \mathrm{Pt} / \mathrm{CeO}_{2}$ & 400 & 1 & 12.5 & 48000 & $\sim 74$ & $\sim 29$ & 86 \\
\hline 8Pt/Au@Pd@1Co NP & 400 & 20 & 3 & 12000 & 18.2 & 96.1 & 100 \\
\hline Pt/Au@Pd@UIO-66 & 400 & 20 & 4 & 24000 & 35.4 & 78.0 & 101 \\
\hline$\alpha-\mathrm{MoC}_{1-\mathrm{x}}$ & 600 & 1 & 4 & 36000 & $\sim 60$ & 100 & 102 \\
\hline
\end{tabular}

\subsection{Production of Alcohols}

\subsection{1. $\mathrm{CO}_{2}$ to Methanol}

From the stages of early development until now, a wide variety of catalysts have been studied for methanol production with a few of them achieving commercial application. Among the catalysts evaluated in literature, copper-based catalysts have been the most widely studied system. In fact, more than $75 \%$ catalysts studied in the last 10-15 years contain copper as an active metal phase. ${ }^{31,103}$ In the 1960 's, Imperial Chemical Industries developed highly active ternary phase $\mathrm{Cu}-\mathrm{ZnO}-\mathrm{Al}_{2} \mathrm{O}_{3}$ catalyst for the selective production of methanol from naphtha and natural gas under mild conditions. ${ }^{104}$ Based on this study, major focus has been given to $\mathrm{Cu}$-based catalysts, mainly $\mathrm{Cu}-\mathrm{Zn}$ combinations. ${ }^{105-109}$ 


\subsubsection{Cu-based catalysts}

Typical preparations of $\mathrm{Cu}-\mathrm{ZnO}-\mathrm{Al}_{2} \mathrm{O}_{3}$ catalysts follow the co-precipitation method, which has produced catalysts with higher activity as compared to other reported methods. The main reason for this superior performance is the high dispersion and stability of $\mathrm{Cu}$ species due to the unique microstructure of the catalyst achieved after reduction. $\mathrm{ZnO}$ acts as a matrix/spacer to achieve high dispersion of $\mathrm{Cu}$ and the inert $\mathrm{Al}_{2} \mathrm{O}_{3}$ phase enhances the thermal and chemical stability. On comparing $\mathrm{Cu}$ catalysts synthesized with similar preparation protocols, it was observed that catalysts with different extents of accessible $\mathrm{Cu}$ surface area exhibited different activities, indicating that methanol synthesis over $\mathrm{Cu}$ is a structuresensitive reaction. Several experiments were done to understand the role of $\mathrm{Cu}$ and $\mathrm{Zn}$ as well as the interaction between catalyst surface and reaction intermediates. ${ }^{94,}{ }^{110-113}$ It was proposed that the defects and lattice strain in the $\mathrm{Cu}$ NPs affect the intrinsic activity of the $\mathrm{Cu}$ surface. Behrens et al. studied the role of defects in $\mathrm{Cu}-\mathrm{ZnO}-\mathrm{Al}_{2} \mathrm{O}_{3}$ catalyst system and observed that presence of steps at the $\mathrm{Cu}$ surface was essential to achieve high activity. ${ }^{111}$ A highly active $\mathrm{Cu}$ surface could be stabilized by bulk defects like stacking faults or twin boundaries terminating at the surface. The presence of $\mathrm{Zn}^{\delta+}$ at the defective (stepped) $\mathrm{Cu}$ surface induces a dynamic SMSI effect, which increases the binding capability of the oxygen-bound intermediates in order to increase the activity. Sehested and coworkers observed that the activity of methanol production is highly dependent on the surface $\mathrm{Zn}$ coverage of industrial-type $\mathrm{Cu}$ $\mathrm{ZnO}-\mathrm{Al}_{2} \mathrm{O}_{3}$ catalyst. ${ }^{12}$ Catalysts with smaller $\mathrm{ZnO}$ particles are more active because of an enhanced spillover of $\mathrm{Zn}$ to the $\mathrm{Cu}$ surfaces. Although the role of $\mathrm{Zn}$ was investigated in some reports, identifying the active species was a matter of debate. Between the two possibilities, one possibility could be the interface of $\mathrm{Cu}$ and $\mathrm{ZnO}$ that activates $\mathrm{CO}_{2}$. The second possibility was the formation of highly active $\mathrm{ZnCu}$ bimetallic alloy by partial reduction during the reaction. Studies by Kattel et al. showed that during the reaction, active $\mathrm{ZnCu}$ phase undergoes surface oxidation by $* \mathrm{O}$ species (produced from $* \mathrm{CO}_{2}$ dissociation) to form $\mathrm{ZnO} .{ }^{94}$ This lead to high dispersion of $\mathrm{Zn}$ sites on $\mathrm{Cu}$ surface which increased the overall methanol production.

Since the $\mathrm{CO}_{2}$-to-methanol transformation reaction is sensitive towards the size and structure of the active phase of the catalyst, ${ }^{114-118}$ it is very important to maintain the particle size of active metals and stabilize them against sintering under reaction conditions. Considering the example of novel ternary phase $\mathrm{Cu}-\mathrm{ZnO}-\mathrm{Al}_{2} \mathrm{O}_{3}$ catalyst, water is formed as one of the main byproducts due to its significant activity in RWGS reaction. ${ }^{119}$ As a result, deactivation of the active phase occurs by water-induced sintering. ${ }^{120}$ Taking advantage of the high activity of copper, several studies were done with other materials such as $\mathrm{ZrO}_{2}, \mathrm{TiO}_{2}, \mathrm{CeO}_{2}, \mathrm{SiO}_{2}$ and zeolites as support in order to achieve high dispersion of $\mathrm{Cu}$, and as expected, the $\mathrm{CO}_{2}$ hydrogenation activity was improved in most cases. ${ }^{113,}{ }^{121-133}$ For example, $\mathrm{Cu}$ has been reported to strongly interact with $\mathrm{ZrO}_{2}$, leading to more dispersed NPs and enhanced catalyst stability. ${ }^{134}$ It was also observed that the $\mathrm{Cu}-\mathrm{ZrO}_{2}$ interface was more active than pure $\mathrm{Cu}$ surface due to formation of oxygen vacancies by $\mathrm{ZrO}_{2} \cdot{ }^{93}, 113,135$ Along this line, Tada and coworkers studied the formation mechanism of specific active $\mathrm{Cu}$ sites on $\mathrm{ZrO}_{2}$ samples of different phases (such as amorphous, tetragonal and monoclinic). When copper nitrate solution was impregnated in amorphous $\mathrm{ZrO}_{2}\left(\mathrm{a}-\mathrm{ZrO}_{2}\right)$, most of the $\mathrm{Cu}$ species entered into $\mathrm{a}-\mathrm{ZrO}_{2}$, leading to the formation of a $\mathrm{Cu}-\mathrm{Zr}$ mixed oxide $\left(\mathrm{Cu}_{\mathrm{a}} \mathrm{Zr}_{1-\mathrm{a}} \mathrm{O}_{\mathrm{b}}\right)$, which upon $\mathrm{H}_{2}$ reduction produced the active $\mathrm{Cu}$ NPs. Relatively higher dispersion of $\mathrm{Cu}$ species was observed on a$\mathrm{ZrO}_{2}$ than those on $\mathrm{m}-\mathrm{ZrO}_{2}$ and $\mathrm{t}-\mathrm{ZrO}_{2}$, and the $\mathrm{Cu}^{+}$species next to the oxygen vacancy sites were supposed to work as acid sites active for methanol production. A recent study has also shown that $\mathrm{ZrO}_{2}$ can form a solid solution with another oxide (e.g., $\mathrm{ZnO}$ ) to make a binary oxide catalyst, which showed a 
methanol selectivity of up to 86 to $91 \%$ with $\mathrm{CO}_{2}$ single-pass conversion of more than $10 \% .{ }^{136}$ More interestingly, the catalyst was resistant to sintering at higher temperatures for at least $500 \mathrm{~h}$ on stream, showing the advantage of using $\mathrm{ZrO}_{2}$ in making a high performance solid solution catalyst. Taking the advantage of $\mathrm{ZnO}-\mathrm{ZrO}_{2}$ interaction, Wang et al. recently prepared ternary phase three-dimensional ordered macroporous $\mathrm{Cu} / \mathrm{ZnO} / \mathrm{ZrO}_{2}$ catalyst that was able to achieve $80 \%$ methanol selectivity at a $\mathrm{CO}_{2}$ conversion of $\sim 19 \% .{ }^{137}$ The $\mathrm{ZrO}_{2}-\mathrm{ZnO}$ interface was supposed to act as active sites for $\mathrm{CO}_{2}$ adsorption to carbonate species and its subsequent conversion to formate, which was further hydrogenated to methanol over the active $\mathrm{Cu}$ sites.

Although most of the studies based on a $\mathrm{Cu}-\mathrm{Zr}$ system explained the reason behind improved activity as the better adsorption properties of the $\mathrm{Cu}-\mathrm{Zr}$ interface, the actual role of the $\mathrm{ZrO}_{2}$ support was not clear at a molecular level. In many studies, it was proposed that the oxygen vacancies created on $\mathrm{ZrO}_{2}$ and the electronic charge transfer between $\mathrm{Cu}$ and the support could be the most probable reasons for the enhanced performance. ${ }^{93,134,138}$ However, the nature of the $\mathrm{Zr}$ site participating in $\mathrm{CO}_{2}$ hydrogenation, i.e. $\mathrm{Zr}$ (III) vs $\mathrm{Zr}(\mathrm{IV})$, was a matter of debate because the earlier characterization techniques were mainly applied to probe the reactivity of $\mathrm{ZrO}_{2}$ in the bulk phase. Copéret and coworkers recently developed an interesting approach to understand the local properties of $\mathrm{Zr}$ atoms next to active $\mathrm{Cu}$ centers on the surface. ${ }^{139}$ Using a surface organometallic chemistry approach, they functionalized a silica support with isolated $\mathrm{Zr}(\mathrm{IV})$ surface sites and doped $\mathrm{Cu}$ NPs $(\sim 3 \mathrm{~nm})$ on it (Figure 14a). The designed catalyst exhibited increased activity and $\mathrm{CH}_{3} \mathrm{OH}$ selectivity compared to the $\mathrm{Cu}$ catalyst supported on $\mathrm{SiO}_{2}$ without $\mathrm{Zr}$ promotion, while the catalytic activity was comparable to the corresponding $\mathrm{Cu} / \mathrm{ZrO}_{2}$ containing bulk $\mathrm{ZrO}_{2}$ phase (Figure 14b). As observed by solid-state NMR studies, similar surface intermediates (formate and methoxy) were formed on both $\mathrm{Cu} / \mathrm{Zr}_{0.9} @ \mathrm{SiO}_{2}$ and $\mathrm{Cu} / \mathrm{ZrO}_{2}$, but not on $\mathrm{Cu} / \mathrm{SiO}_{2}$ (Figure 14c), implying that the $\mathrm{Cu}-\mathrm{Zr}$ interaction was a crucial factor and the reaction proceeded via a similar mechanism on both $\mathrm{Cu} / \mathrm{Zr}_{0.9} @ \mathrm{SiO}_{2}$ and $\mathrm{Cu} / \mathrm{ZrO}_{2}$. Based on the catalytic results, it could be concluded that the structural and bulk properties of $\mathrm{ZrO}_{2}$, such as oxygen vacancies or alloy formation, were not the important factors behind different activities. Rather, the presence of isolated Lewis acidic $\mathrm{Zr}$ (IV) sites on the silica surface was sufficient to increase the activity and selectivity. Furthermore, ex situ and in situ X-ray absorption spectroscopy showed no change in oxidation state of the isolated $\mathrm{Zr}$ (IV) sites in $\mathrm{Cu} / \mathrm{Zr}_{0.9} @ \mathrm{SiO}_{2}$ system under pretreatment or reaction conditions (Figure 14d), which confirmed that $\mathrm{Zr}^{4+}$ was the actual species responsible in $\mathrm{CO}_{2}$ activation. Following this work, the authors recently reported better intrinsic activity by introducing $\mathrm{Ga}(\mathrm{III})$ single sites in the system. ${ }^{140}$ The improved performance was attributed to $\mathrm{Cu}(0) / \mathrm{Ga}$ (III) interfaces that only stabilized methoxy and not formate intermediates. 

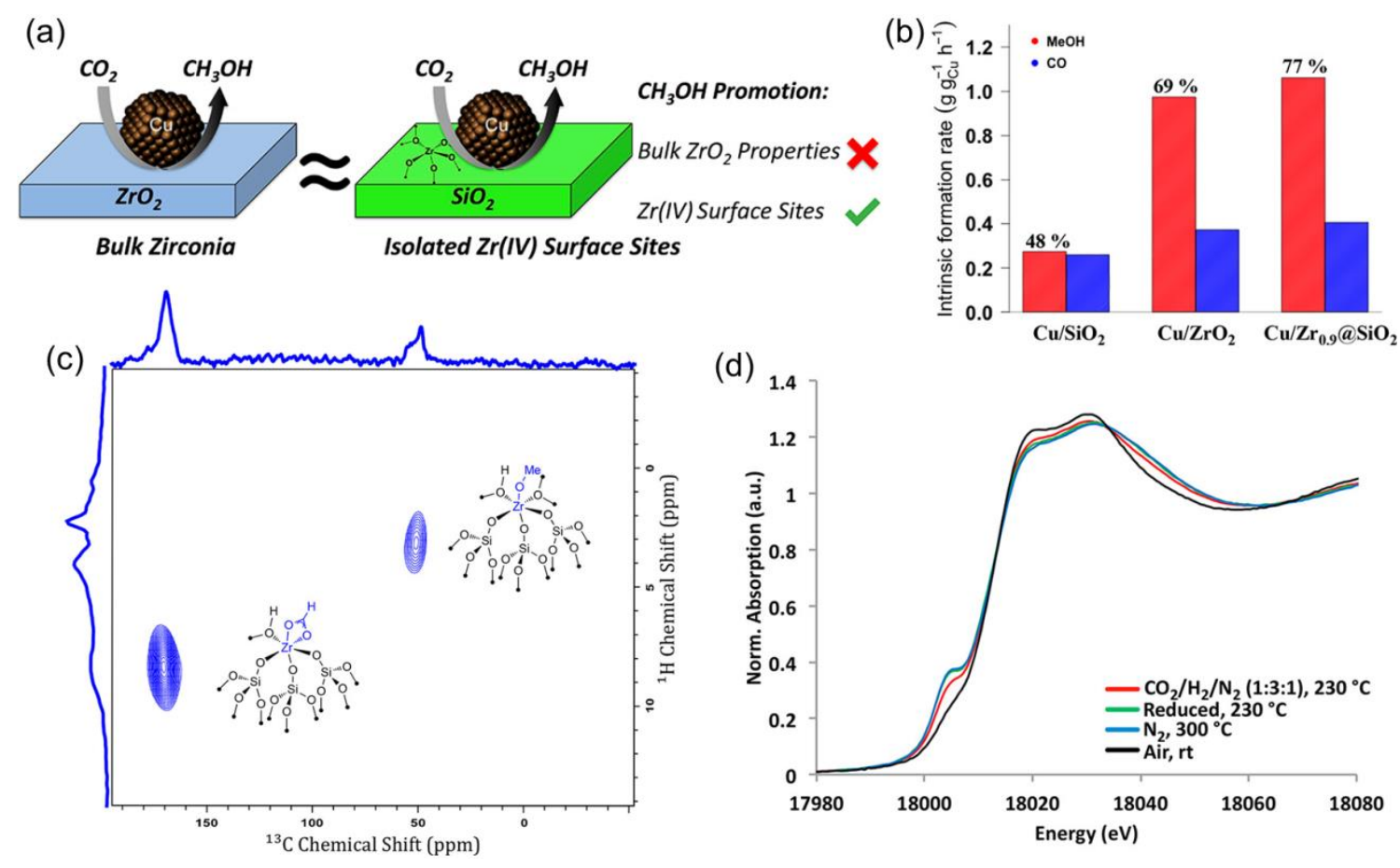

Figure 14. (a) Schematic diagram of $\mathrm{Cu} / \mathrm{ZrO}_{2}$ and $\mathrm{Cu} / \mathrm{Zr}_{0.9} @ \mathrm{SiO}_{2}$ systems showing bulk and surface properties of $\mathrm{ZrO}_{2}$. (b) Comparison of catalytic activities of three different catalysts. (c) Ex situ solid-state NMR studies of $\mathrm{Cu} / \mathrm{Zr}_{0.9} @ \mathrm{SiO}_{2}$ after exposure to ${ }^{13} \mathrm{CO}_{2}$ and ${ }^{1} \mathrm{H}_{2}$ (in a 3:1 ratio) at 5 bar and $230{ }^{\circ} \mathrm{C}$. (d) In situ X-ray absorption spectroscopy (showing $\mathrm{Zr}$ K-edge XANES spectra) of $\mathrm{Cu} / \mathrm{Zr}_{0.9} @ \mathrm{SiO}_{2}$ under different conditions. Reproduced with permission from ref. 139. Copyright 2018 American Chemical Society.

Other than $\mathrm{ZrO}_{2}$, Li et al. achieved improved dispersion of $\mathrm{Cu}$ with high surface areas over layered double hydroxide (LDH) nanosheets, producing high space-time yield of methanol. ${ }^{141}$ Ultrathin LDH structures feature distinctive local steric and electrostatic stabilization to embed active $\mathrm{Cu}(\mathrm{Zn})$ species in the cationic layers. Due to the high surface area of silica materials, they can stabilize high metal loadings without agglomeration. For example, micro-spherical $\mathrm{SiO}_{2}$ prepared by the spray-drying method was able to maintain uniform distribution of $\mathrm{Cu}$ and $\mathrm{Zn}$ up to a metal loading of $48 \mathrm{wt} \%$ due to its highly porous nature. ${ }^{142}$ However, the $\mathrm{CO}_{2}$ conversion started to decrease slightly above $\mathrm{Cu}$ loading of $28 \mathrm{wt} \%$ due to pore blockage and decreased reducibility of catalysts caused by excess metal incorporation into the pores of $\mathrm{SiO}_{2}$. In some cases, basic support (such as lanthanum oxide) showed good performance due to both superior dispersion and increased $\mathrm{CO}_{2}$ adsorption capacity. ${ }^{143,}{ }^{144}$ Formation of $\mathrm{Cu}^{\delta+}$ species at the $\mathrm{Cu} / \mathrm{La}_{2} \mathrm{O}_{2} \mathrm{CO}_{3}$ interfacial area and presence of basic sites work together to play a synergetic effect that can stabilize $* \mathrm{HCOO}$ and $* \mathrm{CH}_{3} \mathrm{O}$ intermediates against their decomposition into $\mathrm{CO}$.

An excellent technique to stabilize and restrict particle growth of the active $\mathrm{Cu}$ phase was reported by Rungtaweevoranit et al., where a metal-organic framework (MOF)-based $\mathrm{Cu}$ catalyst (CucUiO-66) was prepared by encapsulating $18 \mathrm{~nm}$ single $\mathrm{Cu}$ nanocrystal (NC) within $\mathrm{Zr}$-based single crystal UiO-66 MOF. ${ }^{145}$ The catalyst outperformed the benchmark $\mathrm{Cu} / \mathrm{ZnO} / \mathrm{Al}_{2} \mathrm{O}_{3}$ catalyst to give a steady 8 -fold enhanced yield and 100\% methanol selectivity. Multiple oxidation states of $\mathrm{Cu}$ and the higher interfacial contact area between $\mathrm{Cu}$ NCs and Zr oxide secondary building units of the MOF were believed 
to be the main reasons behind high TOF for methanol formation. A similar approach was reported by An et al., where they used metal-organic frameworks (MOFs) to anchor ultrasmall $\mathrm{Cu} / \mathrm{ZnO}_{x}$ NPs (Figure 15a). ${ }^{146} \mathrm{Zr}$ and bipyridine were used to construct a thermally stable UiO-bpy MOF, in which bipyridine moieties worked as anchoring units. A sequential post-synthetic metalation of $\mathrm{Cu}$ and $\mathrm{Zn}$ precursors followed by an in situ hydrogenation at $250{ }^{\circ} \mathrm{C}$ was used in order to obtain the final catalyst. NPs of diameter less than $1 \mathrm{~nm}$ were entrapped in tetrahedral and octahedral cages confined by the ligands providing excellent stability against sintering. The resulting $\mathrm{Cu} / \mathrm{ZnO}_{x} @ \mathrm{MOF}$ catalysts showed high stability over $100 \mathrm{~h}$ and a space-time yield of up to $2.59 \mathrm{~g}_{\mathrm{MeOH}} \mathrm{kg}_{\mathrm{Cu}}{ }^{-1} \mathrm{~h}^{-1}$ with $100 \%$ methanol selectivity. The excellent activity was attributed to the high degree of mixing between $\mathrm{Cu}$ and $\mathrm{ZnO}_{x}$ phases, leading to the formation of low-valence $\mathrm{Zn}$ and $\mathrm{Zr}$ in the presence of $\mathrm{H}_{2}$ at $250{ }^{\circ} \mathrm{C}$. Very recently, Kobayashi and coworkers reported a catalyst consisting of $\mathrm{Cu}$ NPs covered with a zirconium/hafnium-based MOF and demonstrated the correlation between activity and metal-support interaction. ${ }^{147}$ To compare the support effect, $\mathrm{CO}_{2}$ hydrogenation was studied over different catalysts such as $\mathrm{Cu} / \gamma-\mathrm{Al}_{2} \mathrm{O}_{3}, \mathrm{Cu} / \mathrm{ZIF}-8, \mathrm{Cu} / \mathrm{MIL}-$ 100 and $\mathrm{Cu} / \mathrm{UiO}-66$ composites that contained different metals in the MOF skeleton. Among the tested catalysts, $\mathrm{Cu} / \mathrm{Zr}-\mathrm{UiO}-66$ was found to be the most effective, producing methanol at a rate 70 times larger than that of $\mathrm{Cu} / \gamma-\mathrm{Al}_{2} \mathrm{O}_{3}$ and the activity was increased by three times when $\mathrm{Zr}^{4+}$ was replaced by $\mathrm{Hf}^{4+}$ in UiO-66. Interestingly, the substituent in the MOF structure played a crucial role in the catalytic activity. For example, methanol production rate on $\mathrm{Cu} / \mathrm{Zr}-\mathrm{UiO}-66-\mathrm{COOH}$ was significantly higher compared to $\mathrm{Cu} / \mathrm{Zr}-\mathrm{UiO}-66$ or $\mathrm{Cu} / \mathrm{Zr}-\mathrm{UiO}-66-\mathrm{NH}_{2}$, which was mainly due to the higher degree of charge transfer from $\mathrm{Cu}$ to UiO-66, as evidenced from XPS analysis (Figure 15b). Very recently, Liu et al. developed a series of $\mathrm{Cu} @ \mathrm{ZrO}_{x}$ catalysts with a three-dimensional porous framework structure via partial pyrolysis of sizeconfined Cu@UiO-66 precursor. ${ }^{148}$ The final catalysts could achieve a highest methanol space-time yield of $0.796 \mathrm{~g} \mathrm{~g}_{\mathrm{cat}}{ }^{-1} \mathrm{~h}^{-1}$ at $260{ }^{\circ} \mathrm{C}$.

(a)

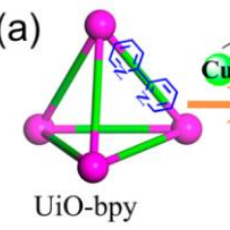

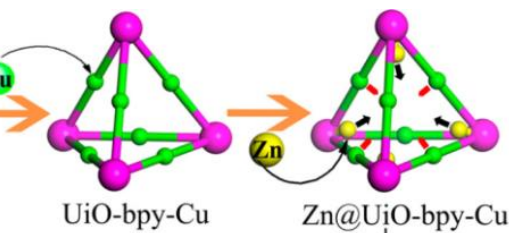

Post-synthetic Modification

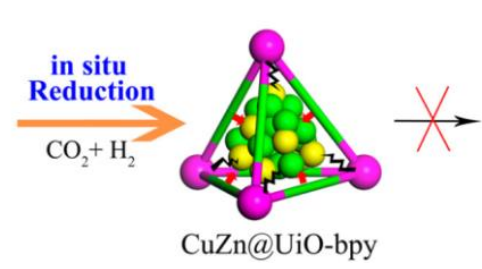

on

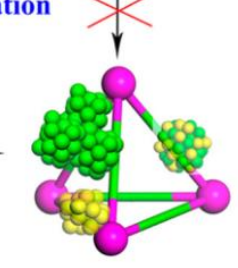

(b)

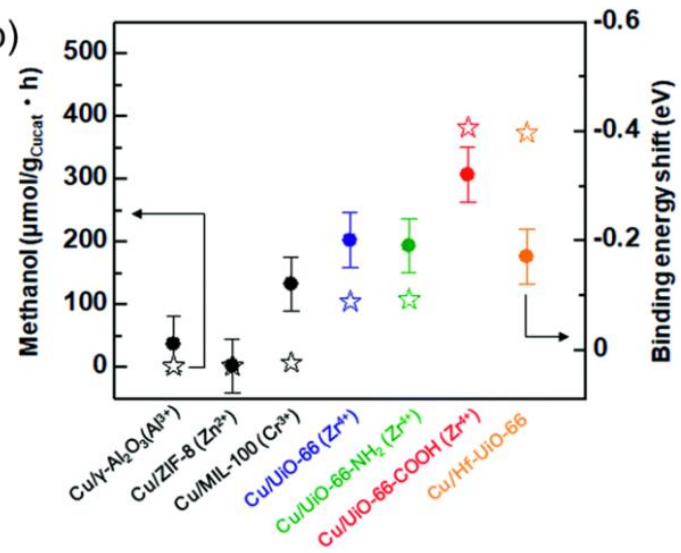

Figure 15. (a) Synthesis of CuZn@UiO-bpy catalyst via postsynthetic metalation followed by in situ reduction. (b) Relationship between methanol production rate and binding energy shift for $\mathrm{Cu} / \gamma-\mathrm{Al}_{2} \mathrm{O}_{3}$ and $\mathrm{Cu} / \mathrm{MOF}$ catalysts. Reproduced with permission from ref. 146 and 147. Copyright 2017 American Chemical Society and 2019 Royal Society of Chemistry.

\subsubsection{Non-Cu-based catalysts}

Recently, some intermetallic catalytic systems other than the classical $\mathrm{Cu}-\mathrm{Zn}$ combination were found to be comparably active or better in terms of both $\mathrm{CO}_{2}$ hydrogenation kinetics and methanol selectivity. ${ }^{149-160}$ Studt et al. reported silica supported $\mathrm{Ni}-\mathrm{Ga}$ catalyst as better than the existing 
$\mathrm{Cu} / \mathrm{ZnO} / \mathrm{Al}_{2} \mathrm{O}_{3}$ catalyst in terms of reduced RWGS activity. ${ }^{149}$ The catalyst was able to reduce $\mathrm{CO}_{2}$ to methanol at ambient pressure and it was observed that a specific stoichiometric ratio $\left(\mathrm{Ni}_{5} \mathrm{Ga}_{3}\right)$ was required in the catalyst formulation to achieve high selectivity. Similarly, after the discovery of excellent methanol selectivity and remarkable stability of indium oxide $\left(\operatorname{In}_{2} \mathrm{O}_{3}\right),{ }^{161}$ different bimetallic indium catalysts were also studied. ${ }^{147,150,151,153,162-169}$ A second metal is usually required because the $\mathrm{H}_{2}$-splitting ability of In is limited. Among recent examples, Pd-In bimetallic system showed that intermetallic Pd-In nanoparticles were able to produce methanol at around $70 \%$ higher rates as compared to $\mathrm{Cu} / \mathrm{ZnO} / \mathrm{Al}_{2} \mathrm{O}_{3}$ catalyst at $210{ }^{\circ} \mathrm{C} .{ }^{151}$ The catalyst was far more active than individual $\mathrm{Pd}(0)$ or $\operatorname{In}_{2} \mathrm{O}_{3}$ catalyst in liquid phase $\mathrm{CO}_{2}$ hydrogenation, but a stoichiometric ratio (Pd:In = 1:1) was important to form Pd-In intermetallic phase, which means a significant amount of Pd was required. Furthermore, the Pd-In catalyst was highly active for the parasitic RWGS reaction when applied in the gas phase as nanoparticles supported on silica. To overcome this problem, Pérez-Ramírez and his group recently adopted coprecipitation (CP) method to incorporate isolated $\mathrm{Pd}$ atoms in the $\mathrm{In}_{2} \mathrm{O}_{3}$ lattice. ${ }^{164}$ Indium atoms in the active $\mathrm{In}_{3} \mathrm{O}_{5}$ ensemble were replaced by $\mathrm{Pd}$ atoms that attracted additional $\mathrm{Pd}$ atoms and deposited onto the surface forming low-nuclearity Pd clusters. The catalyst produced a record space-time yield of 0.96 $\mathrm{g}_{\mathrm{MeOH}} \mathrm{h}^{-1} \mathrm{~g}_{\mathrm{cat}}{ }^{-1}$ even after $500 \mathrm{~h}$ on stream. A microkinetic model was derived to explain the Pd promotion in this system (Figure 16). The apparent activation energy for methanol production was lowered by 56 or $4 \mathrm{~kJ} \mathrm{~mol}^{-1}$ when 1 or 2 exposed Pd atoms were present, respectively, and the RWGS reaction was hindered by a barrier higher by at least $+80 \mathrm{~kJ} \mathrm{~mol}^{-1}$ compared with $\operatorname{In}_{2} \mathrm{O}_{3}$. When 3 or more exposed $\mathrm{Pd}$ atoms were present (in case of catalyst prepared via dry impregnation (DI) method), the barrier of the RWGS reaction was decreased by $-7 \mathrm{~kJ} \mathrm{~mol}^{-1}$ and the active sites started behaving like metallic Pd that hindered the methanol production.
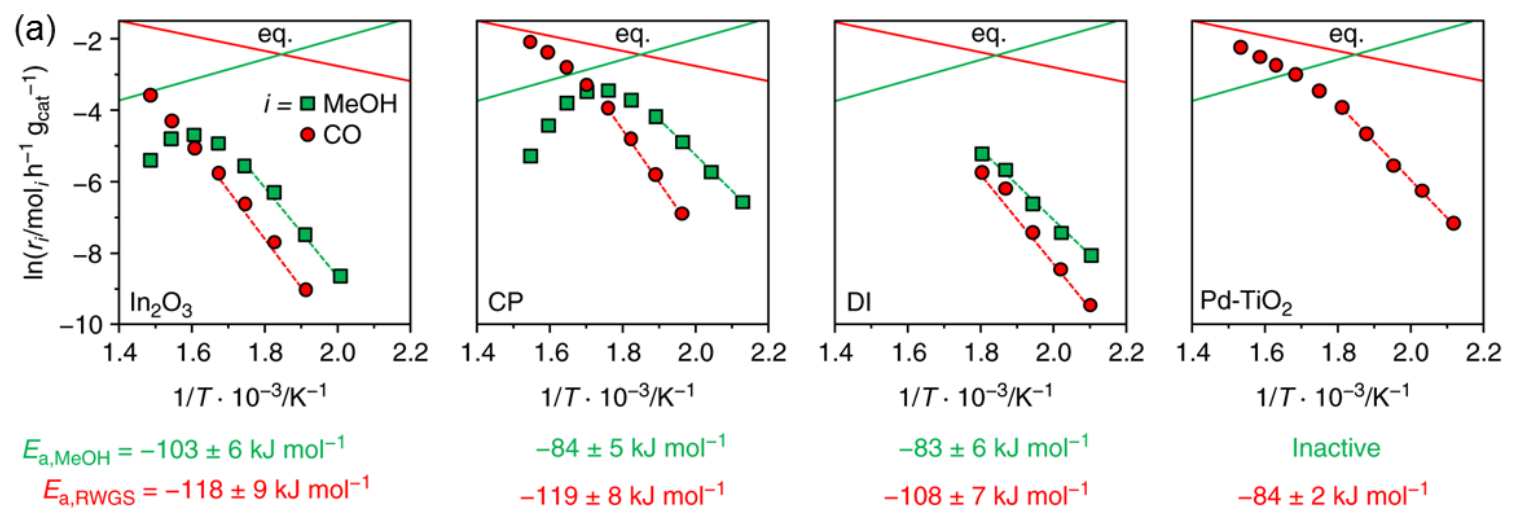

(b)
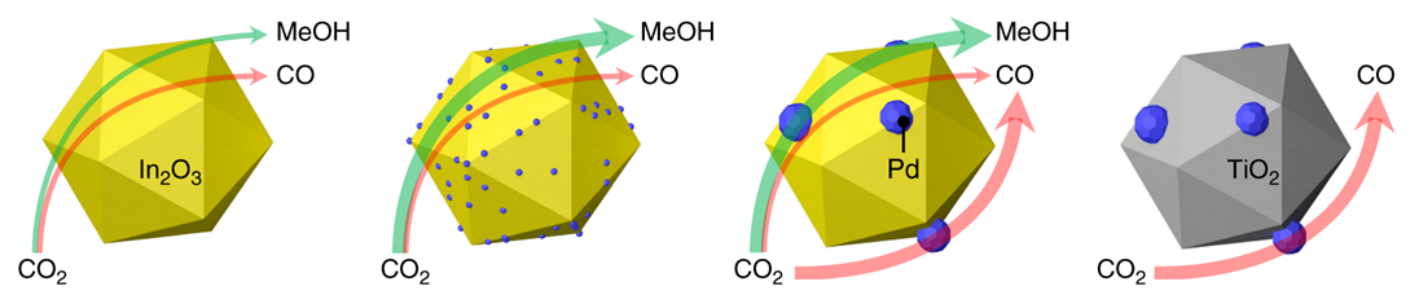

Figure 16. Promotion effect of $\mathrm{Pd}$ in $\mathrm{In}_{2} \mathrm{O}_{3}$ catalysts. (a) Arrhenius plots and calculated apparent activation energies $\left(E_{\mathrm{a}}\right)$ for $\mathrm{CO}_{2}$ hydrogenation over $\mathrm{In}_{2} \mathrm{O}_{3}, \mathrm{Pd}-\mathrm{In}_{2} \mathrm{O}_{3}-\mathrm{CP}, \mathrm{Pd}-\mathrm{In}_{2} \mathrm{O}_{3}-\mathrm{DI}$, and $\mathrm{Pd}-\mathrm{TiO}_{2}$ catalysts. (b) Schematic representation of the distinct role of Pd in equilibrated CP and DI systems with $\mathrm{In}_{2} \mathrm{O}_{3}$ and $\mathrm{Pd}-\mathrm{TiO}_{2}$ as references. The thickness of the arrows qualitatively indicates the products formation rates. Reproduced with permission from ref. 164. Copyright 2019 Springer Nature. 
Another promising In based system was recently reported by Bavykina et al. ${ }^{165}$ In particular, the authors developed a highly stable bimetallic In@Co system that achieved $\mathrm{CO}_{2}$ conversion levels close to thermodynamic equilibrium at $300{ }^{\circ} \mathrm{C}$. While the individual In and $\mathrm{Co}$ components act as $\mathrm{CO}$ and methane producers, respectively, their combination ( $\mathrm{In} @ \mathrm{Co}$ ) acts as an active methanol catalyst. DFT calculations showed that the charge transfer between the Co support and the $\operatorname{In}_{2} \mathrm{O}_{3}$ enhanced the surface of $\mathrm{In}_{2} \mathrm{O}_{3}$ with $\mathrm{O}$ vacancies, which served as the active sites for this reaction. A similar phenomenon was observed in case of $\mathrm{In}_{2} \mathrm{O}_{3}-\mathrm{ZrO}_{2}$ mixed oxide system, but only monoclinic $\mathrm{ZrO}_{2}$ showed pronounced effects on $\mathrm{In}_{2} \mathrm{O}_{3}$ due to the lattice mismatching. ${ }^{170}$ The performance of the catalysts was highly dependent on their synthesis method. $\mathrm{In}_{2} \mathrm{O}_{3}-\mathrm{ZrO}_{2}$ materials synthesized via coprecipitation formed a solid solution to create maximal interaction between the two metal oxides, which resulted in inferior activity. By contrast, deposition synthesis method formed subnanometric islands of $\operatorname{In}_{2} \mathrm{O}_{3}$ on the carrier to pronounce more tensile forces, which triggered the formation of an excess of oxygen vacancies and enhanced the indium-specific activity. Taking the advantage of $\operatorname{In}_{2} \mathrm{O}_{3}-\mathrm{ZrO}_{2}$ synergy, Jiang et al. did a combined experimental and DFT study to elucidate the role of water on the activity and selectivity of $\operatorname{In}_{2} \mathrm{O}_{3} / \mathrm{ZrO}_{2}$ catalyst. ${ }^{171}$ It was found that the $\mathrm{CH}_{3} \mathrm{OH}$ formation rate could be enhanced by $20 \%$ by adding an appropriate amount of $\mathrm{H}_{2} \mathrm{O}(0.1 \mathrm{~mol} \%)$ in the feed gas. XPS and TPD analyses revealed the formation of $\mathrm{H}_{2} \mathrm{O}$-induced oxygen vacancies and $\mathrm{InOOH}$ species on the $\operatorname{In}_{2} \mathrm{O}_{3}(110) / \mathrm{ZrO}_{2}$ surface, which appeared to improve $\mathrm{CO}_{2}$ adsorption and hydrogenation ability. According to DFT calculations, addition of $\mathrm{H}_{2} \mathrm{O}$ facilitated surface $\mathrm{InOOH}$ formation, suppressed $\mathrm{CO}$ formation from $\mathrm{COOH}^{*}$ intermediate, and promoted $\mathrm{CH}_{3} \mathrm{OH}$ formation through $\mathrm{HCOO}^{*}$ intermediate. The activation energy for $\mathrm{HCOO}^{*}$ formation was reduced by $\sim 29 \%$ due to the presence of $\mathrm{H}_{2} \mathrm{O}$ at an adjacent In site (Figure 17), and altered the transition state formation route and stability as compared to the case without $\mathrm{H}_{2} \mathrm{O}$. As a result, the $\mathrm{COOH}^{*}$ pathway to produce $\mathrm{CO}$ was suppressed and the methanol production was enhanced via the $\mathrm{HCOO}^{*}$ intermediate.

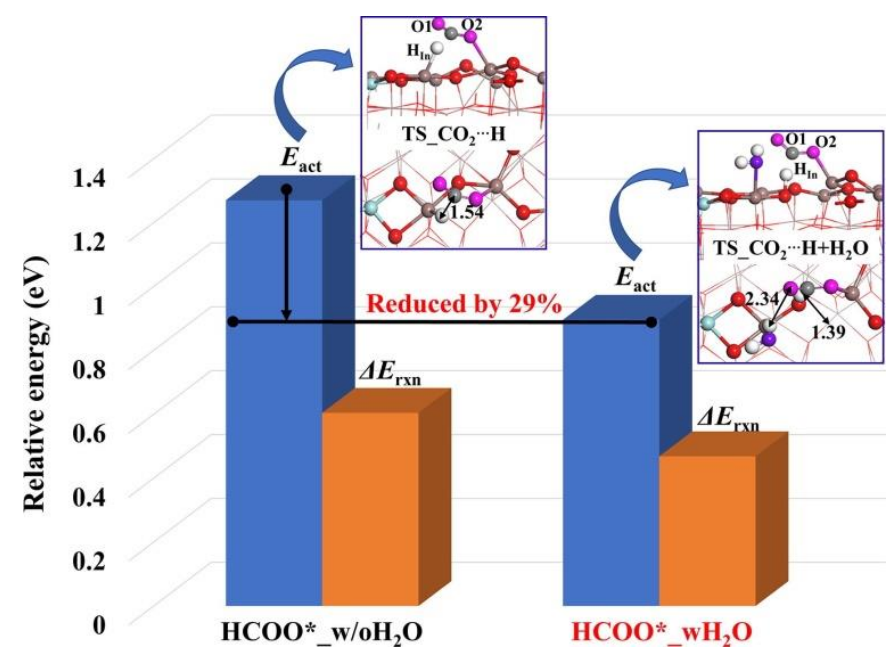

Figure 17. Promotional effect of water: the reaction energy and activation barrier for $\mathrm{CO}_{2}$ hydrogenation to HCOO* intermediate in the absence and presence of $\mathrm{H}_{2} \mathrm{O}$ on the $\mathrm{In}_{2} \mathrm{O}_{3}(110) / \mathrm{ZrO}_{2}$ surface. Reproduced with permission from ref. 171. Copyright 2020 Elsevier.

Similar bimetallic effects were observed in case of $\mathrm{PdZn}$ alloy supported on $\mathrm{CeO}_{2}{ }^{152}$ About $\sim 100 \%$ methanol selectivity was achieved when Ca was doped on this system as a promoter. The improved activity and selectivity of the catalyst were mainly because of the excellent $\mathrm{H}_{2}$ dissociation 
ability of the PdZn alloy to actively hydrogenate the adsorbed carbonaceous species. Furthermore, according to XPS analysis, $\mathrm{Ce}^{3+}$ ions facilitated the generation of oxygen-vacant sites over the surface of the catalyst, which assisted $\mathrm{CO}_{2}$ dissociation effectively in order to achieve higher methanol formation rates. Very recently, Jiang et al. reported $\mathrm{Pd}-\mathrm{Cu}$ bimetallic catalysts, where $\mathrm{CO}_{2}$ was found to be adsorbed as carbonate and bicarbonate species on the surface. ${ }^{172}$ The bimetallic catalysts were observed to provide a significant enhancement of $\mathrm{CO}_{2}$ adsorption as compared to their monometallic counterpart. The synergetic effect was maximum at a particular $\mathrm{Pd} /(\mathrm{Pd}+\mathrm{Cu})$ atomic ratio of 0.33 , where the formation of $\mathrm{HCOO}^{*}$ experienced the lowest energy barrier. The alloy effect of $\mathrm{Pd}-\mathrm{Cu}$ bimetallic system was studied in detail by DFT calculations and proved with experimental results. ${ }^{173}$ According to the DFT calculations, the stepped $\mathrm{PdCu}(111)$ surface (with low-coordinated $\mathrm{Pd}$ atoms exposed on top of the surface) showed better adsorption and activation of $\mathrm{CO}_{2}$ and $\mathrm{H}_{2}$, resulting in superior activity for $\mathrm{CO}_{2}$ hydrogenation as compared to the flat $\mathrm{Cu}$-rich $\mathrm{PdCu}_{3}(111)$ surface. Complementary to the DFT results, experiments over $\mathrm{SiO}_{2}$-supported bimetallic catalysts showed that the $\mathrm{Pd}-\mathrm{Cu}(0.50)$, rich in the $\mathrm{PdCu}$ alloy phase, was more selective to methanol than the $\mathrm{PdCu}_{3}$-rich $\mathrm{Pd}-\mathrm{Cu}(0.25)$.

Apart from these examples discussed above based on metal-metal interaction, electronic modification can also be achieved through the metal-support interaction. For instance, an electronic polarization at the metal-support interface was observed in case of Au nanoparticles anchored and stabilized on a $\mathrm{CeO}_{x} / \mathrm{TiO}_{2}$ substrate. ${ }^{174}$ Small coverages of $\mathrm{CeO}_{\mathrm{x}}(\sim 0.1 \mathrm{ML})$ were found to stabilize the formation of small Au nanoparticles, which significantly promoted their activity in RWGS to produce $\mathrm{CO}$. On the other hand, electronic metal-support interaction led to charge redistribution in the metal near the Au-CeO ${ }_{x}$ interface that effectively adsorbed and activated $\mathrm{CO}_{2}$ and stabilized carboxylate species. The combined effect led to the selective formation of methanol through RWGS via $* \mathrm{HCO}, * \mathrm{H}_{2} \mathrm{CO}$, and ${ }^{*} \mathrm{H}_{3} \mathrm{CO}$ intermediates. Following these examples, Zeng and coworkers showed that the presence of nitrogen can significantly change the hydrogenation activity of Co ${ }^{175}$ Incorporation of $\mathrm{N}$ atoms into Co nanosheets resulted in a huge drop in activation energy compared to pure Co nanosheets and therefore exhibited excellent TOF for methanol. According to mechanistic studies by in situ DRIFTS, $\mathrm{Co}_{4} \mathrm{~N}$ nanosheets were reconstructed into $\mathrm{Co}_{4} \mathrm{NH}_{\mathrm{x}}$ by adsorbing $\mathrm{H}$ atoms on $\mathrm{N}$ atoms (stretching vibration of $\mathrm{N}-\mathrm{H}$ at $3140 \mathrm{~cm}^{-1}$ in Figure 18). These amido-hydrogen atoms in $\mathrm{Co}_{4} \mathrm{NH}_{\mathrm{x}}$ species directly interacted with the $\mathrm{CO}_{2}$ to form $\mathrm{HCOO}^{*}$ intermediates. In addition, the adsorbed $\mathrm{H}_{2} \mathrm{O}^{*}$ species were found to activate amido-hydrogen atoms via H-bonding, which also facilitated the hydrogenation process. This example shows an effective way to boost the catalytic activity of non-noble metal catalysts toward hydrogenation reactions just by incorporating $\mathrm{N}$ atoms. 
(a)

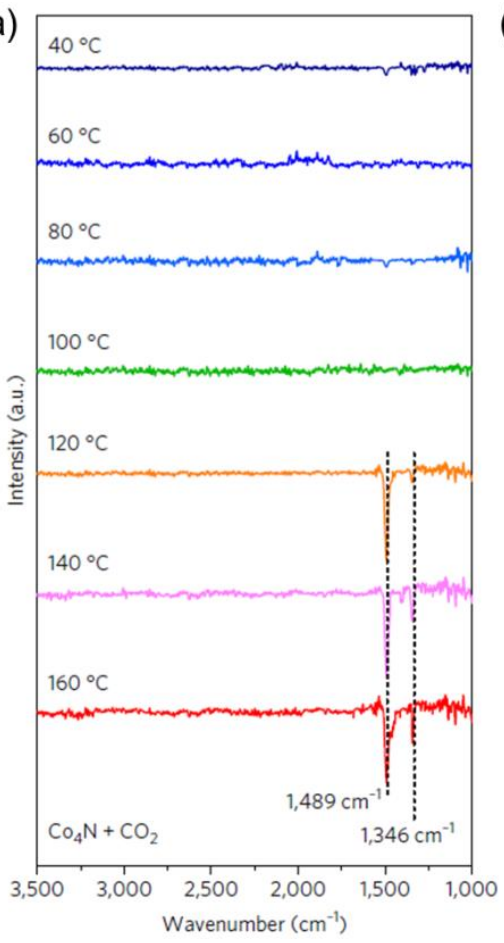

(b)

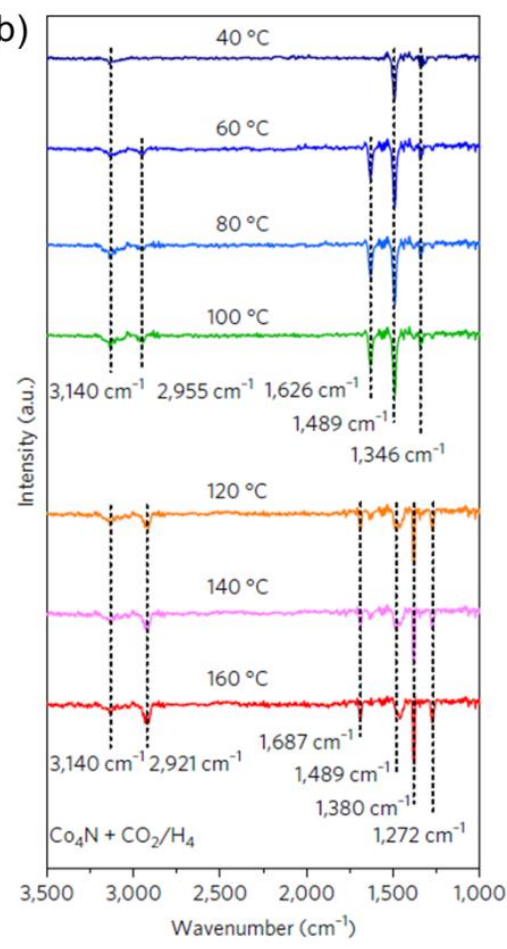

Figure 18. Mechanistic studies by in situ DRIFT analysis showing $\mathrm{Co}_{4} \mathrm{~N}$ nanosheets after the exposure to (a) $\mathrm{CO}_{2}$ and (b) $\mathrm{CO}_{2} / \mathrm{H}_{2}$ mixed gas $\left(\mathrm{CO}_{2} / \mathrm{H}_{2}=1: 3,1\right.$ bar) at different temperatures with a purge time of 30 min. Reproduced with permission from ref. 175. Copyright 2017 Springer Nature.

Another interesting approach was recently employed by Li et al., where the synergetic interaction between neighboring active centers played a significant role in $\mathrm{CO}_{2}$ hydrogenation. ${ }^{176}$ A detailed activity comparison was made between two distinct catalytic systems, in which one consisted of isolated Pt atoms $\left(0.2 \% \mathrm{Pt} / \mathrm{MoS}_{2}\right)$ and the other consisted of neighboring Pt atoms with dense population $\left(7.5 \% \mathrm{Pt} / \mathrm{MoS}_{2}\right)$. In case of $7.5 \% \mathrm{Pt} / \mathrm{MoS}_{2}$ catalyst, activated $\mathrm{S}$ atoms (those which were directly bonded to Pt atoms) were close to each other, which triggered the $\mathrm{H}_{2}$ dissociation more efficiently. Therefore, the catalyst containing neighboring Pt monomers was found to produce much higher activity than isolated Pt atoms. Combined characterization by TPD, in situ DRIFTS, in situ XPS, and DFT calculations showed that the two systems followed different reaction mechanisms. In case of isolated Pt monomers, $\mathrm{CO}_{2}$ was transformed into methanol without the formation of formic acid, whereas neighboring $\mathrm{Pt}$ monomers followed sequential formation of formic acid and then methanol. On $0.2 \% \mathrm{Pt} / \mathrm{MoS}_{2}$ system, $\mathrm{COOH}^{*}$ was considered as the stable intermediate upon the addition of the first $\mathrm{H}$ atom to $\mathrm{CO}_{2}$ with an energy barrier of $0.40 \mathrm{eV}$ (Figure 19a). The stable $\mathrm{COOH}^{*}$ intermediate was then transformed into $\mathrm{C}(\mathrm{OH})_{2}{ }^{*}$, which was further hydrogenated to form $\mathrm{CH}(\mathrm{OH})_{2}{ }^{*}, \mathrm{CHOH}^{*}$ and $\mathrm{CH}_{2} \mathrm{OH}^{*}$ sequentially. In contrast, $\mathrm{HCOOH}$ was more favorable than $\mathrm{C}(\mathrm{OH})_{2} *$ on $7.5 \% \mathrm{Pt} / \mathrm{MoS}_{2}$ system because of lower energy barrier (1.01 eV vs. 1.34 $\mathrm{eV}$ ), and the formed $\mathrm{HCOOH}$ was directly observed in the catalytic test (Figure 19b). In the subsequent steps, $\mathrm{HCOOH}$ was further hydrogenated into $\mathrm{CH}(\mathrm{OH})_{2}{ }^{*}, \mathrm{CHOH}^{*}$ and $\mathrm{CH}_{2} \mathrm{OH}^{*}$. Most interestingly, the energy barrier for the transformation of $\mathrm{CH}_{2} \mathrm{OH}^{*}$ into $\mathrm{CH}_{3} \mathrm{OH}$ over $7.5 \% \mathrm{Pt} / \mathrm{MoS}_{2}$ system $(0.44 \mathrm{eV})$ was much lower than that over $0.2 \% \mathrm{Pt} / \mathrm{MoS}_{2}$ system $(1.19 \mathrm{eV})$, which probably made the $7.5 \% \mathrm{Pt} / \mathrm{MoS}_{2}$ system more active (Figures 19c \& 19d). 
(a)

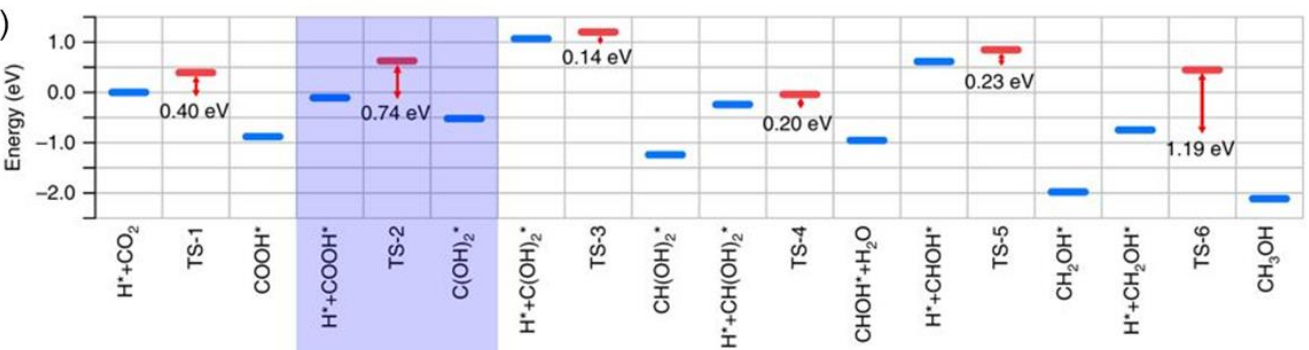

(b)
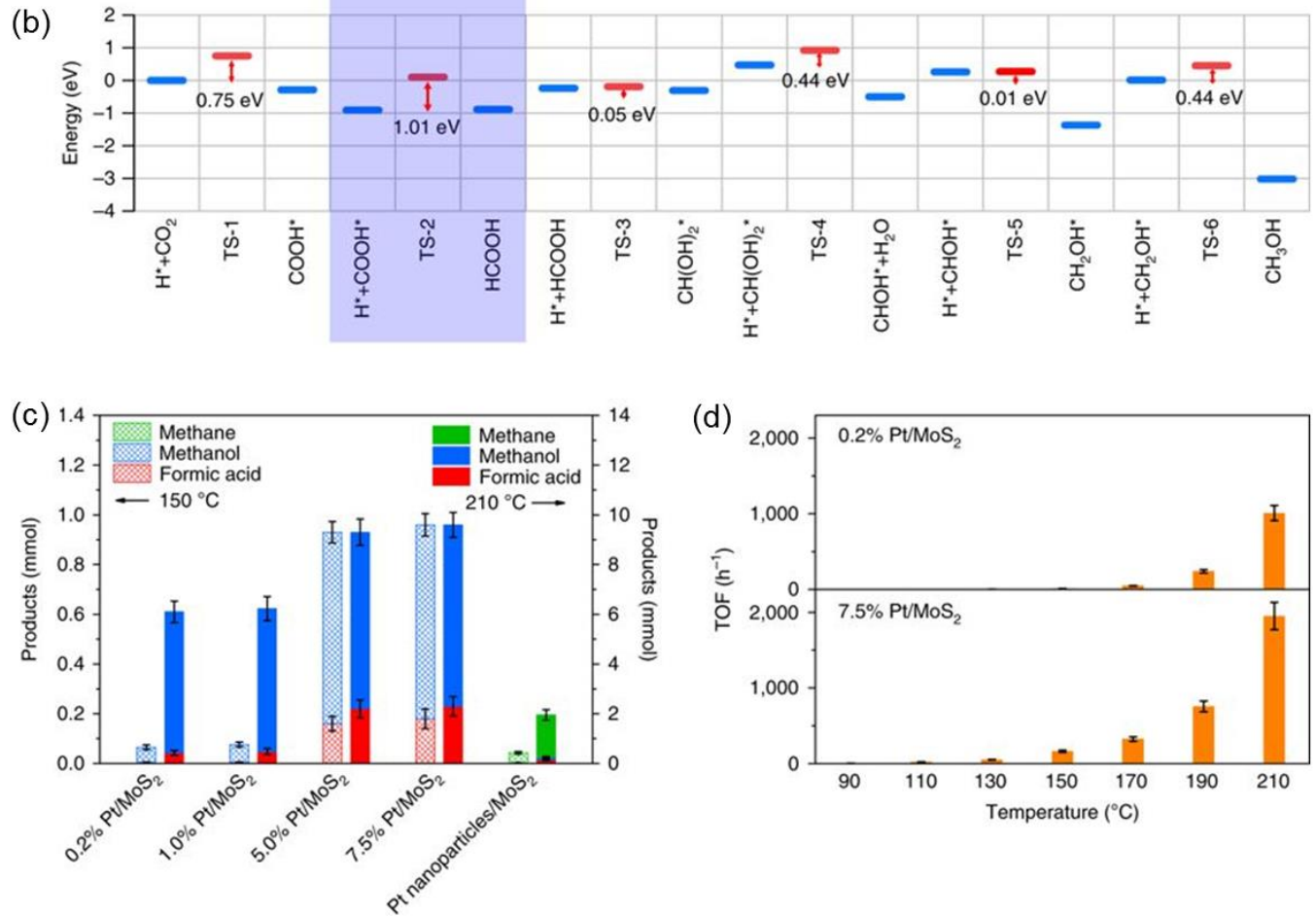

(d)

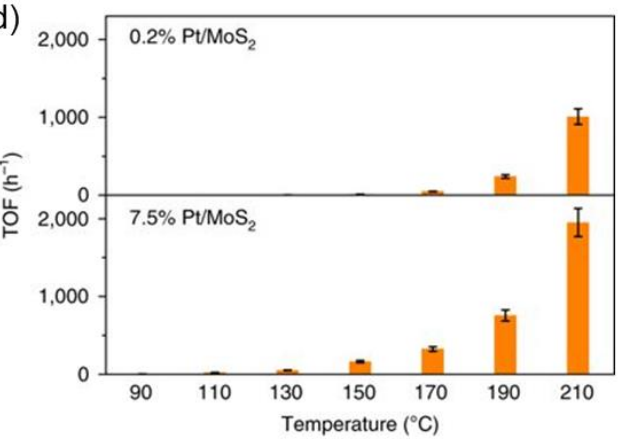

Figure 19. Optimized reaction paths in $\mathrm{CO}_{2}$ hydrogenation for (a) $0.2 \% \mathrm{Pt} / \mathrm{MoS}_{2}$ and (b) $7.5 \% \mathrm{Pt} / \mathrm{MoS}_{2}$ system, respectively. Catalytic performance of different $\mathrm{Pt} / \mathrm{MoS}_{2}$ catalysts: (c) Comparison of products obtained over different $\mathrm{Pt} / \mathrm{MoS}_{2}$ catalysts ranging from atomically dispersed Pt to Pt NPs at different Pt loadings. (d) Comparison of TOFs for methanol production with $0.2 \% \mathrm{Pt} / \mathrm{MoS}_{2}$ and $7.5 \% \mathrm{Pt} / \mathrm{MoS}_{2}$ catalysts at different temperatures. Reproduced with permission from ref. 176. Copyright 2018 Springer Nature.

\subsubsection{Reaction mechanism}

From the viewpoint of the reaction mechanism, the transformation of $\mathrm{CO}_{2}$ to methanol is still a matter of debate. According to literature reports, the two accepted pathways are (i) $\mathrm{CO}$ intermediate pathway (through the RWGS reaction and subsequent hydrogenation) and (ii) formate (*HCOO) pathway with the reaction pathway being dependent on the catalytic system. In most cases, it is observed that the catalysts active for $\mathrm{CO}_{2}$ to methanol transformation are also active for $\mathrm{CO}$ to methanol transformation. Therefore, it is obvious that the catalysts suitable for $\mathrm{CO}$ to methanol transformation would most likely follow the $\mathrm{CO}$ intermediate pathways. Although the formation of *HCOO species is easier and there is a higher possibility to follow the formate pathway, in reality, the exact pathway depends on the stability of the intermediates. For example, considering the examples of $\mathrm{Cu} / \mathrm{TiO}_{2}$ and $\mathrm{Cu} / \mathrm{ZrO}_{2}$ systems, significant 
amount of ${ }^{*} \mathrm{HCOO}$ species can be formed on both surfaces (as evidenced by DRIFTS measurements). ${ }^{93}$ However, methanol production via the formate pathway becomes inefficient over time due to the poisoning effect of $* \mathrm{HCOO}$ species, and as a result, the RWGS/CO-hydrogenation pathway becomes the dominating route. In general, it is usually observed that oxide supports with reducible properties (such as $\mathrm{TiO}_{2}, \mathrm{Cu} / \mathrm{ZrO}_{2}, \mathrm{CeO}_{2}$ etc.) follow $\mathrm{CO}$ intermediate pathway as they are efficient for RWGS process. On the other hand, in case of catalysts with nonreducible supports (such as industrial $\mathrm{Cu} / \mathrm{ZnO}$ catalysts), formate pathway dominates over RWGS. This is mainly due to the stabilization of $\mathrm{HCOOH}$ via $\mathrm{Zn}-\mathrm{O}$ interaction, which leads to activation of the $\mathrm{HCOO}^{*}$ through hydrogenation. ${ }^{94}$

During the past decades, several studies were carried out in order to obtain the performance descriptors required to lower the activation energy of this process. It was observed that the $\mathrm{CO}_{2}$ hydrogenation activity can effectively be improved by modifying different surface electronic properties such as negative charge density, d-band center and electronic polarization. Studies have shown that this type of modification can be easily achieved by tuning the arrangement and composition of surface atoms. For example, bimetallic catalysts with different shapes based on Pt and Co were designed by combining sharp-tip and alloy effects. ${ }^{177}$ A unique feature was observed in the $\mathrm{Pt}_{3} \mathrm{Co}$ octapod structure showing the accumulation of negative charges on Pt in the vertices of the nanocrystals due to the charge transfer between Pt and Co. Highly negative Pt atoms promoted the activation of $\mathrm{CO}_{2}$ and accordingly enhanced the catalytic activity. Similar studies were done with RhW system, where the accumulation of negative charge was observed on $\mathrm{Rh}$ for $\mathrm{RhW}$ nanosheets. ${ }^{178}$ As a result, the negatively charged $\mathrm{Rh}$ atoms strongly adsorbed $\mathrm{CO}_{2}$ to transform it into $\mathrm{CO}_{2}{ }^{\delta-}$ and further into $\mathrm{HCOO}^{*}$. Based on mechanistic studies, the authors claimed that the enhanced adsorption and activation of $\mathrm{CO}_{2} \mathrm{on} \mathrm{Rh}_{75} \mathrm{~W}_{25}$ nanosheets was due to the higher d-band center induced by one-dimensional quantum confinement and negatively charged Rh surface because of alloy effects.

The reader is invited to refer to two recently published excellent reviews by Jiang et al. and Zhong et al. ${ }^{26,27}$ for a detailed overview with updated information regarding the reaction mechanism of the $\mathrm{CO}_{2}$-to-methanol process.

\subsubsection{Summary and challenges}

In summary, multiple catalytic systems have been developed for $\mathrm{MeOH}$ production from $\mathrm{CO}_{2}$ with some of the above discussed examples having commercial prospects. A complete overview of these systems can be found in Table 4. For practical applications, the catalyst preparation method should be simple, cheap, scalable, and reproducible. Until now, $\mathrm{Cu}$-based catalysts are used for large-scale methanol production due to their low price, well established reproducible synthesis methods and good methanol formation rate. However, the methanol selectivity is compromised significantly at higher $\mathrm{CO}_{2}$ conversions and therefore there is still some room for enhancing the overall productivity (or space-time yield). Besides the conversion-selectivity issue, water-tolerance ability of $\mathrm{Cu}$-based catalysts is another concern as they suffer from low stability due to $\mathrm{Cu}$ oxidation. Several studies have been reported, not only on developing various new $\mathrm{Cu}$-based catalysts, but also on optimizing reaction parameters and reactor configuration. For instance, use of membrane reactors has attracted great attention to improve methanol yield by removing water after reaction. ${ }^{26,179}$ Along this line, more research is required to improve the permeation ability of membrane materials, which can scale up the process from laboratory-scale to large-scale production. 
Recently, the use of intermetallic systems, such as In- and Ga-based materials, has shown emerging prospects to deal with both activity and stability issues. As observed from Table 4, In-based catalysts can provide decent space-time yields with very high methanol selectivity (> 80\%) and a comparable formation rate (as compared to Cu-based catalysts). Although higher selectivity is achieved due to suppressed RWGS reaction, the conversion is still compromised at lower temperature and therefore a high temperature is usually required. This creates thermodynamic limitation since $\mathrm{CO}_{2}$-to-methanol favors low temperature due to its exothermic nature. According to descriptor-based computational calculations a new class of $\mathrm{Ni}-\mathrm{Ga}$ low-pressure catalysts was developed, which experimentally showed unique activity for $\mathrm{CO}_{2}$-to-methanol transformation with suppressed $\mathrm{CO}$ production. ${ }^{149}$ Above $220{ }^{\circ} \mathrm{C}$, the $\mathrm{Ni}_{5} \mathrm{Ga}_{3}$ catalyst showed 10 times lower CO-to-methanol ratio and higher methanol yield (per active metal center basis) than the well-established $\mathrm{Cu} / \mathrm{ZnO} / \mathrm{Al}_{2} \mathrm{O}_{3}$ catalyst, which is indeed a good start towards a new alternative catalyst. Furthermore, we have seen that water has a promotional effect on methanol synthesis and In-based catalysts are generally water-resistant in nature compared to the $\mathrm{Cu}$-based catalysts. In spite of these advantages, there are still some drawbacks of In-based catalysts that need to be considered for future task. For example, high oxygen vacancy of $\operatorname{In}_{2} \mathrm{O}_{3}$, which is responsible for $\mathrm{CO}_{2}$ adsorption and activation, also causes high $\mathrm{H}_{2}$ consumption and the consumed vacancy cannot be recovered by aircalcination. Besides this, another major issue is the growth of crystallite size of $\operatorname{In}_{2} \mathrm{O}_{3}$ that reduces the active surface area for the reaction and causes deactivation. ${ }^{161}$

As we have seen that low temperature is always favored in methanol synthesis due to thermodynamic constraints, a new catalyst or a new catalytic route is required to tackle this issue. Recently, Ting et al. reported well-dispersed subnanometer sized Re catalyst on $\mathrm{TiO}_{2}$ support that exhibited activity (total TON of 44 based on Re and $82 \%$ methanol selectivity) at $150{ }^{\circ} \mathrm{C} .{ }^{180}$ Another $\mathrm{ReO}_{x} / \mathrm{TiO}_{2}$ catalyst was reported by Vidinha and co-workers for selective $\mathrm{CO}_{2}$-to-methanol conversion in a supercritical flow process at $200{ }^{\circ} \mathrm{C}$, where $98 \%$ methanol selectivity could be achieved at $\sim 20 \% \mathrm{CO}_{2}$ conversion. ${ }^{181}$ Tsubaki and co-workers developed a new concept of low-temperature methanol synthesis (LTMS) in liquid medium from syngas containing $\mathrm{CO}_{2}$ using $\mathrm{Cu} / \mathrm{ZnO} / \mathrm{Al}_{2} \mathrm{O}_{3}$ catalysts prepared by oxalate-gel coprecipitation (Figure 20). ${ }^{182,183}$ LTMS can be achieved from pure syngas over strong base catalysts, but the situation is very different when $\mathrm{CO}_{2}$ is used, because a trace amount of $\mathrm{CO}_{2}$ or water can quickly deactivate the basic catalyst. Therefore, an alcohol (including methanol itself) is used as both solvent and homogeneous cocatalyst to change the reaction pathway to low-temperature direction. Using a semi-batch reactor at $170{ }^{\circ} \mathrm{C}$ and 50 bar pressure, $25.9 \% \mathrm{CO}_{2}$ conversion was achieved with $72.9 \%$ methanol selectivity when 2 -octanol was used as solvent. In a recent study, they managed to get a spacetime yield of $0.456 \mathrm{~g}_{\mathrm{MeOH}} \mathrm{g}_{\mathrm{cat}}{ }^{-1} \mathrm{~h}^{-1}$ using binary $\mathrm{Cu} / \mathrm{ZnO}$ catalyst at $200{ }^{\circ} \mathrm{C}$ in a continuous fixed-bed reactor. ${ }^{184}$ This is indeed a new promising approach that can be adopted for future methanol production process. The externally added alcohols can be recycled during the reaction, which is a big advantage of this process. Since the process is not well established yet, reactor design and parameter optimization would be essential tasks to commercialize the process. 


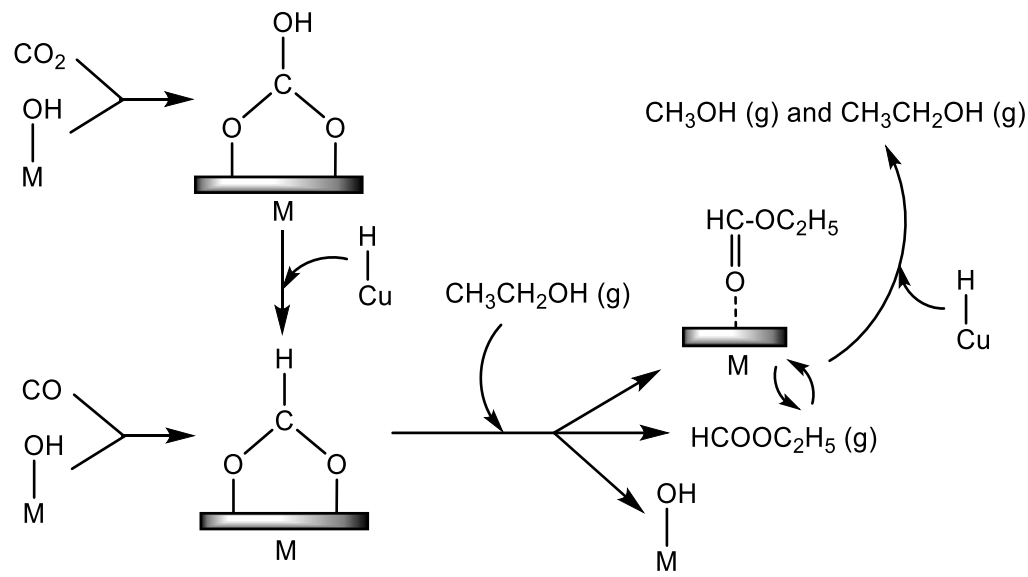

Figure 20. Reaction pathway for low-temperature methanol synthesis $(\mathrm{M}=\mathrm{Cu} / \mathrm{ZnO})$. Adapted from ref. 183.

Table 4. Catalytic performance of different catalysts in $\mathrm{CO}_{2}$ hydrogenation to methanol

\begin{tabular}{|c|c|c|c|c|c|c|c|c|}
\hline \multirow[t]{2}{*}{ Catalyst } & \multicolumn{4}{|c|}{ Reaction conditions } & \multicolumn{3}{|c|}{ Catalytic performance } & \multirow[t]{2}{*}{ Ref. } \\
\hline & $\begin{array}{l}T \\
\left({ }^{\circ} \mathrm{C}\right)\end{array}$ & $\begin{array}{l}\mathrm{P} \\
\text { (bar) }\end{array}$ & $\mathrm{H}_{2} / \mathrm{CO}_{2}$ & $\begin{array}{l}\text { GHSV (mL } \\
\left.\mathrm{g}_{\text {cat }}{ }^{-1} \mathrm{~h}^{-1}\right)\end{array}$ & $\begin{array}{l}X_{\mathrm{CO} 2} \\
(\%)\end{array}$ & $\begin{array}{l}\mathrm{S}_{\mathrm{MeOH}} \\
(\%)\end{array}$ & $\begin{array}{l}\text { STY }\left(\mathrm{g}_{\mathrm{MeOH}}\right. \\
\left.\mathrm{g}_{\mathrm{cat}}{ }^{-1} \mathrm{~h}^{-1}\right)\end{array}$ & \\
\hline CZA-r@CZM & 240 & 30 & 3 & 32000 & 11.7 & 73.0 & 0.73 & 109 \\
\hline $40 \% \mathrm{Cu} / \mathrm{TiO}_{2}$ & 260 & 30 & 3 & 3600 & - & 64.7 & 0.066 & 122 \\
\hline $\mathrm{Cu}-\mathrm{ZnO}-\mathrm{ZrO}_{2}(6: 3: 1) / \mathrm{LDH}$ & 250 & 30 & 3 & 2000 & 4.9 & 78.3 & 0.037 & 123 \\
\hline CuZnAlZr(1.5:1:0.8:0.2) & 250 & 30 & 3 & 4000 & 25.9 & 49.2 & 0.232 & 132 \\
\hline $13 \% \mathrm{ZnO}-\mathrm{ZrO}_{2}$ & 320 & 50 & 3 & 24000 & $\sim 10$ & 86.0 & $\sim 0.71$ & 136 \\
\hline $\mathrm{Cu} / \mathrm{ZnO} / \mathrm{ZrO}_{2}(5: 2: 3)$ & 220 & 30 & 3 & 6000 & 18.9 & 80.2 & 0.297 & 137 \\
\hline $33.5 \% \mathrm{Cu}-\mathrm{LDH} 30 \mathrm{Ga}$ & 270 & 45 & 3 & 18000 & $\sim 20$ & $\sim 49$ & 0.59 & 141 \\
\hline $28 \% \mathrm{Cu} / \mathrm{Zn} / \mathrm{SiO}_{2}$ & 220 & 30 & 3 & 2000 & 14.1 & 57.2 & 0.055 & 142 \\
\hline $10 \% \mathrm{Cu}_{1} \mathrm{La}_{0.2} / \mathrm{SBA}-15$ & 240 & 30 & 3 & 12000 & 5.7 & 81.2 & 0.191 & 144 \\
\hline CuZn@UiO-bpy(6.9\% Cu) & 250 & 40 & 3 & 18000 & 3.3 & 100 & 0.212 & 146 \\
\hline $12.4 \% \mathrm{Cu} @ \mathrm{ZrO}_{x}$ & 260 & 45 & 3 & 21600 & 13.1 & 78.8 & 0.796 & 148 \\
\hline $0.91 \% \mathrm{Pd}-\mathrm{P} / \mathrm{In}_{2} \mathrm{O}_{3}$ & 300 & 50 & 4 & 21000 & $\sim 20$ & $\sim 70$ & 0.89 & 150 \\
\hline $0.5 \mathrm{Ca}-5 \mathrm{Pd}-5 \mathrm{Zn} / \mathrm{CeO}_{2}$ & 220 & 30 & 3 & 2400 & 7.7 & 100 & 0.066 & 152 \\
\hline $9.2 \% \mathrm{Pd}-5.2 \% \mathrm{Zn} / \mathrm{CeO}_{2}$ & 220 & 20 & 3 & 3600 & 14.1 & 97.2 & 0.166 & 159 \\
\hline $2.5 \% \mathrm{Pd} / \mathrm{ZnO}-3.93 \mathrm{Al}$ & 250 & 30 & 3 & 6000 & 14.2 & 51.6 & 0.157 & 160 \\
\hline $9 \% \mathrm{In}_{2} \mathrm{O}_{3} / \mathrm{ZrO}_{2}$ & 300 & 50 & 4 & 20000 & 5.2 & 99.8 & 0.295 & 161 \\
\hline $0.75 \% \mathrm{Pd}-\mathrm{In}_{2} \mathrm{O}_{3} \mathrm{CP}$ & 280 & 50 & 4 & 48000 & 9.7 & 78.0 & 1.01 & 164 \\
\hline 56\%In@Co & 300 & 50 & 4 & 27500 & 15.7 & $\sim 80$ & 0.86 & 165 \\
\hline $9.7 \% \mathrm{Ni} / \mathrm{In}_{2} \mathrm{O}_{3}$ & 300 & 50 & 4 & 21000 & 18.5 & 54.0 & 0.55 & 167 \\
\hline $10 \% \mathrm{Pd} / \mathrm{In}_{2} \mathrm{O}_{3} / \mathrm{SBA}-15$ & 260 & 50 & 4 & 15000 & 12.6 & 83.9 & 0.352 & 168 \\
\hline $\mathrm{Cu}_{0.25}-\mathrm{In}_{0.75}-\mathrm{Zr}_{0.5}-\mathrm{O}$ & 250 & 25 & 3 & 18000 & $\sim 1.5$ & 79.7 & $\sim 0.076$ & 169 \\
\hline $5 \% \mathrm{In}_{2} \mathrm{O}_{3} /$ monoclinic- $\mathrm{ZrO}_{2}$ & 280 & 50 & 4 & 24000 & 4.8 & 84.0 & 0.27 & 170 \\
\hline $5 \% \mathrm{In}_{2} \mathrm{O}_{3} /$ tetragonal- $\mathrm{ZrO}_{2}$ & 280 & 50 & 4 & 24000 & 0.5 & 82.0 & 0.04 & 170 \\
\hline 8.7Pd- $10 \mathrm{Cu} / \mathrm{SiO}_{2}$ & 250 & 41 & 3 & 3600 & $\sim 6.7$ & $\sim 33$ & $\sim 0.036$ & 172 \\
\hline $15.7 \%\left(\mathrm{Pd}_{1} \mathrm{Cu}_{3}\right) / \mathrm{SiO}_{2}$ & 250 & 50 & 3 & 30000 & 2.8 & 18.5 & 0.052 & 173 \\
\hline 8Cu-6.6In@ $\mathrm{SiO}_{2}$ & 280 & 30 & 3 & 20000 & 9.8 & 78.1 & 0.438 & 185 \\
\hline
\end{tabular}




\subsection{2. $\mathrm{CO}_{2}$ to Higher Alcohols (HAS)}

Production of ethanol and higher alcohols from $\mathrm{CO}_{2}$ is usually considered as a combination of different steps including the RWGS reaction followed by the subsequent reaction of syngas through $\mathrm{C}-\mathrm{C}$ coupling. Because of the multistep nature and requirement of keeping one $\mathrm{C}-\mathrm{O}$ bond intact throughout the process, $\mathrm{CO}_{2}$-to-ethanol transformation is far more challenging than $\mathrm{CO}_{2}$-to-methanol transformation. Based on the reaction steps, it is obvious that a suitable catalyst should have the capabilities of performing both FT synthesis and methanol synthesis.

\subsubsection{Catalyst development}

Early efforts made on this transformation process achieved low yield and selectivity to ethanol, and in most cases methanol and higher $\left(\mathrm{C}_{2+}\right)$ hydrocarbons were observed as major byproducts. ${ }^{153}$ Although a few catalysts such as $\left[\mathrm{Rh}_{10} \mathrm{Se}\right] / \mathrm{TiO}_{2}$, physically mixed $\mathrm{Fe}$ - and $\mathrm{Cu}$-based composites, and $\mathrm{K} / \mathrm{Cu}-\mathrm{Zn}-\mathrm{Fe}$ achieved significant selectivity for $\mathrm{C}_{2+} \mathrm{OH}$, the reaction temperature was considerably higher (330-350 $\left.{ }^{\circ} \mathrm{C}\right){ }^{186-188}$ Recently, Han and coworkers reported high selectivity for $\mathrm{C}_{2}-\mathrm{C}_{4}$ alcohols over $\mathrm{Pt} / \mathrm{Co}_{3} \mathrm{O}_{4}$ carrying out the reaction in liquid phase as opposed to gas phase in different solvents including water and other organic solvents. ${ }^{189}$ Based on $\mathrm{D}_{2} \mathrm{O}$ and ${ }^{13} \mathrm{CH}_{3} \mathrm{OH}$ labeling experiments, water was found to act as a $\mathrm{H}_{2}$ source in order to promote the reaction kinetically with other solvents, producing ethanol via $\mathrm{CH}_{3} \mathrm{OH}$ as an intermediate. However, one of the main drawbacks of this work was the use of high boiling organic solvents, such as 1,3-dimethyl-2-imidazolidinone (DMI) to achieve high yield, which restricts its application in large scale production. Liu et al. reported mesoporous $\mathrm{Co}_{3} \mathrm{O}_{4}$ catalysts for the production of higher alcohols and studied the promotion effect of $\mathrm{Pt}$ to decrease the hydrocarbon selectivity. ${ }^{190,191}$ Compared to the $\mathrm{Co}_{3} \mathrm{O}_{4} \mathrm{NPs}$, mesoporous $\mathrm{Co}_{3} \mathrm{O}_{4}$ showed higher efficiency in the growth of carbon chains and reduced the selectivity for $\mathrm{CH}_{4}$ to give a higher yield of $\mathrm{C}_{2+} \mathrm{OH}$. Introduction of $\mathrm{Pt}$ further helped to decrease the formation of $\mathrm{CH}_{4}$ and increase the selectivity for $\mathrm{CO}$ and alcohols due to its excellent RWGS activity, but the $\mathrm{CO}_{2}$ conversion was decreased with lower yield of alcohols. Recently, Yang et al. studied Rh-based catalysts supported on $\mathrm{TiO}_{2}$ nanorods ( $\left.\mathrm{RhFeLi} / \mathrm{TiO}_{2} \mathrm{NR}\right)$ and achieved $31.3 \%$ ethanol selectivity at a $\mathrm{CO}_{2}$ conversion of $15.7 \% .{ }^{192}$ Although the catalyst showed high selectivity for methane due to the high reducing ability of $\mathrm{Rh}$, this is one of the best results achieved in terms of ethanol yield in a continuous flow reactor in the gas phase. Based on the catalytic results and in situ DRIFTS studies, it was proposed that the abundant hydroxyl groups on $\mathrm{TiO}_{2} \mathrm{NRs}$ helped to stabilize the formate species and protonate the as formed methanol, which was easily dissociated into ${ }^{*} \mathrm{CH}_{x}$ and favored the formation of ethanol upon $\mathrm{CO}$ insertion. The same mechanism was experimentally supported by Wang et al., where vanadium oxide promoted Rh-based catalysts were studied. ${ }^{193}$

From the above discussion, it can be inferred that the selective production of ethanol is quite challenging because mixed alcohols are often formed during carbon chain growth. Therefore, a fine tuning in catalyst composition and structure is required to make $\mathrm{CO}_{2}$-to-ethanol transformation practically viable. Along this line, Huang's group designed bimetallic ordered nanoparticle catalysts based on Pd and $\mathrm{Cu}$, and studied the effect of different supports on product distribution. ${ }^{194} \mathrm{Pd}$ was chosen due to its excellent $\mathrm{C}-\mathrm{C}$ coupling activity and reducibility, as well as to replace the scarcer noble metals (e.g., Rh). Among the different supports $\left(\mathrm{SiO}_{2}, \mathrm{CeO}_{2}, \mathrm{Al}_{2} \mathrm{O}_{3}\right.$ and P25) studied, $\mathrm{P} 25$ showed the highest activity (Figure 21b). Further optimization of $\mathrm{Pd} / \mathrm{Cu}$ ratio resulted in the highest activity on $\mathrm{Pd}_{2} \mathrm{Cu} \mathrm{NPs} / \mathrm{P} 25$ (Figure 21c), exhibiting $92 \%$ ethanol selectivity and the highest TOF of $359 \mathrm{~h}^{-1}$. DRIFTS results 
indicated that the rate-determining step was ${ }^{*} \mathrm{CO}$ hydrogenation to $* \mathrm{HCO}$, which was beneficial to decrease $* \mathrm{CO}$ coverage on the catalyst surface and weaken $* \mathrm{CO}$ poisoning. Furthermore, upon increasing the $\mathrm{Pd} / \mathrm{Cu}$ ratio, the bonding mode of ${ }^{*} \mathrm{CO}$ on $\mathrm{Pd}$ was changed from 2 -fold bridge-bond (in case of $\mathrm{Pd}_{1} \mathrm{Cu}$ $\mathrm{NPs} / \mathrm{P} 25$ ) to 3 -fold bridge-bond (in case of $\mathrm{Pd}_{2} \mathrm{Cu} \mathrm{NPs} / \mathrm{P} 25$ ), and as a result, ${ }^{*} \mathrm{CO}$ species were more easily converted into ethanol over $\mathrm{Pd}_{2} \mathrm{Cu}$ NPs/P25 (Figure 21a). Another recent report by Caparrós explored $\mathrm{Pd}$-based single atom catalyst supported on $\mathrm{Fe}_{3} \mathrm{O}_{4}$ for the selective hydrogenation of $\mathrm{CO}_{2}$ into ethanol. ${ }^{195}$ At $300{ }^{\circ} \mathrm{C}$, ethanol was selectively formed at $0.1 \mathrm{wt} \% \mathrm{Pd}$ loading where the catalyst contained mostly atomically dispersed $\mathrm{Pd}$ at very low $\mathrm{CO}_{2}$ conversion levels. Increase in Pd loading resulted in a drop in selectivity due to the formation of Pd cluster/NPs. At higher temperatures, $\mathrm{CO}$ was formed as the major product. Other inorganic oxide supports like $\mathrm{Al}_{2} \mathrm{O}_{3}, \mathrm{ZrO}_{2}$, and $\mathrm{CeO}_{2}$ were also tested, but they showed negligible or no selectivity for ethanol, implying that a specific interaction between $\mathrm{Pd}$ single atoms and $\mathrm{Fe}_{3} \mathrm{O}_{4}$ was necessary for $\mathrm{C}-\mathrm{C}$ coupling. Wang et al. did a comparative study by screening different noble metals (such as $\mathrm{Pd}, \mathrm{Rh}, \mathrm{Ir}, \mathrm{Au}$, and $\mathrm{Pt}$ ) on different supports, where Au-based catalysts supported on anatase $\mathrm{TiO}_{2}$ showed the highest efficiency with a space time yield of over $900 \mathrm{mmol}$ EtOH $\mathrm{g}_{\mathrm{Au}}{ }^{-1} \mathrm{~h}^{-1}$ and an ethanol selectivity of $>99 \% .{ }^{196,197}$ But the use of organic solvents, such as $N$-methyl-2pyrrolidone (NMP) and $N, N$-dimethylformamide (DMF), was one of the key strategies to dissolve $\mathrm{CO}_{2}$ and other reaction intermediates.

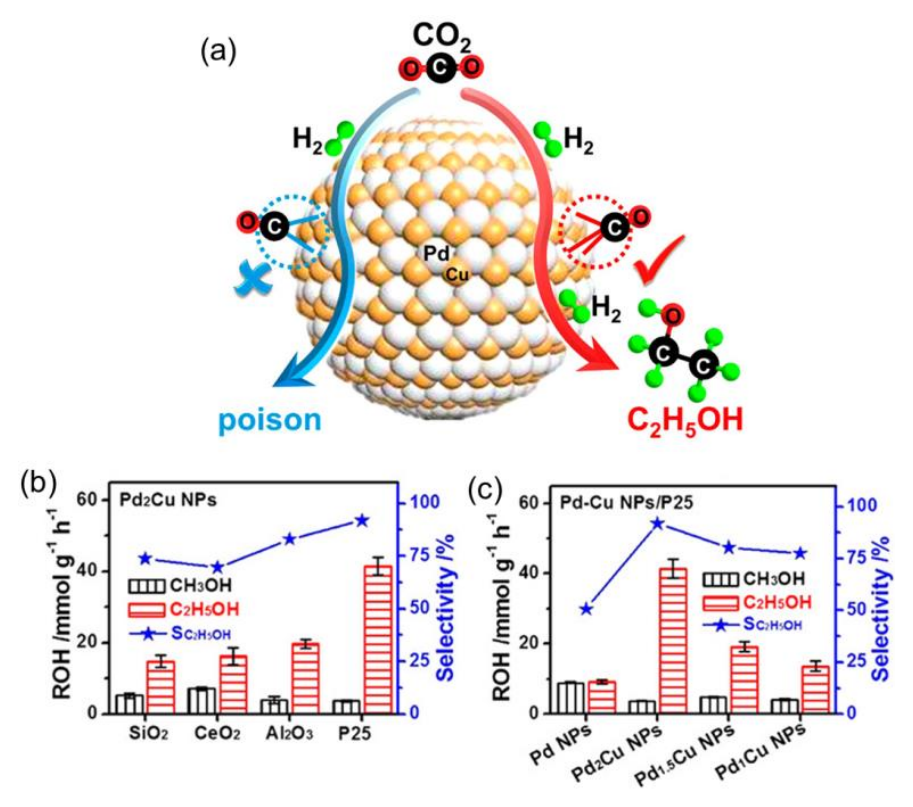

Figure 21. (a) Schematic diagram of bimetallic Pd-Cu catalyst showing different binding mode of CO. Effect of (b) different supports and (c) catalyst composition on the product selectivity. Reproduced with permission from ref. 194. Copyright 2017 American Chemical Society.

Based on the literature of $\mathrm{CO}_{2}$-to-ethanol catalysts, it can be observed that $\mathrm{Pd}$ and $\mathrm{Rh}$ are highly active for this reaction, but they are also active in overhydrogenation reaction to make hydrocarbons if not engineered properly. Some recent reports showed that $\mathrm{Co}$ - and $\mathrm{Cu}$-based catalysts can be very active due to their $\mathrm{C}-\mathrm{C}$ coupling activity and therefore can replace expensive noble metals. ${ }^{198-202}$ Contrary to the earlier study by Han's group, ${ }^{189}$ which showed the formation of mixed alcohols over mesoporous $\mathrm{Co}_{3} \mathrm{O}_{4}$, Wang et al. achieved high ethanol selectivity over a mixed Co oxide catalyst. ${ }^{198}$ The catalysts derived from a Co-Al layered double hydroxide (LDH) outperformed all abundant-metal catalysts previously 
employed for this reaction, producing $92.1 \%$ ethanol selectivity at $140{ }^{\circ} \mathrm{C}$ with an ethanol time yield at $0.444 \mathrm{mmol} \mathrm{g}^{-1} \mathrm{~h}^{-1}$. The exact reason behind this superior activity was not clear, but it was proposed that the presence of surface oxide species with coexisting $\mathrm{Co}-\mathrm{CoO}$ phases improved the formation of relatively stable ${ }^{*} \mathrm{CH}_{x}$ (key intermediate for ethanol production) for converting formate into acetate via an insertion mechanism as observed by operando FT-IR spectroscopy. Zhang et al., on the other hand, claimed that $\mathrm{CO}_{2} \mathrm{C}$ was the active phase, which was generated by $\mathrm{CO}$ induction during reaction. ${ }^{200}$ The active $\mathrm{Co}_{2} \mathrm{C}$ phase was stabilized on $\mathrm{SiO}_{2}$ and $\mathrm{Si}_{3} \mathrm{~N}_{4}$ support due to strong metal-support interaction (SMSI) obtained by $\mathrm{Si}-\mathrm{O}-\mathrm{Co}$ bond. According to in situ DRIFTS results, CO produced from RWGS inserted into ${ }^{*} \mathrm{CH}_{x}$ intermediates to form ethanol.

A very interesting study was done by $\mathrm{An}$ et al., where $\mathrm{Cu}$-based methanol-selective catalyst was transformed into ethanol-selective catalyst just by tuning the oxidation state of $\mathrm{Cu}$ (Figure 22). ${ }^{201}$ Cooperative $\mathrm{Cu}^{\mathrm{I}}$ sites stabilized on a $\mathrm{Zr}_{12}$-MOF exhibited a high ethanol selectivity of $>99 \%$ with the assistance of a $\mathrm{Cs}$ promoter. The excellent activity was attributed to the cooperative nature of the bimetallic $\mathrm{Cu}_{2}{ }_{2}$ centers, which facilitated both $\mathrm{H}_{2}$ activation and $\mathrm{C}-\mathrm{C}$ coupling of methanol and formyl species. Multiple hydrogen addition to $\mathrm{CO}_{2}$ was fulfilled by $\mathrm{H}$ spillover from adjacent $\mathrm{Cu}$ sites. The formyl intermediate was stabilized by the electron-rich $\mathrm{Cu}$ center aided by the alkali metal promoter and the extent of formyl-stabilization was controlled by changing the promoter from Li to Cs. Higher electron-donating capacity of $\mathrm{Cs}^{+}$resulted in more electron-rich $\mathrm{Cu}$ centers and increased the basicity of an oxygen atom coordinated to $\mathrm{Cu}$, which facilitated the formation of formyl species from $\mathrm{CH}_{2} \mathrm{O}_{2}$ intermediate (6 in Figure 22c). In addition, the electron-rich $\mathrm{Cu}$ centers also promoted the oxidative addition of hydrogen and increased the hydricity of $\mathrm{Cu}^{\mathrm{I}-}-\mathrm{H}^{-}$to enhance the activity. 
(a)

$\mathrm{ZrO}_{2}$ support
Randomly supporting active centres
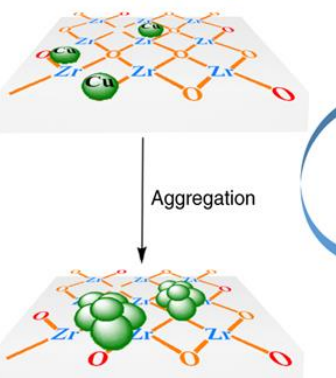

(b)

MOF support

Supporting bimetallic centres

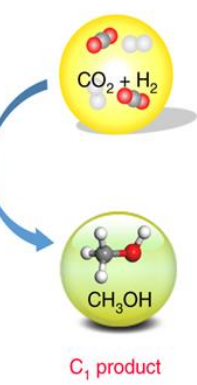

Versus

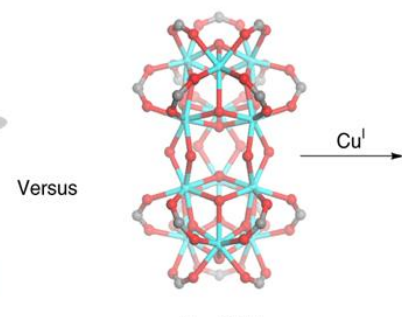

$\mathrm{Zr}_{12}$ SBU
$\mathrm{Zr}_{12} \mathrm{O}_{8}\left(\mu_{3}-\mathrm{OH}\right)_{8}\left(\mu_{2}-\mathrm{OH}\right)_{6}\left(\mathrm{CO}_{2}\right)_{18}$

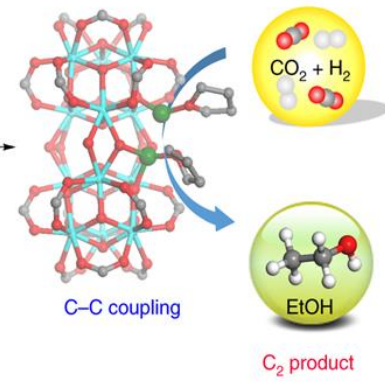

(c)

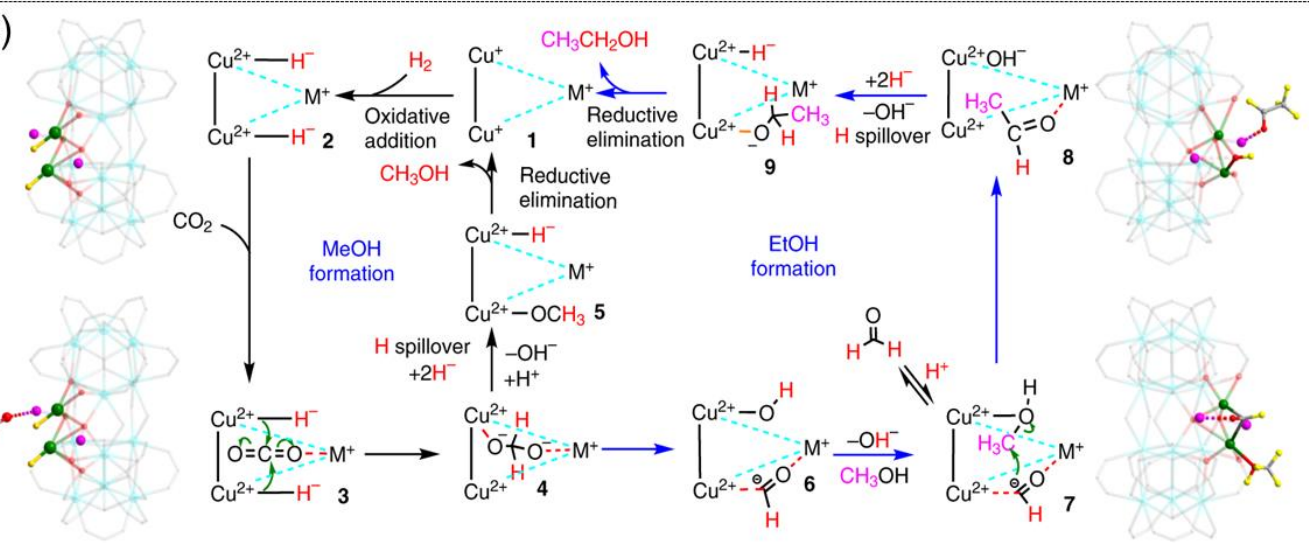

Figure 22. Schematic showing (a) $\mathrm{Cu}$ supported on $\mathrm{ZrO}_{2}$ for $\mathrm{CO}_{2}$ hydrogenation to methanol and (b) bimetallic $\mathrm{Cu}$ centers supported on $\mathrm{Zr}_{12}$-SBUs in a MOF for producing $\mathrm{C}_{2+}$ oxygenates. (c) Proposed mechanism of methanol and ethanol synthesis from $\mathrm{CO}_{2}$ hydrogenation over $\mathrm{Zr}_{12}$-bpdc-Cu catalysts. Reproduced with permission from ref. 201. Copyright 2019 Springer Nature.

Recently, a plasma-assisted selective $\mathrm{CO}_{2}$-to-ethanol conversion was reported over commercial $\mathrm{Cu} / \mathrm{ZnO} / \mathrm{Al}_{2} \mathrm{O}_{3}$ catalyst. ${ }^{203}$ Instead of using molecular $\mathrm{H}_{2}$, water was used as the $\mathrm{H}$ source. Ethanol was claimed as the only liquid product and the production rate of ethanol was dependent on the input power and water vapor content. The adsorbed species on the surface of the catalyst during reaction were analyzed by FTIR (Figure 23). As $\mathrm{Cu} / \mathrm{ZnO} / \mathrm{Al}_{2} \mathrm{O}_{3}$ catalyst is well known for $\mathrm{CO}_{2}$-to-methanol conversion, the key intermediate was methanol in this case. The excellent ethanol selectivity was supposed to have been achieved by efficient decomposition of methanol by high-energy electrons from the negative corona plasma to produce $\mathrm{CH}_{3} \mathrm{OH}^{-}$, which could be further dissociated into ${ }^{*} \mathrm{CH}_{3}$ and $* \mathrm{OH}$. 


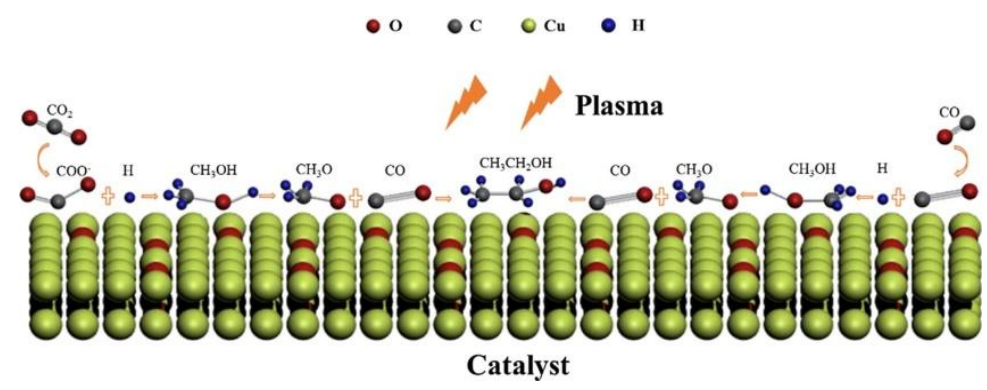

Figure 23. Schematic diagram showing different intermediates during plasma-assisted $\mathrm{CO}_{2}$-to-ethanol transformation on $\mathrm{Cu} / \mathrm{ZnO} / \mathrm{Al}_{2} \mathrm{O}_{3}$ catalyst. Reproduced with permission from ref. 203. Copyright 2018 Elsevier.

\subsubsection{Summary and challenges}

Summing up, the production of HAS from $\mathrm{CO}_{2}$ is way more challenging than the methanol counterpart as achieving high selectivities is not straightforward due to the multistep nature of the process. Moreover, we can observe that these results (see Table 5) lie far from the ones discussed for the methanol synthesis (see Table 4), and therefore, the major challenge here is to find a catalytic system that could display high activity and selectivity towards ethanol. Additionally, most of the literature on $\mathrm{CO}_{2}$-toethanol focuses on batch synthesis where reasonable ethanol selectivities can be achieved. This fact highlights the challenge of continuous heterogeneous gas phase synthesis of HAS from $\mathrm{CO}_{2}$, whereas there are several excellent catalysts reporting high $\mathrm{C}_{2+} \mathrm{OH}$ selectivity in batch mode. From the practical application point of view, continuous flow operation is more attractive for large-scale production, and therefore more efforts need to be given in this direction.

Another major concern is the design of future catalysts as the HAS selectivities over most of the explored catalysts are quite low. Until now, noble metals ( $\mathrm{Rh}, \mathrm{Pd}, \mathrm{Pt}$ ) have shown some promising activities for HAS synthesis. The main reason is the high activity of these metals for $\mathrm{C}-\mathrm{C}$ coupling reaction, which is the key step for HAS synthesis. However, all these metals are highly expensive and need to be replaced by cheaper alternatives. Although a few transition metal-based catalysts have shown good selectivities for higher alcohols at a descent $\mathrm{CO}_{2}$ conversion, their synthesis is not straightforward and not scalable for large-scale use. For instance, $\mathrm{Cu}$ containing MOF catalysts showed excellent activity (96\% $\mathrm{CO}_{2}$ conversion, 99\% ethanol selectivity), ${ }^{201}$ but the activity depends on the precise control of the oxidation state of $\mathrm{Cu}$, which is difficult for a large-scale operation. Therefore, the urgent need is the design of a robust catalyst (similar to the matured $\mathrm{Cu}-\mathrm{ZnO}$ system for methanol synthesis), which will be cost-effective and will operate under industrial conditions. Compared to the matured $\mathrm{CO}_{2}$-to-methanol process, $\mathrm{CO}_{2}$-to-HAS conversion is a new field and therefore it requires more in depth studies on reaction mechanism and reactant-catalyst interaction to identify the active catalysts. 
Table 5. Catalytic performance of different catalysts in $\mathrm{CO}_{2}$ hydrogenation to $\mathrm{C}_{2}+\mathrm{OH}$ alcohols

\begin{tabular}{|c|c|c|c|c|c|c|c|c|c|}
\hline \multirow[t]{3}{*}{ Catalyst } & \multirow{3}{*}{$\begin{array}{l}\text { Reactor } \\
\text { configuration }\end{array}$} & \multicolumn{4}{|c|}{ Reaction conditions } & \multicolumn{3}{|c|}{ Catalytic performance } & \multirow[t]{3}{*}{ Ref. } \\
\hline & & \multirow{2}{*}{$\begin{array}{l}T \\
\left({ }^{\circ} \mathrm{C}\right)\end{array}$} & \multirow{2}{*}{$\begin{array}{l}\mathrm{P} \\
\text { (bar) }\end{array}$} & \multirow[t]{2}{*}{$\mathrm{H}_{2} / \mathrm{CO}_{2}$} & \multirow{2}{*}{$\begin{array}{l}\text { GHSV (mL } \\
\left.\mathrm{g}_{\mathrm{cat}}{ }^{-1} \mathrm{~h}^{-1}\right)\end{array}$} & \multirow[t]{2}{*}{$X_{\mathrm{CO} 2}(\%)$} & \multicolumn{2}{|c|}{ Selectivity (\%) } & \\
\hline & & & & & & & $\mathrm{C}_{2+} \mathrm{OH}$ & $\mathrm{EtOH}$ & \\
\hline $\mathrm{KFeCuAl}$ & Continuous & 350 & 80 & 3 & 32000 & 43.3 & - & 8.2 & 187 \\
\hline $\begin{array}{l}\mathrm{KCuZnAlGaPd}+ \\
\mathrm{KFeCuAl}(1: 1)\end{array}$ & Continuous & 330 & 80 & 3 & 20000 & 47.0 & - & 17.4 & 187 \\
\hline $1 \% \mathrm{Pt} / \mathrm{Co}_{3} \mathrm{O}_{4}$ & $\mathrm{Batch}^{a}$ & 200 & 80 & 3 & - & - & 82.5 & - & 189 \\
\hline $1 \% \mathrm{Rh} / \mathrm{Co}_{3} \mathrm{O}_{4}$ & $\mathrm{Batch}^{a}$ & 200 & 80 & 3 & - & - & 65.4 & - & 189 \\
\hline $1 \% \mathrm{Pt} / \mathrm{Co}_{3} \mathrm{O}_{4}$-nanorod & Continuous & 200 & 20 & 3 & 6000 & 27.8 & 3.2 & - & 191 \\
\hline $2.5 \% \mathrm{RhFeLi} / \mathrm{TiO}_{2} \mathrm{NRs}$ & Continuous & 250 & 30 & 3 & 6000 & 15.7 & - & 31.3 & 192 \\
\hline 2Rh-0.3VO $x$ /MCM-41 & Continuous & 250 & 30 & 3 & 6000 & 12.1 & - & 24.1 & 193 \\
\hline $1.23 \% \mathrm{Pd}_{2} \mathrm{Cu} \mathrm{NPs} / \mathrm{P} 25$ & $\mathrm{Batch}^{b}$ & 200 & 32 & 3 & - & - & - & 92.0 & 194 \\
\hline $0.1 \% \mathrm{Pd} / \mathrm{Fe}_{3} \mathrm{O}_{4}$ & Continuous & 250 & 30 & 3 & 8000 & 1.4 & 98.0 & - & 195 \\
\hline $0.1 \% \mathrm{Pd} / \mathrm{Fe}_{3} \mathrm{O}_{4}$ & Continuous & 300 & 30 & 3 & 8000 & 2.9 & 46.1 & - & 195 \\
\hline $0.3 \% \mathrm{Au} / \mathrm{a}-\mathrm{TiO}_{2}$ & Batch $^{c}$ & 200 & 60 & 3 & - & - & - & $>99.0$ & 197 \\
\hline $\mathrm{CoAlO}_{x}(\mathrm{Co} / \mathrm{Al}=2.7)$ & $\mathrm{Batch}^{b}$ & 140 & 40 & 3 & - & - & - & 92.1 & 198 \\
\hline $\mathrm{Co} .{ }_{2} \mathrm{Ni}_{0.48} \mathrm{AlO}_{x}$ & $\mathrm{Batch}^{b}$ & 200 & 40 & 3 & - & - & - & 85.7 & 199 \\
\hline $2 \% \mathrm{Na}-20 \% \mathrm{Co} / \mathrm{SiO}_{2}$ & Continuous & 250 & 50 & 3 & 4000 & 18.8 & - & 6.0 & 200 \\
\hline $\mathrm{Zr}_{12}$-bpdc-CuCs & $\mathrm{Batch}^{d}$ & 100 & 20 & 3 & - & 96.0 & - & $>99.0$ & 201 \\
\hline $\mathrm{Zr}_{12}$-bpdc-CuLi & $\mathrm{Batch}^{d}$ & 100 & 20 & 3 & - & 50.0 & - & 66.3 & 201 \\
\hline $\mathrm{Cs}-\mathrm{Cu}_{0.8} \mathrm{Fe}_{1} \mathrm{Zn}_{1}$ & Continuous & 330 & 50 & 3 & 4500 & 36.6 & 19.8 & - & 202 \\
\hline
\end{tabular}

\subsection{Production of Multi-carbon Hydrocarbons}

There are different possible routes to synthesize hydrocarbons from $\mathrm{CO}_{2}$, either by direct hydrogenation of $\mathrm{CO}_{2}$ or by converting $\mathrm{CO}_{2}$ into $\mathrm{CO}$ /methanol and subsequent transformation into hydrocarbons (Figure 24). Current technologies have shown rapid development in designing advanced catalysts for the direct transformation of $\mathrm{CO}_{2}$ into hydrocarbons. ${ }^{204-210}$
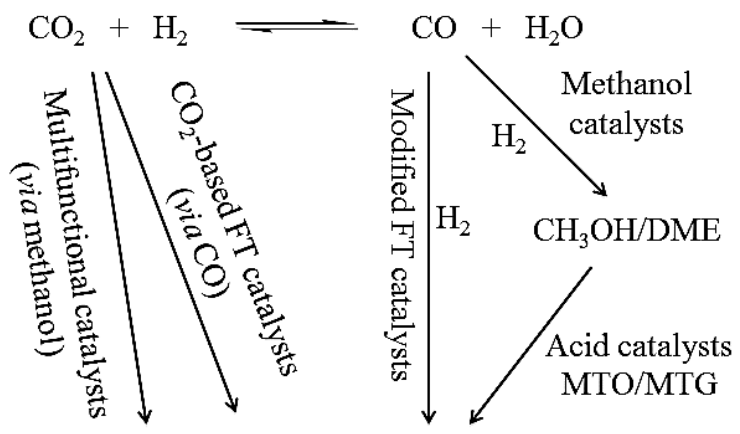

Hydrocarbons

(olefin/LPG/gasoline/aromatic)

Figure 24. Different possible routes for the production of value-added hydrocarbons from $\mathrm{CO}_{2}$ hydrogenation.

This direct (single pot) transformation of $\mathrm{CO}_{2}$ can be carried out by (i) standalone catalysts (usually containing $\mathrm{Fe}$ and/or Co as a component) via a Fischer-Tropsch like reaction $\left(\mathrm{CO}_{2}-\mathrm{FT}\right)$ and (ii) tandem 
catalysts where a zeolite/zeotype is paired with either an Fe/Co catalyst as described in (i) or a methanol synthesis catalyst.

\subsubsection{Standalone catalysts}

As mentioned before, since Fe- and Co-based materials are well known catalysts for the pure FT process, most of the catalysts reported in literature have been designed including one or the other element. Specifically, Fe has gained much more attention due to its high RWGS and FT activity and stability under the required reaction conditions. When compared to the CO-FT process, earlier catalysts designed for $\mathrm{CO}_{2}$-FT showed much higher $\mathrm{CO}$ conversion (up to 87\%) than $\mathrm{CO}_{2}$ conversion (up to $45 \%$ ), ${ }^{211}$ indicating that better catalysts are needed to improve the $\mathrm{CO}_{2}$ conversion.

Initial improvements were achieved by introducing different promoters. For instance, addition of $\mathrm{K}$ in Fe-based catalyst stabilizes the iron carbide phase and addition of boron increases the selectivity of light olefins. ${ }^{212}$ It is most likely that $\mathrm{K}$ promotes $\mathrm{CO}_{2}$ adsorption and hinders $\mathrm{H}_{2}$ adsorption in order to suppress the methane formation. There are many recent studies from different groups using $\mathrm{K}$ promoter with $\mathrm{Fe}$ catalysts to produce mainly light olefins with improved selectivities. ${ }^{213-218}$ Along with K, various other promoters ranging from alkali metals to transition base metals were also investigated. ${ }^{219}{ }^{220}$ For example, a systematic study of the effect of different promoters on hydrocarbon selectivity was recently reported by our group. ${ }^{219} \mathrm{An}$ interesting approach of deriving well dispersed $\mathrm{Fe} / \mathrm{C}$ catalyst with high metal loading (up to $41 \mathrm{wt} \% \mathrm{Fe}$ ) was described, where Fe-based metal organic framework (Basolite F300) was chosen as catalyst precursor (Figure 25a) and a promoter was subsequently incorporated. Various incorporated elements $(\mathrm{Cu}, \mathrm{Mo}, \mathrm{Li}, \mathrm{Na}, \mathrm{K}, \mathrm{Mg}, \mathrm{Ca}, \mathrm{Zn}, \mathrm{Ni}, \mathrm{Co}, \mathrm{Mn}, \mathrm{Fe}, \mathrm{Pt}$, and $\mathrm{Rh}$ ) were studied and a diverse variety of promotional behaviors was observed. For instance, $\mathrm{Cu}$ and $\mathrm{Pt}$ increased the $\mathrm{CO}_{2}$ conversion and the selectivities for $\mathrm{CH}_{4}$ and $\mathrm{C}_{2}-\mathrm{C}_{6}$ paraffins; $\mathrm{Mn}, \mathrm{Mg}$, and Mo enhanced $\mathrm{CO}$ selectivity; and $\mathrm{Ni}, \mathrm{Co}$, and $\mathrm{Rh}$ mostly promoted methanation. However, most interestingly, only $\mathrm{K}$ was found to enhance the olefin selectivity (Figure 25b). Further investigation showed that the K-promoted catalyst was very different from other catalysts since it formed both the $\mathrm{Fe}_{5} \mathrm{C}_{2}$ and the $\mathrm{Fe}_{7} \mathrm{C}_{3}$ carbides, and the $\mathrm{Fe}_{7} \mathrm{C}_{3}$ phase had the highest intrinsic activity among iron carbides. ${ }^{206}$ On the other hand, unpromoted and $\mathrm{Pt} / \mathrm{Mo}$-promoted catalyst only formed the $\mathrm{Fe}_{3} \mathrm{C}$ phase, which was reported as less active than the $\mathrm{Fe}_{5} \mathrm{C}_{2}$ and $\mathrm{Fe}_{7} \mathrm{C}_{3}$ phases in FTS. 
(a)

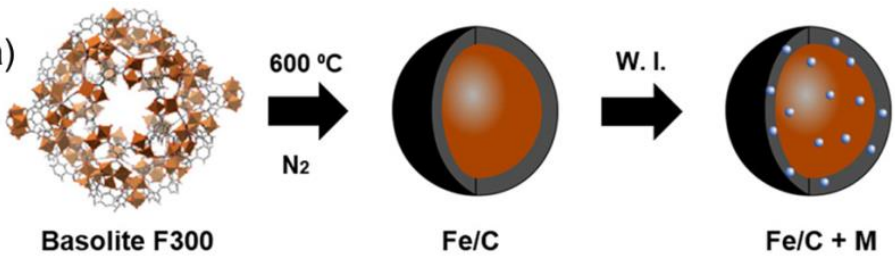

(b)

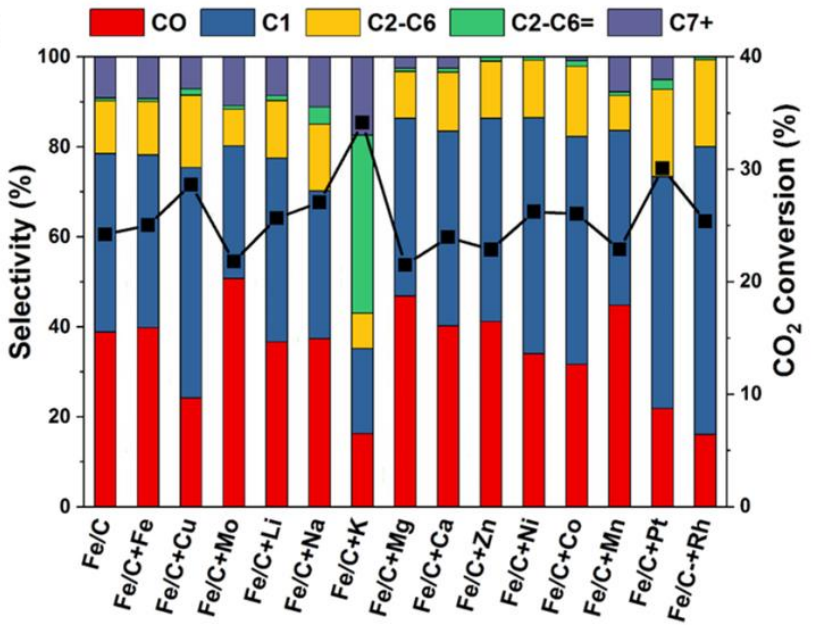

Figure 25. (a) Synthesis of Fe/C catalyst via carbonization of Basolite F300 MOF. (b) Effect of different promoters on product distribution during $\mathrm{CO}_{2}$ hydrogenation; reaction conditions: $320{ }^{\circ} \mathrm{C}, 30 \mathrm{bar}, \mathrm{H}_{2} / \mathrm{CO}_{2}$ $=3$, and GHSV $=24000 \mathrm{~mL} \mathrm{~g}^{-1} \mathrm{~h}^{-1}$, TOS $=50 \mathrm{~h}$. Reproduced with permission from ref. 219. Copyright 2018 American Chemical Society.

Most of the catalysts reported have focused on the efficient utilization of $\mathrm{CO}_{2}$ as a strategy to mitigate climate change. Our group recently reported on a strategy that not only provides high yields of light olefins from $\mathrm{CO}_{2}$ but also provides an avenue to address an additional environmental problem in the form of red mud utilization. ${ }^{221}$ Large amounts of red mud are produced (0.3-2.5 ton per ton of alumina) as waste during the production of aluminum oxide via the Bayer process. This creates a waste management crisis since red mud presents an ecological hazard.

Sodium $(\mathrm{Na})$ has also been explored as an effective promoter by increasing the basicity of the support, which favors higher olefin selectivity. ${ }^{222,}{ }^{223}$ In addition, increasing $\mathrm{Na}$ content significantly improves the carbonization of the Fe catalysts. A recent study by Liang et al. showed evidence that the content of $\mathrm{Fe}_{5} \mathrm{C}_{2}$ is related to the amount of $\mathrm{Na}^{224}$ Another study by the same group showed that further addition of $\mathrm{Mn}$ to the $\mathrm{Na} / \mathrm{Fe}$ catalyst could facilitate the formation of active $\mathrm{Fe}_{5} \mathrm{C}_{2}$ phase that helped to achieve $30.2 \%$ selectivity of light olefins with high olefin/paraffin ratio (7.5). ${ }^{225}$ Combined characterization by Mössbauer spectroscopy, XRD and XPS evidenced the strong interaction between the $\mathrm{Mn}$ promoter and Fe species, which decreased the $\mathrm{CO}$ adsorption ability and consequently inhibited the chain-growth reaction in order to achieve high selectivity of light olefins.

In addition to alkali metals (such as $\mathrm{Na}, \mathrm{K}$ ), transition base metals like $\mathrm{Cu}$ were also reported to promote $\mathrm{CO}_{2}$ hydrogenation to synthesize hydrocarbons. ${ }^{226}$ The promotion behavior of $\mathrm{Cu}$ was different from other promoters typically used (e.g., $\mathrm{K}, \mathrm{Mn}, \mathrm{Zn}$, etc.). $\mathrm{Cu}$ promoted Fe catalyst showed decreased selectivity of $\mathrm{C}_{2}=-\mathrm{C}_{4}{ }^{=}$, but a significant improvement in $\mathrm{C}_{5+}$ product selectivity. Recently, bimetallic 
catalysts with $\mathrm{Fe}$ as active metal were studied to promote $\mathrm{CO}_{2}$ conversion. ${ }^{227-231}$ Especially, addition of Co was found to increase the carbide formation, which was beneficial for the chain propagation reaction. It was also observed that the product selectivity could be tuned by changing the Fe/Co ratio. For example, Gnanamani et al. showed that the selectivity to $\mathrm{C}_{2}-\mathrm{C}_{4}$ hydrocarbons over Co-Fe catalyst was increased with increasing Fe fraction, while alcohol selectivity was found to increase with increasing Fe content up to $50 \%$, but then it dropped with further addition of $\mathrm{Fe} .{ }^{227}$

Finally, although Co is active in CO-FT process, very few reports are available on Co-based catalysts for $\mathrm{CO}_{2}$-FT. ${ }^{232,233}$ The main issue with pure Co-based catalysts is their low RWGS activity and that they act as methanation catalysts under $\mathrm{CO}_{2} / \mathrm{H}_{2}$ regime and restrict FT chain growth. This problem however can be overcome by introducing a second functional group that can drive the formation of chain growth by increasing the $\mathrm{CO}$ productivity via RWGS reaction. Xie et al. designed a bifunctional $\mathrm{CeO}_{2}-\mathrm{Pt} @ m \mathrm{SiO}_{2}-\mathrm{Co}$ core-shell catalyst for the targeted synthesis of $\mathrm{C}_{2}-\mathrm{C}_{4}$ hydrocarbons. ${ }^{234}$ High RWGS activity of $\mathrm{CeO}_{2} / \mathrm{Pt}$ facilitated the formation of $\mathrm{CO}$, which underwent FT process on the neighboring $\mathrm{Co} / \mathrm{mSiO}_{2}$ interface to yield $\mathrm{C}_{2}-\mathrm{C}_{4}$ hydrocarbons. However, the $\mathrm{CH}_{4}$ selectivity was still significantly high $(\sim 60 \%)$, suggesting that Fe-based catalysts are far better than Co-based catalysts in $\mathrm{CO}_{2}$-FT process.

\subsubsection{Tandem catalysts}

While standalone catalysts following the $\mathrm{CO}_{2}$-FT route have proven effective in providing large hydrocarbon yields from $\mathrm{CO}_{2}$, selectivity towards a target product remains an issue since the product mixture formed tends to consist of a large variety of hydrocarbons. This limits the potential for industrial application as low selectivity tends to lead to large separation costs thus making the process uneconomical. Tandem catalysis offers a solution to this problem wherein a zeolite placed downstream from the $\mathrm{CO}_{2}$-FT catalyst can play a product 'redistribution' role by catalyzing several reactions including hydrocracking/isomerization, oligomerization, cyclization etc. thus improving selectivity to target products. This characteristic of zeolites also allows for their pairing with methanol synthesis catalysts where the methanol generated by the preceding catalyst gets converted to hydrocarbons in the zeolite via the classical Methanol-to-Hydrocarbons (MTH) reaction. This approach has been successful in offering high selectivities for target products at least in the hydrocarbon fraction of the products. Thus, this section will discuss the advancements in catalyst development for the direct transformation of $\mathrm{CO}_{2}$ into higher hydrocarbons using tandem catalysis focusing on the two alternate pathways i.e. (a) a Fischer-Tropsch like synthesis $\left(\mathrm{CO}_{2}\right.$-FT) pathway with $\mathrm{CO}$ as an intermediate and (b) a methanol-mediated pathway where the methanol obtained from $\mathrm{CO}_{2}$ is subsequently transformed into hydrocarbons over a zeolite.

\subsubsection{1. $\mathrm{CO}_{2}$-based Fischer-Tropsch pathway}

The production of hydrocarbons via this pathway has the advantage of high hydrocarbon yields and very low $\mathrm{CO}$ selectivity even at high $\mathrm{CO}_{2}$ conversions. The choice of an appropriate zeolite becomes an important factor for tuning the selectivity of products. Thus, Wei et al. designed a multifunctional catalyst by coupling $\mathrm{Na}-\mathrm{Fe}_{3} \mathrm{O}_{4} \mathrm{CO}_{2}$-FT catalyst with different zeolites, which showed different product distribution based on the nature of the zeolites. ${ }^{7}$ This approach has also been advocated as a strategy to overcome the ASF distribution limit of the $\mathrm{CO}_{2} / \mathrm{CO}-\mathrm{FT}$ process due to the product redistribution capability of zeolites. Over $\mathrm{Na}-\mathrm{Fe}_{3} \mathrm{O}_{4} / \mathrm{HZSM}-5$ catalyst, gasoline-range $\left(\mathrm{C}_{5}-\mathrm{C}_{11}\right)$ hydrocarbons with selectivity up to $78 \%$ were achieved at a $\mathrm{CO}_{2}$ conversion of $22 \%$ and low methane selectivity (only $4 \%$ ). 
The main reason was the multifunctional nature of the catalyst providing the appropriate proximity of three types of active sites $\left(\mathrm{Fe}_{3} \mathrm{O}_{4}, \mathrm{Fe}_{5} \mathrm{C}_{2}\right.$ and acid sites), synergistically catalyzing the tandem reaction. $\mathrm{Fe}_{3} \mathrm{O}_{4}$ sites performed RWGS, $\mathrm{Fe}_{5} \mathrm{C}_{2}$ sites performed $\alpha$-olefin synthesis, while oligomerization/aromatization/isomerization was facilitated over zeolite acid sites (Figure 26a). It was observed that the degree of olefin oligomerization and product selectivity were dependent on the acidity and pore structure of the zeolite. Among the different zeolites (HY, HBEA, HMOR, HZSM-23, HMCM22 and HZSM-5) used, three types of zeolites with 10 member ring channels (HZSM-5, HMCM-22, and HZSM-23) exhibited higher $\mathrm{C}_{5}-\mathrm{C}_{11}$ selectivities (Figure 26b). Furthermore, the zeolite with stronger acidity was found to cause the over-cracking of heavy hydrocarbons to $\mathrm{C}_{1}-\mathrm{C}_{4}$ hydrocarbons, whereas the zeolite with weaker acidity was unable to perform the oligomerization/isomerization/aromatization of primary $\mathrm{CO}_{2}$-FT products, thus both disfavored the production of $\mathrm{C}_{5}-\mathrm{C}_{11}$ hydrocarbons. Tuning the acidity of the zeolite, HZSM-5 $(\mathrm{Si} / \mathrm{Al}=160)$ was found to be selective for $\mathrm{C}_{5}-\mathrm{C}_{11}$ hydrocarbon synthesis due to the presence of medium/strong acid sites and 10-ring 3-dimensional pore structure. The same group investigated a similar multifunctional catalyst $\mathrm{Na}-\mathrm{Fe}_{3} \mathrm{O}_{4} / \mathrm{HMCM}-22$, which produced $74 \%$ isoparaffins at a $\mathrm{CO}_{2}$ conversion of $26 \% .{ }^{235}$ In this case, Brønsted acidity of HMCM-22 effectively promoted isomerization, while suppressing aromatization. However, the main disadvantage was that the microporous nature of HMCM-22 initiated the coke deposition inside the micropores, which caused the decline of isoparaffin yield.

(a)

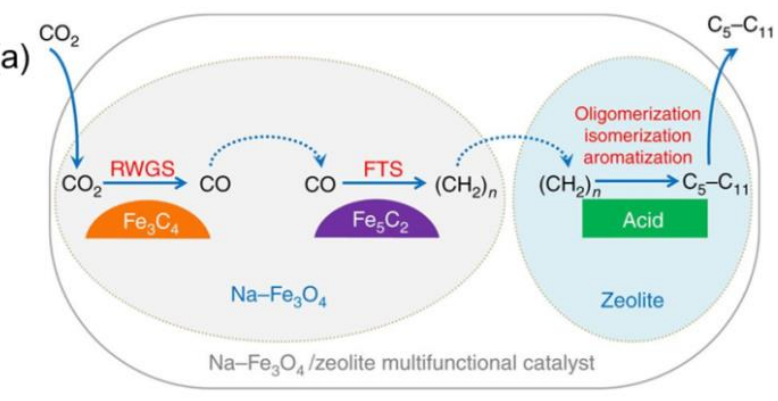

(b)

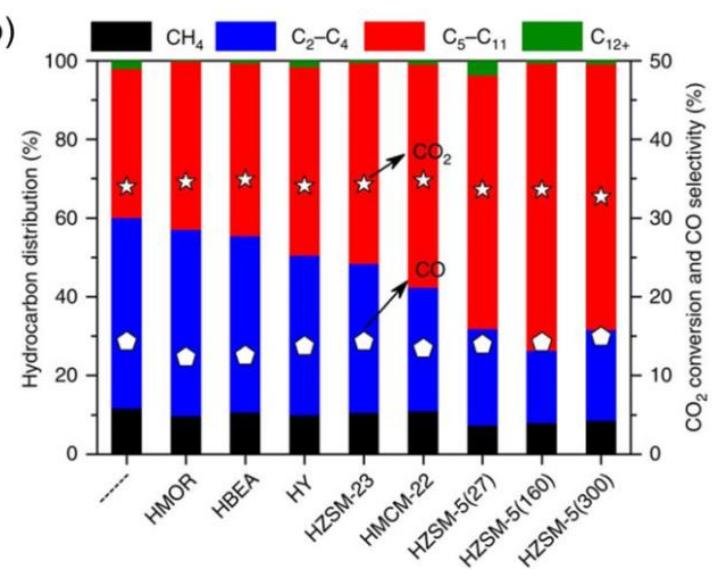

Figure 26. (a) Role of different active sites of a multifunctional catalyst in $\mathrm{CO}_{2}$ hydrogenation to make gasoline-range hydrocarbons. (b) Product selectivity over different $\mathrm{Na}-\mathrm{Fe}_{3} \mathrm{O}_{4}$ /zeolite catalysts; reaction conditions: $\mathrm{H}_{2} / \mathrm{CO}_{2}=3$, GHSV $=4000 \mathrm{~mL} \mathrm{~g}_{\text {cat }}{ }^{-1} \mathrm{~h}^{-1}$, $320{ }^{\circ} \mathrm{C}, 3 \mathrm{MPa}$. Reproduced with permission from ref. 7. Copyright 2017 Springer Nature. 
Considering the fact that ZSM-5 has the ability to generate aromatics and mordenite (MOR) has ethylene shape selectivity within the 8-membered ring, our group recently highlighted the importance of appropriate zeolite selection by studying the effect of the combination of these zeolites with a highly active $\mathrm{Fe}_{2} \mathrm{O}_{3} @ \mathrm{KO}_{2}$ catalyst in a single reactor. ${ }^{236}$ The bifunctional catalysts gave high $\mathrm{CO}_{2}$ conversion $(\sim 50 \%)$ with low CO selectivity (12.8\%) with ZSM-5 selectively producing aromatics and MOR enhancing the production of light olefins with high space-time yields. In-depth characterization via solidstate nuclear magnetic resonance (ssNMR) spectroscopy revealed that the reaction mechanism was driven by the incorporation of $\mathrm{CO}$ in the network in the form of surface formate species. In addition, DFT simulations demonstrated that carbenium ions are crucial intermediates for the conversion of hydrocarbons in zeolites, with ZSM-5 succeeding in activation of long alkenes to form aromatics via carbenium ions. Subsequent reports from our group have also revealed that coupling the $\mathrm{Fe}_{2} \mathrm{O}_{3} @ \mathrm{KO}_{2}$ catalyst with either Ca modified ZSM-5 or ZrS modified SAPO-34 leads to higher light olefin selectivity compared to MOR zeolite. ${ }^{237,238}$

A recent study by Liu and coworkers demonstrated a nice strategy to achieve selective formation of aromatics over a composite catalyst consisting of Na/Fe and HZSM-5. ${ }^{239}$ Under industrially relevant conditions, total selectivity to aromatics in liquid hydrocarbons reached over $94 \%$. The most striking results were observed regarding the selectivity to para-xylene in total xylenes, which was remarkably increased from $24-26 \%$ to $70 \%$ when $\mathrm{HZSM}-5$ zeolite was coated with $\mathrm{SiO}_{2}$. According to the experimental results and DFT calculations, the combined effect of Na-promoted Fe catalyst and high Brønsted acidity of HZSM-5 were believed to be the key factors for enhancing both $\mathrm{CO}_{2}$ conversion and aromatics selectivity. High Brønsted acidity of HZSM-5 zeolite played a critical role in converting $\mathrm{CO}_{2}-$ FT intermediate products into aromatics rather than isoparaffins as the ability of cracking and aromatization increases with increasing Brønsted acidity. Furthermore, coating $\mathrm{SiO}_{2}$ on the external surface of the zeolite efficiently decreased the coverage of the exterior acidic sites, which suppressed the isomerization of as formed para-xylene and para-ethyltoluene in the inner channels of HZSM-5 in order to keep a constant rate of aromatics formation (Figure 27). This study showed an effective way to shift the product distribution from several aromatics to a single product, which can make the separation process easier.

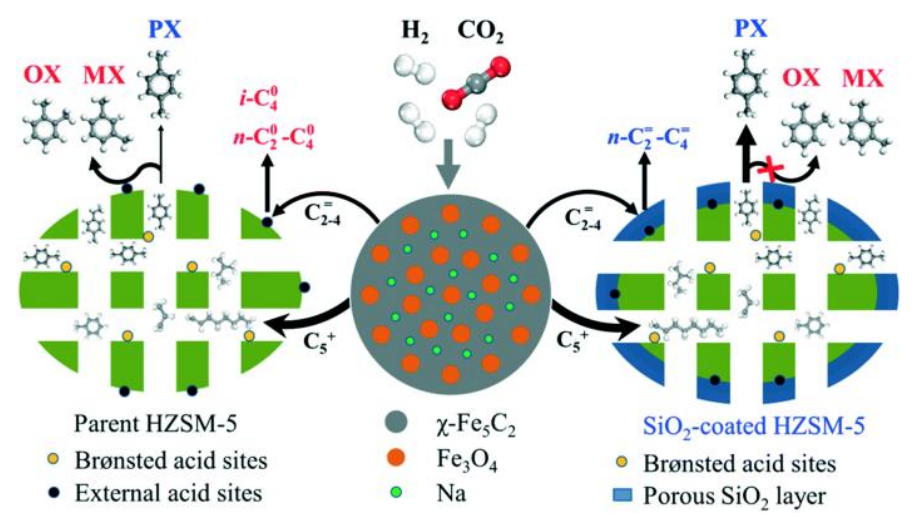

Figure 27. Isomerization of $p$-xylene and $p$-ethyltoluene over the external surface of uncoated and $\mathrm{SiO}_{2}$ coated HZSM-5 zeolite. Reproduced with permission from ref. 239. Copyright 2019 Royal Society of Chemistry. 


\subsubsection{Methanol-mediated pathway}

In this pathway, tandem catalysts composed of a methanol synthesis catalyst (see section 3.2) and a zeolite/zeotype are paired together for production of hydrocarbons from $\mathrm{CO}_{2}$. This pathway is characterized by high selectivity towards target products but suffers from low hydrocarbon yields.

The first report on this transformation was made by Fujimoto and Shikada in 1987. 440 Combination of a $\mathrm{Cu}-\mathrm{Zn}$ catalyst and a dealuminated $\mathrm{Y}$ zeolite (high-silica zeolite) produced $\mathrm{C}_{2}-\mathrm{C}_{5}$ hydrocarbons with selectivities over $90 \%$. A number of recent works have emulated similar combinations for this reaction because of the high activity of the $\mathrm{Cu}-\mathrm{Zn}$ catalyst and zeolite in methanol production and MTH, respectively. For example, Chen et al. used core-shell structured bifunctional CuZnZr@Zn-SAPO34 catalysts for direct hydrogenation of $\mathrm{CO}_{2}$ with a focus on light olefins production. ${ }^{241}$ Distribution of products was significantly affected by the mass ratio of CuZnZr and SAPO-34 as well as the acid density of SAPO-34. Compared to the physically mixed $\mathrm{CuZnZr} / \mathrm{SAPO}-34$, the composite catalyst selectivity produced olefins and suppressed $\mathrm{CH}_{4}$ formation due to reduced contact interface and hydrogenation ability on the metal sites. Interestingly, modification of SAPO-34 by $\mathrm{Zn}$ addition reduced the acidity of SAPO-34, which consequently increased the olefin selectivity by inhibiting the secondary hydrogenation reactions. Over CuZnZr@Zn-SAPO-34 (4/1) catalyst, $\mathrm{C}_{2}-\mathrm{C}_{4}$ olefin selectivity of $72 \%$ was achieved in the hydrocarbon fraction at reaction conditions of $\mathrm{H}_{2} / \mathrm{CO}_{2}=3$, GHSV $=6000 \mathrm{~mL} \mathrm{~g} \mathrm{~g}^{-1} \mathrm{~h}^{-1}, 400{ }^{\circ} \mathrm{C}$ and 2 $\mathrm{MPa}$. On the other hand, decrease in mass loading of $\mathrm{CuZnZr}$ fraction lowered the yield of methanol, which induced the hydrogenation and hydrogen transfer reactions of primary olefins to produce $\mathrm{C}_{3}$ and $\mathrm{C}_{4}$ hydrocarbons.

Based on the high activity of $\mathrm{ZnO}-\mathrm{ZrO}_{2}$ solid solution in methanol production, $\mathrm{Li}$ and coworkers reported $\mathrm{ZnZrO} / \mathrm{SAPO}-34$ tandem catalyst to achieve lower olefins with $80-90 \%$ selectivity among hydrocarbon products. ${ }^{242}$ To explain the tandem catalysis, they compared the catalytic performance of the $\mathrm{ZnZrO/SAPO} \mathrm{catalyst} \mathrm{with} \mathrm{those} \mathrm{of} \mathrm{the} \mathrm{two} \mathrm{individual} \mathrm{catalyst} \mathrm{components} \mathrm{integrated} \mathrm{in} \mathrm{varying} \mathrm{degrees}$ of proximity in a tubular fixed bed reactor (Figure 28). The highest olefin selectivity was observed over the tandem catalyst, which was far better than any other physical mixture of individual components. The results obtained here suggest that the product selectivity is highly dependent on the spatial separation between two active phases of the catalyst and close proximity is essential to create a synergistic effect in tandem catalysis. Similar studies focusing on short chain olefin production were reported over different multifunctional catalysts such as In-Zr/SAPO-34, ${ }^{243},{ }^{244} \mathrm{In}_{2} \mathrm{O}_{3}-\mathrm{ZrO}_{2} / \mathrm{SAPO}-5,{ }^{245} \mathrm{In}_{2} \mathrm{O}_{3} / \mathrm{SAPO}-34,{ }^{246}$ and $\mathrm{ZnGa}_{2} \mathrm{O}_{4} / \mathrm{SAPO}-34^{247}$ catalysts. From the literature reports described here, one thing is clear that SAPO34 has been widely used to obtain high selectivity for lower olefins. The main reason could be the presence of weak acidic sites and small 8-member ring (8MR) windows in SAPO-34, which are essential features to produce small molecules. In fact, the shape-selective nature of SAPO-34 has already been proven since its 8-ring pore structure was found to be beneficial for $\mathrm{C}_{2}-\mathrm{C}_{4}$ formation. ${ }^{248}$ 


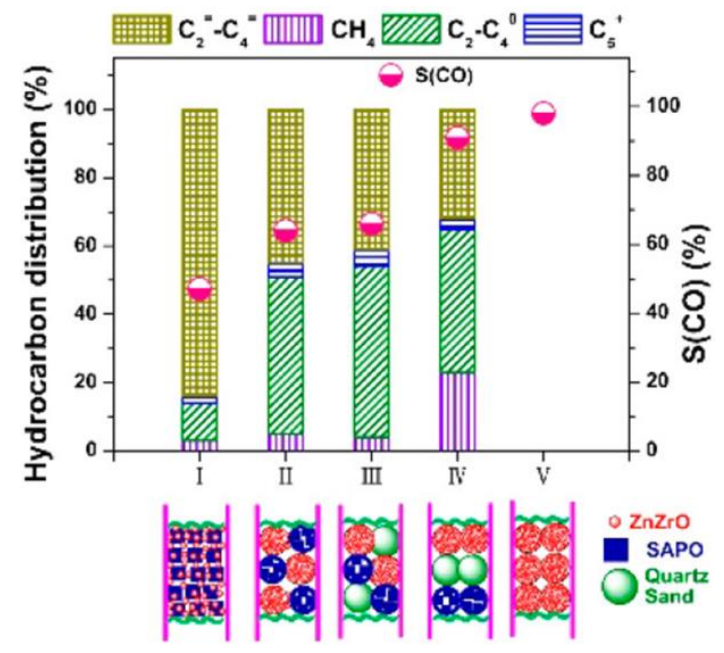

Figure 28. Comparison of catalytic performances between tandem catalyst (ZnZrO/SAPO) and physical mixtures of $\mathrm{ZnZrO}$ and SAPO in the hydrogenation of $\mathrm{CO}_{2}$; reaction conditions: $380{ }^{\circ} \mathrm{C}, 2 \mathrm{MPa}$, GHSV = $3600 \mathrm{~mL} \mathrm{~g}_{\mathrm{cat}}{ }^{-1} \mathrm{~h}^{-1}$. Reproduced with permission from ref. 242. Copyright 2017 American Chemical Society.

As we have seen that zeolites with 10-ring pore structure are suitable for higher hydrocarbon production, ${ }^{6}$ ZSM-5 has also been used by multiple groups to achieve selective production of $\mathrm{C}_{5+}$ hydrocarbons/aromatics. ${ }^{6,216,249-252}$ High Brønsted acidity of ZSM-5 also facilitates the aromatization process to convert primary olefins into aromatics. Wang et al. recently studied a bifunctional catalyst composed of $\mathrm{Cr}_{2} \mathrm{O}_{3}$ and $\mathrm{H}-\mathrm{ZSM}-5$ zeolite, which provided aromatics selectivity of $\sim 76 \%$ in the hydrocarbon fraction with a single-pass $\mathrm{CO}_{2}$ conversion of $34.5 \% .{ }^{249}$ Special emphasis was given towards the modification of zeolite in order to realize the target synthesis of BTX (benzene, toluene, and xylene), especially $p$-xylene (PX). The acidic sites at outer surface of H-ZSM-5 were neutralized by encapsulating with silicalite-1 (S-1) to suppress the undesired alkylation and isomerization of PX to $o$ - or $m$-xylene (Figures 29a \& 29b). Compared to the unmodified catalyst, modified $\mathrm{Cr}_{2} \mathrm{O}_{3} / \mathrm{H}-\mathrm{ZSM}-5 @ \mathrm{~S}-1$ catalyst improved the fractions of BTX and PX in aromatics products from $13.2 \%$ and $7.6 \%$ to $43.6 \%$ and $25.3 \%$, respectively. In another study, $\mathrm{Ni}$ et al. observed that silica modified $\mathrm{ZnAlO}_{x} \& \mathrm{Si}-\mathrm{H}-\mathrm{ZSM}-5$ catalyst could achieve 58.1\% p-xylene in xylenes (Figure 29c). ${ }^{250}$ The hydrogenation of $\mathrm{CO}_{2}$ was initially activated by $\mathrm{Zn}^{2+}$ in $\mathrm{ZnAlO}_{\mathrm{x}}$ as observed by operando DRIFTS study. The as-formed formate species blocked the $\mathrm{ZnAlOx}$ surface to make the metal sites less accessible for hydrogenation of unsaturated olefin intermediates which in turn improves the aromatics selectivity at the expense of $\mathrm{CO}$ (or saturated hydrocarbons) selectivity. 

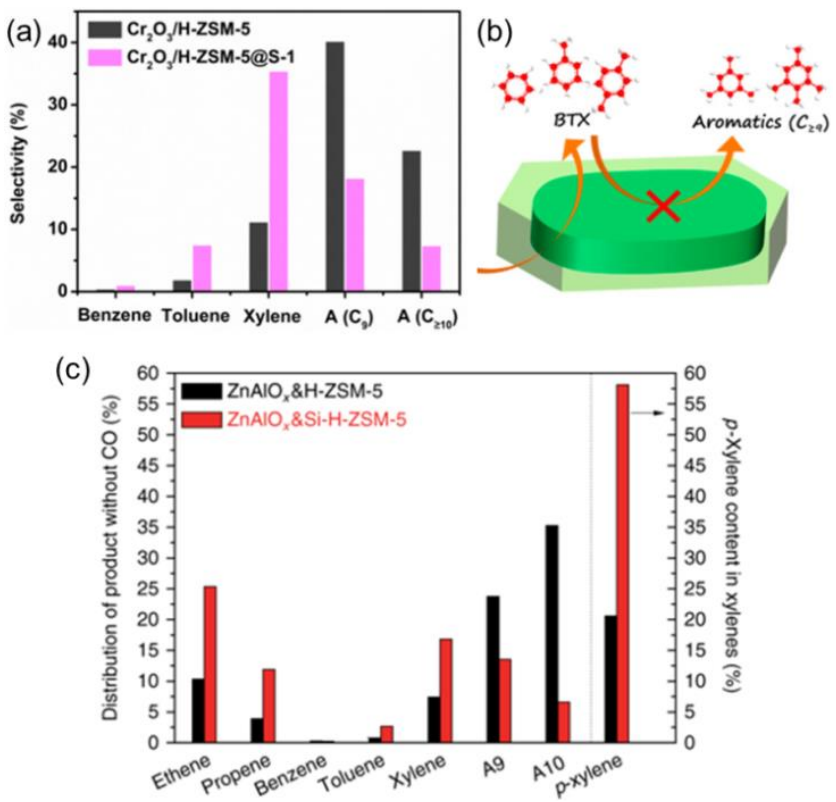

Figure 29. (a) Effect of modification on product selectivity and (b) scheme of highly selective production of BTX over $\mathrm{Cr}_{2} \mathrm{O}_{3} / \mathrm{H}-\mathrm{ZSM}-5 @ \mathrm{~S}-1$. (c) Effect of modification on catalytic behaviors in $\mathrm{CO}_{2}$ hydrogenation. Reproduced with permission from ref. 249 and 250. Copyright 2019 American Chemical Society and 2018 Springer Nature.

\subsubsection{Reaction mechanism}

Unraveling the reaction mechanism for the formation of hydrocarbons from $\mathrm{CO}_{2}$ remains a challenging task since this has not been studied to a great degree especially in the case of tandem catalysis. While a lot of classical reaction mechanisms involving hydrocarbons on zeolites can be applied, the presence of $\mathrm{CO}_{2}$, $\mathrm{CO}$, and $\mathrm{H}_{2} \mathrm{O}$ in the feed going to the zeolite possibly causes subtle differences which are yet to be discerned.

In case of the $\mathrm{CO}_{2}$-FT process, a reverse water gas shift (RWGS) mechanism where the $\mathrm{CO}_{2}$ is converted to $\mathrm{CO}$ followed by a carbide mechanism is widely accepted. As discussed in Section 3.3.1, alkali metals have proven to be effective promoters of $\mathrm{Fe}$ based catalysts for enhancing hydrocarbon yields. Potassium, in particular, seems to be beneficial for the initial conversion of $\mathrm{CO}_{2}$ to $\mathrm{CO}$. This was reported in our study where the $\mathrm{CO}_{2}$ in the feed reacts with the potassium on the Fe catalyst leading to the formation of a $\mathrm{K}_{2} \mathrm{CO}_{3}$ phase. ${ }^{216}$ This $\mathrm{K}_{2} \mathrm{CO}_{3}$ undergoes several transformations eventually releasing $\mathrm{CO}$ (Figure 30). Then $\mathrm{CO}$ is dissociated over the Fe phase and the carbon thus obtained is hydrogenated to form active $\mathrm{CH}_{x}(1 \leq \mathrm{x} \leq 3)$ species as chain initiators and monomer units for chain growth. The chain growth can be terminated either by hydrogenation to produce paraffins or by $\beta$-hydride abstraction to form $\alpha$-olefins. Since FT mechanism follows the Anderson-Schulz-Flory (ASF) law in product distribution, the main challenge of this process is to find proper catalysts that can prevent the formation of methane and light saturated hydrocarbons. 


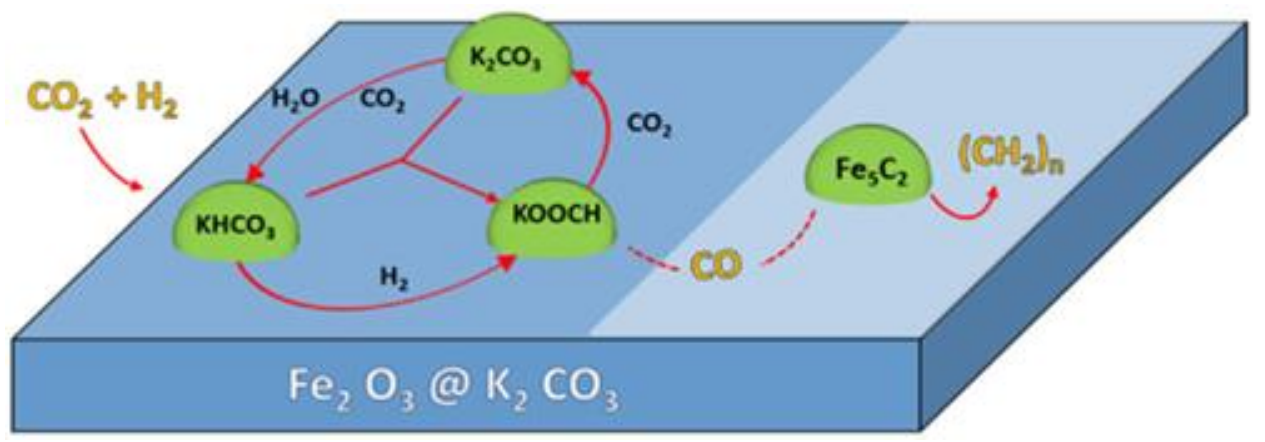

Figure 30. Reaction scheme of the $\mathrm{CO}_{2}$ capture and transformation on the $\mathrm{Fe}_{2} \mathrm{O}_{3} @ \mathrm{~K}_{2} \mathrm{CO}_{3}$ catalyst. The process takes place in two steps: (i) the $\mathrm{CO}_{2}$ is initially activated on the $\mathrm{K}_{2} \mathrm{CO}_{3}$ that undergoes several transformations yielding $\mathrm{KCOOH}$ and $\mathrm{CO}$, which is subsequently hydrogenated (ii) to olefins via FTS. Reproduced from ref. 216.

In the case, of tandem catalysis where a zeolite is paired with a $\mathrm{CO}_{2}$-FT catalyst most of the reactions occurring over the zeolite are classical hydrocracking, $\mathrm{H}$-transfer, oligomerization, cyclization reactions etc. However, as noted above, additional phenomena can occur which has not been widely studied. For instance, we have observed in our studies that the overall $\mathrm{CO}$ selectivity in a tandem catalyst is lower than a standalone $\mathrm{CO}_{2}$-FT catalyst due to the incorporation of $\mathrm{CO}$ in the zeolite via a ketene-like intermediate giving rise to higher production of light olefins (Figure 31). ${ }^{236,237}$ Therefore, in depth studies need to be performed where possible reaction intermediates including $\mathrm{CO} / \mathrm{H}_{2} \mathrm{O}$ are co-fed with $\mathrm{CO}_{2} / \mathrm{H}_{2}$ in order to unravel their effect on product formation. 


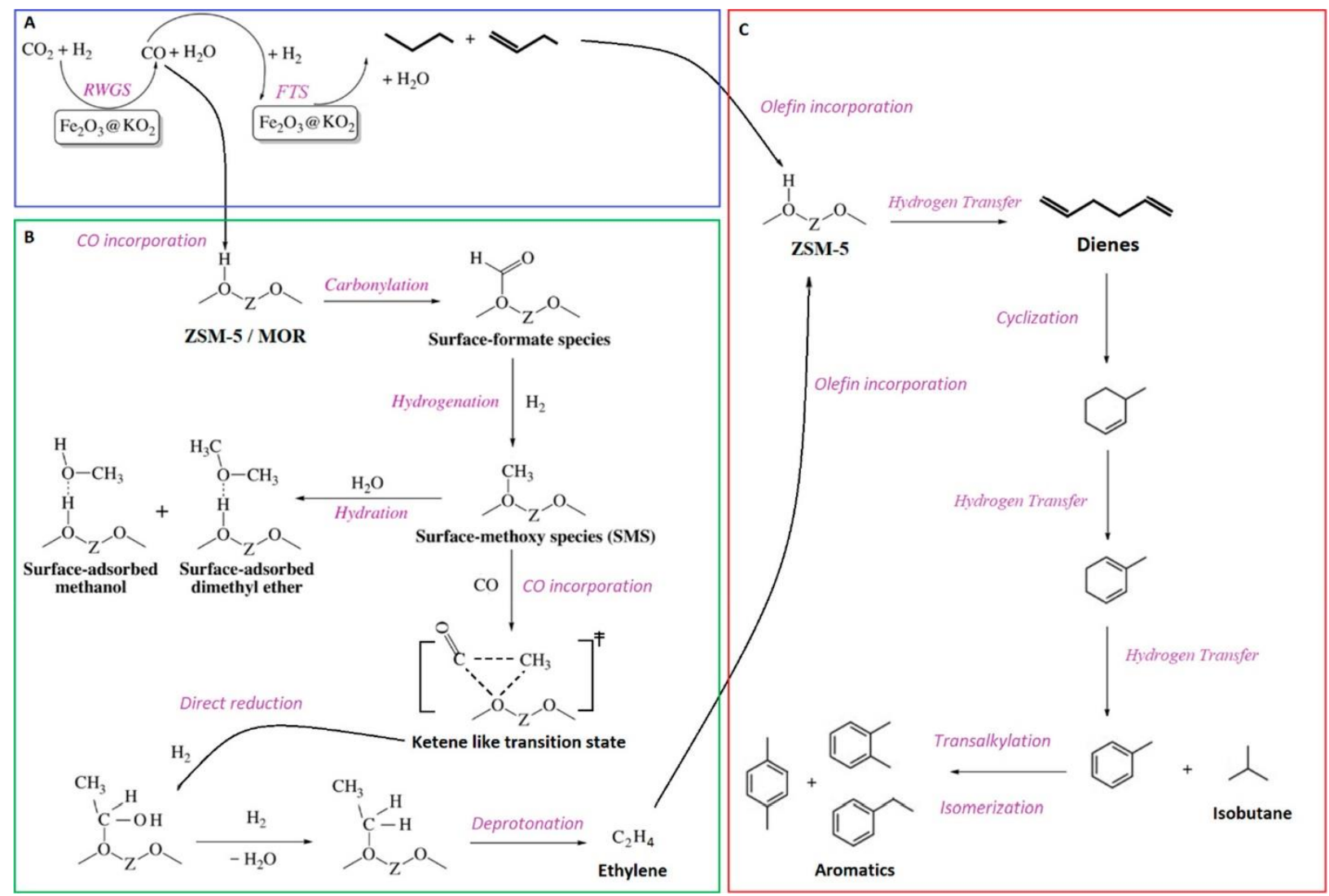

Figure 31. Reaction pathways of the $\mathrm{Fe}_{2} \mathrm{O}_{3} @ \mathrm{KO}_{2}$ /zeolite-catalyzed hydrogenation of $\mathrm{CO}_{2}$ to light olefins and aromatics. (A) $\mathrm{CO}_{2}$ hydrogenation pathway on the stand-alone $\mathrm{Fe}_{2} \mathrm{O}_{3} @ \mathrm{KO}_{2}$ catalyst. (B) $\mathrm{CO}$ incorporation pathway on MOR and ZMS-5. (C) Aromatization pathway on ZSM-5. Reproduced from ref. 236.

Considering now the methanol-mediated pathway, the main advantage of this route is that the ASF law of product distribution does not apply to it and therefore it is possible to obtain selectivities to olefins in the hydrocarbon fraction higher than $80 \%$. However, the main obstacle is associated with the fact that methanol-to-olefin (MTO) transformation requires high temperatures $\left(>350{ }^{\circ} \mathrm{C}\right)$ and it is hard to achieve significant $\mathrm{CH}_{3} \mathrm{OH}$ selectivity at this temperature due to the exothermic nature of the $\mathrm{CO}_{2}$-tomethanol process.

In the first step, $\mathrm{CO}_{2}$ is converted to methanol and the details of the mechanism can be found in Section 3.2.1.3. The methanol thus obtained is then converted into hydrocarbons via the classical methanol-to-hydrocarbon (MTH) mechanism over an acidic zeolite (see Figure 32). ${ }^{253}$ The reaction mechanism follows a short induction period where direct $\mathrm{C}-\mathrm{C}$ bond formation takes place aided by surface methoxy species adsorbed on the zeolite acting as intermediates. This is succeeded by an autocatalytic period where a dual cycle/hydrocarbon pool (HCP) type mechanism takes over. The latter has been widely studied in literature with several reports available. ${ }^{254-256}$ The autocatalytic dual cycle mechanism consists of an olefinic and an aromatic cycle which can be further divided into multiple elementary steps - methylation and cracking of olefins, methylation and dealkylation of aromatics, hydrogen transfer and cyclization. The last two steps also act as a bridge between the two cycles. 

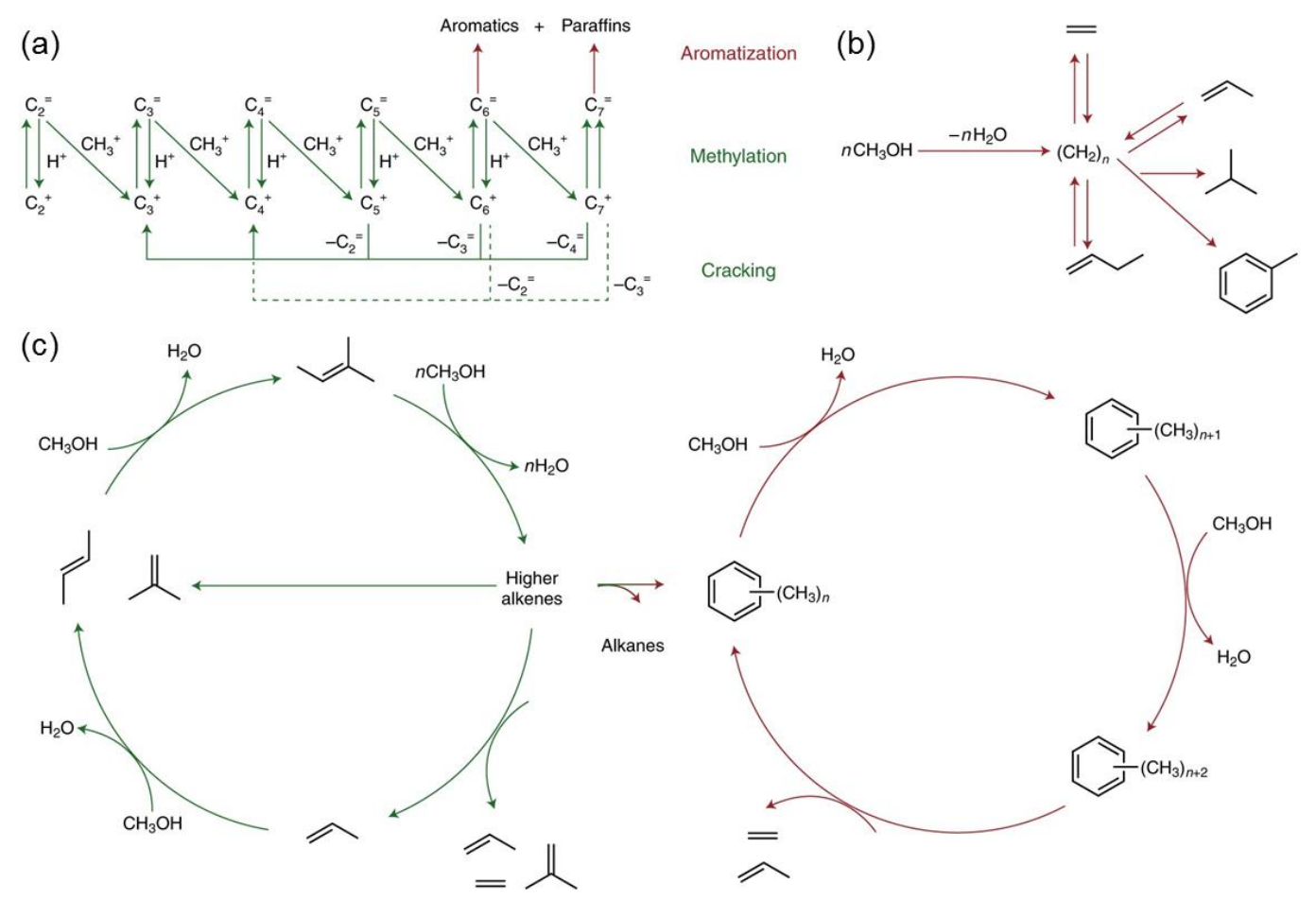

Figure 32. Schematic of MTH mechanism. (a) Steady state kinetics of MTH reaction over ZSM-5 by a sequence of olefins methylation followed by their cracking or aromatization to give either olefins or aromatics. (b) The hydrocarbon-pool (HCP) mechanism of MTH over SAPO-34 - an active intermediate of aromatic nature - through which light olefins are formed by dealkylation. (c) The dual cycle describing two competing cycles running in the zeolite channels governed by olefins and aromatics, both acting as co-catalysts for MTH and being active HCP species. Adapted from ref. 253. Copyright 2018 Springer Nature.

It has been observed that the olefinic cycle is primarily responsible for the production of propylene while the aromatic cycle gives rise to both ethylene and propylene. Thus, suppression or propagation of one cycle or the other by manipulating the operating conditions and/or catalyst modification can allow for the control of product selectivity. Nevertheless, the exact mechanism for the MTH reaction is still a matter of some debate and as noted for the $\mathrm{CO}_{2}$-FT route, starting from $\mathrm{CO}_{2}$ and using tandem catalysis via the $\mathrm{MeOH}$ route implies that the role of additional intermediates including $\mathrm{CO} / \mathrm{CO}_{2} / \mathrm{H}_{2} / \mathrm{H}_{2} \mathrm{O}$ under high pressures along with methanol going to the zeolite is yet to be resolved.

\subsubsection{Summary and challenges}

$\mathrm{CO}_{2}$ to hydrocarbons has attracted a lot of attention in literature recently because of the potential it has for contributing to a circular carbon economy especially in terms of production of fuels and petrochemicals. Tandem catalysis appears to be the method of choice for this reaction as it offers several exciting prospects pertaining to tuning of the product composition as noted in Table 6 .

Owing to the complexity of the process and the scarcity of fundamental investigations it is challenging to identify a specific set of properties which are ideal for a catalyst to be used in this process. This challenge is only magnified when tandem catalysts are brought into the picture since they tend to 
have a higher degree of complexity as there are more parameters which require optimization. For example, product selectivity can be tuned by changing the type or different properties of zeolites (such as $\mathrm{Si} / \mathrm{Al}$ ratio, pore size, and particle size). Additionally, more focus should be placed on understanding the reaction mechanism over the zeolite component. Moreover, very few zeolite types have been explored so far with H-ZSM-5 being the most common choice for aromatics production and SAPO-34 being the zeolite of choice for olefin synthesis (see Table 6). Hence, the exploration of other zeolite topologies also needs to be tackled.

Furthermore, since this is a multistep process, the precise control of the proximity of the active sites is a key factor for designing suitable tandem catalysts. In some cases, acidic sites of the zeolite can be poisoned by the alkaline functionalities of their counterpart due to close proximity and therefore dual bed configuration would be preferred in those cases. In fact, the spatial arrangement between the two phases of a tandem catalyst should be optimized based on the hydrogenation route followed (via $\mathrm{CO}_{2}$-FT or $\mathrm{MeOH})$.

Finally, there seems to be no clear front runner between the $\mathrm{CO}_{2}$-FT route and the $\mathrm{MeOH}$ route. For the former, poor selectivity to target products remains an issue and is a big barrier for implementation requiring to be addressed. A potential solution would be to go beyond the zeolites typically reported in literature in order to uncover a possible winner as mentioned above. For the latter, hydrocarbon yields are a major obstacle due to the thermal incompatibility between a methanol synthesis catalyst and a zeolite. Methanol synthesis catalysts tend to function well at temperatures below $300{ }^{\circ} \mathrm{C}$ while zeolites typically need to reach temperatures of at least $350-400{ }^{\circ} \mathrm{C}$ in order to be effective. One possible solution to this problem is to uncover catalysts which are relatively efficient at producing methanol at higher temperatures $\left(\sim 350{ }^{\circ} \mathrm{C}\right)$. This option, however, is severely limited by thermodynamics. Another feasible option would be to house the methanol synthesis catalyst and the zeolite in separate reactors connected in series with individual temperature control thus overcoming their thermal incompatibility.

Table 6. A non-exhaustive list of catalytic concepts explored for the production of multi-carbon hydrocarbons from $\mathrm{CO}_{2}$

\begin{tabular}{|c|c|c|c|c|c|c|c|c|c|c|}
\hline \multirow[t]{3}{*}{ Catalyst } & \multicolumn{3}{|c|}{ Reaction conditions } & \multirow{3}{*}{$\begin{array}{l}\text { Reaction } \\
\text { route }\end{array}$} & \multicolumn{5}{|c|}{ Catalytic performance } & \multirow[t]{3}{*}{ Ref. } \\
\hline & \multirow{2}{*}{$\begin{array}{l}T \\
\left({ }^{\circ} \mathrm{C}\right)\end{array}$} & \multirow{2}{*}{$\begin{array}{l}\mathrm{P} \\
\text { (bar) }\end{array}$} & \multirow{2}{*}{$\begin{array}{l}\text { GHSV (mL } \\
\left.\mathrm{g}_{\text {cat }}^{-1} \mathrm{~h}^{-1}\right)\end{array}$} & & \multirow{2}{*}{$\begin{array}{l}X_{\mathrm{CO} 2} \\
(\%)\end{array}$} & \multicolumn{4}{|c|}{ Selectivity (\%) } & \\
\hline & & & & & & $\mathrm{CO}$ & $\mathrm{CH}_{4}$ & $\mathrm{C}_{2}-\mathrm{C}_{4}=$ & Arom. & \\
\hline $\mathrm{In}_{2} \mathrm{O}_{3} / \mathrm{HZSM}-5$ & 340 & 30 & 9000 & $\mathrm{MeOH}$ & 13.1 & 44.8 & 0.6 & $\sim 2.0$ & 8.2 & 6 \\
\hline $\mathrm{Na}-\mathrm{Fe}_{3} \mathrm{O}_{4} / \mathrm{HZSM}-5$ & 320 & 30 & 4000 & $\mathrm{CO}_{2}-\mathrm{FT}$ & $\sim 34$ & $\sim 15$ & $\sim 6.9$ & $\sim 3.4$ & $\sim 36.5$ & 7 \\
\hline FeK/SWNTs & 340 & 20 & 9000 & $\mathrm{CO}_{2}$-FT & 52.7 & 9.6 & 13.5 & 22.5 & - & 217 \\
\hline FeK/MWNTs & 340 & 20 & 9000 & $\mathrm{CO}_{2}-\mathrm{FT}$ & 43.6 & 23.4 & 27.1 & 30.7 & - & 217 \\
\hline Red Mud + 2 wt $\%$ K & 375 & 30 & 9600 & $\mathrm{CO}_{2}-\mathrm{FT}$ & 45.0 & 26.0 & 19.0 & 36.0 & - & 221 \\
\hline $\mathrm{ZnFeO}_{x}-\mathrm{Na} / \mathrm{HZSM}-5$ & 320 & 30 & 4000 & $\mathrm{CO}_{2}-\mathrm{FT}$ & 36.2 & 11.0 & 7.3 & 2.8 & 53.4 & 223 \\
\hline Fe-K/HZSM-5 & 375 & 30 & 5000 & $\mathrm{CO}_{2}-\mathrm{FT}$ & 47.4 & 13.7 & 14.9 & 11.8 & 23.4 & 236 \\
\hline $\mathrm{Fe}-\mathrm{K} / \mathrm{MOR}$ & 375 & 30 & 5000 & $\mathrm{CO}_{2}-\mathrm{FT}$ & 47.1 & 12.9 & 13.7 & 33.2 & 2.5 & 236 \\
\hline Fe-K/Ca-ZSM-5 & 375 & 30 & 5000 & $\mathrm{CO}_{2}-\mathrm{FT}$ & 46.6 & 13.0 & 14.4 & 37.9 & 4.1 & 237 \\
\hline Fe-K/ZrS-SAPO-34 & 375 & 30 & 5000 & $\mathrm{CO}_{2}-\mathrm{FT}$ & 49.0 & 13.0 & $\sim 20$ & 48.0 & - & 238 \\
\hline $\mathrm{Zn}-\mathrm{ZrO}_{2} / \mathrm{Zn}-\mathrm{SAPO}-34$ & 380 & 20 & 3600 & $\mathrm{MeOH}$ & $\sim 18$ & $\sim 48$ & 2.1 & 32.0 & - & 242 \\
\hline In-Zr/SAPO-34 & 380 & 30 & 9000 & $\mathrm{MeOH}$ & 26.2 & 63.9 & 0.7 & 26.9 & - & 244 \\
\hline $\mathrm{ZnGa}_{2} \mathrm{O}_{4} / \mathrm{SAPO}-34$ & 370 & 30 & 5400 & $\mathrm{MeOH}$ & 13.0 & $\sim 49.0$ & - & 46.4 & - & 247 \\
\hline In-Zn-Zr/SAPO-34 & 380 & 30 & 9000 & $\mathrm{MeOH}$ & 17.0 & 53.4 & 0.6 & 39.4 & - & 257 \\
\hline K-Fe@Zn & 320 & 30 & 7200 & $\mathrm{CO}_{2}-\mathrm{FT}$ & 30.6 & 18.6 & 16.9 & 33.1 & - & 258 \\
\hline FeK-graphene/HZSM-5 & 340 & 20 & 26000 & $\mathrm{CO}_{2}-\mathrm{FT}$ & 35.0 & 39.0 & 2.1 & - & 41.5 & 259 \\
\hline
\end{tabular}




\begin{tabular}{lllllllllll}
$\mathrm{ZnO}-\mathrm{ZrO} / \mathrm{HZSM}-5$ & 340 & 40 & 7200 & $\mathrm{MeOH}$ & 16.0 & 34.3 & 0.2 & 4.3 & 49.9 & 260 \\
$\mathrm{NiCu}-\mathrm{CeO}_{2} / \mathrm{SAPO}-34$ & 375 & 20 & 12000 & $\mathrm{MeOH}$ & 15.3 & 65.0 & 0.7 & 26.8 & - & 261 \\
$\mathrm{Na}-\mathrm{Fe} @ \mathrm{C} / \mathrm{H}-\mathrm{ZSM}-5$ & 320 & 30 & 9000 & $\mathrm{CO}_{2}-\mathrm{FT}$ & 33.3 & 13.3 & 4.2 & 0.7 & 43.5 & 262 \\
\hline
\end{tabular}

\section{PROCESS DESIGN CONSIDERATIONS}

In the previous sections, we have seen the advances made in catalyst design for the thermocatalytic conversion of $\mathrm{CO}_{2}$. However, despite its importance, not a lot of effort has been dedicated to studying how these results will fit into a real process and their economic considerations.

Not surprisingly, most of the works in the field have been done in the methanol synthesis pathway where the commercial CuZn catalyst was mostly studied. ${ }^{263-267}$ It should be noted that the CuZn catalyst has been effectively commercialized with respect to the production of methanol from syngas. While it has proven to be quite active in the production of methanol from $\mathrm{CO}_{2}$, multiple studies have been published with very different catalysts performing much better than the CuZn catalysts (see Table 3). However, due to the large amount of data available in open literature concerning this catalytic system owing to decades of study, it becomes the first choice for process modelling. Recently, Slotboom et al. compiled all results available for this system and refitted the kinetic model. ${ }^{267}$ This refitted model with only six parameters (and valid for pressures from 20 to 70 bar and temperatures from 450 to $530 \mathrm{~K}$ ) showed that the rate determining steps are most likely to be the dissociation of the oxygen from formate and the $\mathrm{CO}_{2}$ dissociation in the RWGS reaction. In addition to these works on the commercial $\mathrm{CuZn}$ catalyst, Chiavassa et al. ${ }^{268}$ and Ahmad et al. ${ }^{269}$ studied another promising system: the Ga based catalyst $\left(\mathrm{Ga}_{2} \mathrm{O}_{3}-\mathrm{Pd} /\right.$ silica and $\mathrm{Ga}_{3} \mathrm{Ni}_{5}$, respectively). They discovered that the mechanism in this case is a competitive adsorption mechanism where adsorbed hydrogen occupies the same active sites as the oxygenated surface intermediates and $\mathrm{H}_{2} \mathrm{O}, \mathrm{CO}_{2}, \mathrm{CO}$ and $\mathrm{H}_{2}$ coverages are decisive.

Outside of the methanol pathway, only global final kinetic rate equations appear in the literature. Riedel et al. studied the $\mathrm{CO}_{2}$ conversion to hydrocarbons on a K-promoted Fe catalyst in a fixed-bed microreactor. ${ }^{270}$ Despite the global kinetics used, their results showed that, in contrast to the traditional Fischer-Tropsch reaction (FTS), equilibrium limitations exist for $\mathrm{CO}_{2}$ conversion. The experimental results reflect a two-step reaction mechanism with the RWGS $\mathrm{CO}_{2}$ reduction to $\mathrm{CO}$ as the primary step (equilibrium-limited with kinetic control) followed by subsequent CO FTS reaction (with kinetic control). Willauer et al. performed a kinetic study on a similar catalyst system (Mn and K-promoted Fe catalyst) and observed that this second FTS step rate was much slower than the RWGS rate. ${ }^{271}$ Their model was expanded to show the potential beneficial effects of water removal as the water formed under typical FTS conditions influences catalyst activity by re-oxidizing the catalyst. By removing water vapor on the catalyst surface, the equilibrium at the catalyst surface shifted to the production of desired intermediates and the predicted $\mathrm{C}_{3} \mathrm{H}_{6}$ yield increased from 27.5 to $63.3 \%$. Finally, Saeidi et al. revised the mechanisms and kinetics of $\mathrm{CO}_{2}$ hydrogenation to value-added products and proposed new mechanistic LHHW-type kinetic rates. ${ }^{272}$ Moreover, they suggest a novel integrated dual reactor configuration with a water permselective component in the first reactor and a $\mathrm{H}_{2}$ perm-selective component in the second that should greatly shift the equilibrium and enhance the overall $\mathrm{CO}_{2}$ conversion (see Figure 33). 


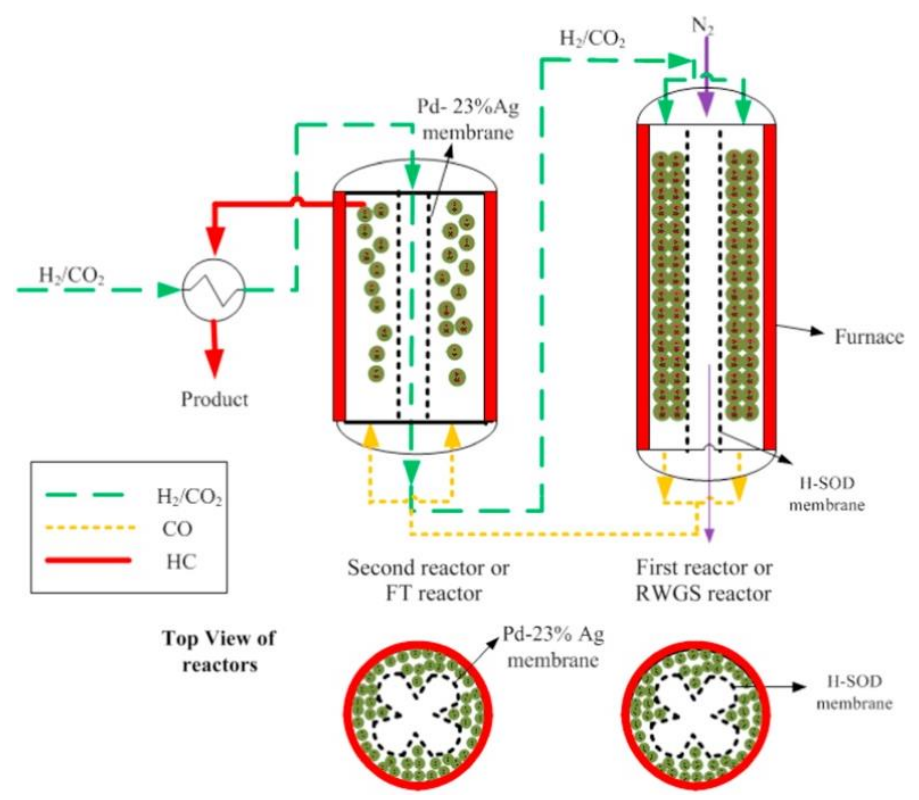

Figure 33. Schematic diagram of dual-type reactor with water and $\mathrm{H}_{2}$ perm-selective membrane. Reproduced with permission from ref. 272. Copyright 2017 Elsevier.

Hence, despite being brief, the kinetic studies showed us a key factor: water removal could greatly help overcome thermodynamic limitations and increase the conversion levels. With this information in hand, research groups have started to develop reactor systems that can take advantage of water removal. Currently, the most popular reactor design is the membrane reactor ${ }^{273}$ where water is removed from the gaseous stream. ${ }^{274-277}$ Recently, Li el al. demonstrated that water conducting nanochannels could be created by assembling $\mathrm{NaA}$ zeolite crystals into a continuous, defect-free separation membrane (Figure 34). ${ }^{274}$ Water separation with high $\mathrm{H}_{2} \mathrm{O} / \mathrm{CO}_{2}$ selectivity $(\sim 550)$ was the result of a gating effect of the $\mathrm{Na}^{+}$ions located in the 8-oxygen ring apertures that regulated their effective size. This highly efficient, in situ water removal through water-conducting nanochannels led to a substantial increase in $\mathrm{CO}_{2}$ conversion (up to 61.4\%, above the equilibrium conversion), resulting in a methanol space-time yield (STY) of $0.809 \mathrm{~g} \mathrm{~g}_{\mathrm{cat}}{ }^{-1} \mathrm{~h}^{-1}$ at GHSV of $10500 \mathrm{~mL} \mathrm{~g}_{\mathrm{cat}}{ }^{-1} \mathrm{~h}^{-1}, 250{ }^{\circ} \mathrm{C}$ and $35 \mathrm{bar}$, the highest value ever reported under similar conditions. 
(a)
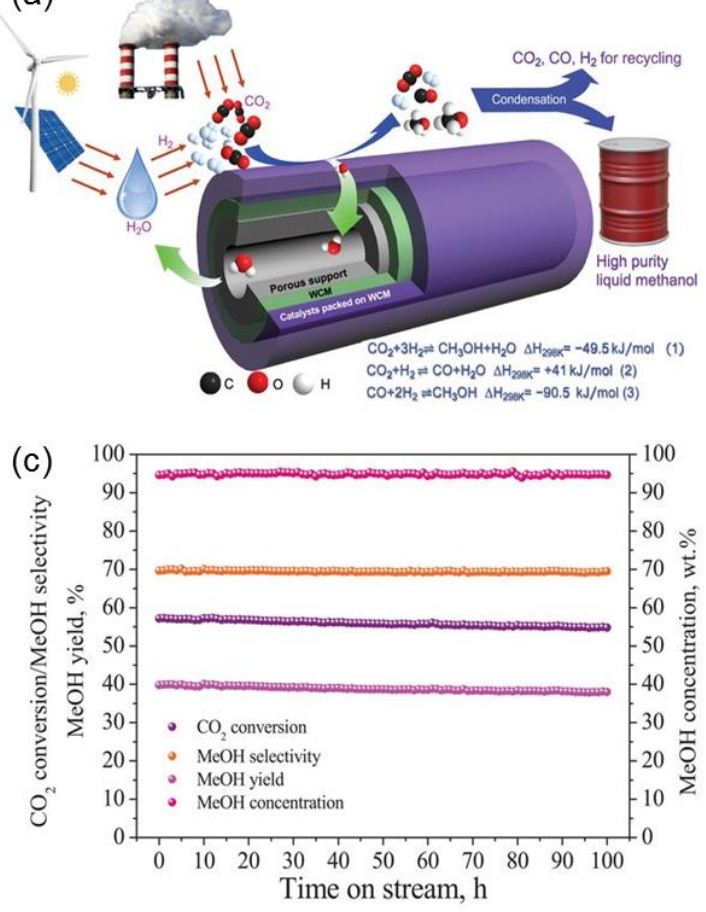
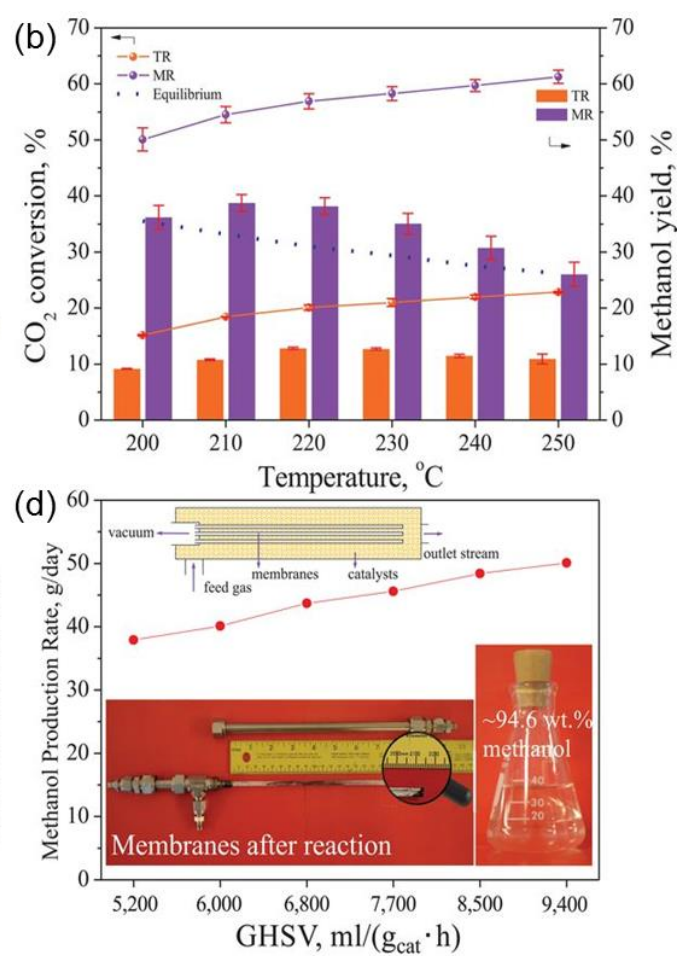

Figure 34. Schematics of the membrane reactor (MR) concept and catalytic performance of the MR. Reproduced with permission from ref. 274. Copyright 2020 The American Association for the Advancement of Science.

However, this promising concept has only been experimentally applied to the methanol synthesis pathway. Nevertheless, some revealing works can still be found in the literature outside this pathway. For instance, $\mathrm{Li}$ et al. studied a dual reactor in series with inter-stage water removal to enhance the liquefied petroleum gas (LPG) synthesis from $\mathrm{CO}_{2} \cdot{ }^{278}$ They used a CuZnZrAl/Pd- $\beta$ bifunctional catalyst in the first reactor to synthesize DME-rich products and then a Pd- $\beta$ zeolite in the second stage to transform the DME into LPGs (see Figure 35). The removal of water enhanced the stability of the Pd- $\beta$ zeolite second component as the poisoning of acid sites by water molecules was suppressed. Guo et al. used a similar approach by removing water between two fixed bed reactors, although the catalyst was the same in both stages, a K-Co/Fe catalyst highly selective to $\mathrm{C}_{5+}$ hydrocarbons. ${ }^{230}$ Owing to the water removal, the $\mathrm{CO}_{2}$ conversion was increased from $35 \%$ up to $65 \%$ at similar catalyst overall loadings and reaction conditions. In a different approach, Kim et al. studied the effect of the reactor type on the $\mathrm{CO}_{2}$ conversion to olefins by comparing a slurry, a fixed bed and a fluidized bed reactor. ${ }^{279}$ They found that temperature profiles are crucial in $\mathrm{CO}_{2}$ hydrogenation as most of the intermediate reactions (i.e., $\mathrm{CO}_{2}$ to methanol or hydrocarbon synthesis) are exothermic in nature. Hence, fixed-bed reactors are not optimal due to heat accumulation inside the reactor. This heat accumulation was recently studied by Cui et al. by comparing three fixed bed reactor types (the adiabatic, water-cooled and gas-cooled reactor). ${ }^{280}$ The simulation results showed that in the adiabatic and the gas-cooled reactor the hot spot temperatures inside the system can be within the typical operating temperature range for the catalyst and only the water-cooled system showed advantages in terms of efficient heat removal. 


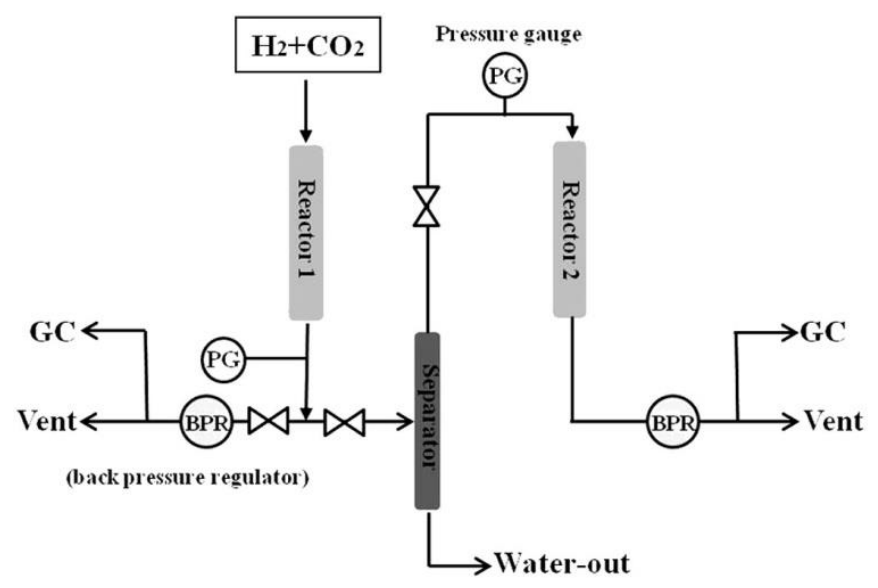

Figure 35. Diagram of improved two-stage process for LPG production. Reproduced with permission from ref. 278. Copyright 2015 Elsevier.

Finally, when looking at ASPEN process simulations, a similar trend is again observed ${ }^{281-287}$ with most of the works being done in the methanol pathway field, ${ }^{281-285}$ probably owing to the easier downstream separation of this process. ${ }^{286}$ Here, a typical process comprises an initial feed with pressurization steps followed by a fixed bed reactor. The subsequent unit operations consist of a flash separation where the liquid fraction is removed, a recycle stream of the water-free gases to the reactor, a small purge vent to avoid the accumulation of inert gases and a final distillation based separation unit to obtain the high purity product, typically methanol. Thanks to the recycle of the gaseous stream $\mathrm{CO}_{2}$ conversions close to $100 \%$ can be achieved ${ }^{281}$. Therefore, single pass conversion is not as critical as the high selectivity. However, we need to point out that despite the claim of using renewable $\mathrm{H}_{2}$ from electrolysis, none of the models start with $\mathrm{H}_{2}$ at atmospheric pressure and high pressure feeds (30 bar) are assumed. This will definitely hinder the overall economic viability of the process, as the costs associated with pre-compressing atmospheric $\mathrm{H}_{2}$ are vast.

Summing up, thanks to the recycling stream and the water removal of certain reactor configurations, $\mathrm{CO}_{2}$ conversions above the thermodynamic limitations can be achieved. Hence, focusing on water removal might have more impact on the overall process than developing complex and expensive catalytic systems. Nevertheless, as stated above, developing catalyst with low selectivity to undesired inert products (e.g., methane) is still crucial to minimize the vent purge and increase the recycle and, as a consequence, the overall conversion. Additionally, studies of how the components of this recycle stream $\left(\mathrm{CO}, \mathrm{CH}_{4}\right.$, traces of $\mathrm{C}_{2+}$, etc.) can affect the catalyst is a must. Moreover, very few studies have taken the trouble to analyze if the $\mathrm{CO}_{2}$ removal levels of their processes are in fact significant. ${ }^{19,288,289}$ Last but not least, economic considerations should also be taken in consideration when developing a catalyst for the $\mathrm{CO}_{2}$ conversion as, with the current green $\mathrm{H}_{2}$ prices, the $\mathrm{CO}_{2}$ conversion to hydrocarbons is economically hindered. ${ }^{290}$

\section{CONCLUSIONS AND FUTURE DIRECTIONS}

As has been concluded by multiple studies, addressing $\mathrm{CO}_{2}$ emissions and the associated climate change challenges would require an assortment of innovative solutions. This can be likened to the principles of waste management (termed as waste hierarchy) which includes 'Reduce, Reuse, Recycle, Recovery and 
Disposal'. In this context, 'Reduce' would not only imply practices designed to minimize energy use but also, for example, designing engines and/or power plants that are more efficient so that more energy can be extracted from the same amount of fuel thus reducing the amount needed. 'Reuse', in the technical sense of the word, is not applicable to this situation since fuels and energy sources are ephemeral. 'Recycle' and 'Recovery' are combined into the concept of CCU or a circular carbon economy and finally 'Disposal' relates to CCS. Since the five terms of the waste hierarchy are ordered in terms of desirability, the mix of $\mathrm{CO}_{2}$ abatement solutions can be considered in a similar fashion. However, based on the current state of the art, CCS is an easier solution to implement which could cause an appreciable impact in the short term. If the technical challenges associated with both DAC and production of renewable $\mathrm{H}_{2}$ via water electrolysis could be addressed, then CCU has the potential to cause a significant impact in addressing climate change. Furthermore, for the effective implementation of CCU, proper catalyst and process design is required.

Based on the studies on catalyst design discussed here, it can be concluded that the current trend in $\mathrm{CO}_{2}$ conversion research is towards the design of highly active and more selective catalysts. Different fundamental approaches have been adopted by researchers to identify the active sites and their interaction with reaction intermediates, which has helped in the design of better catalysts. Based on the active sites of catalysts, different reaction pathways were proposed and, in some cases, it was possible to select a more favorable pathway for a particular transformation just by tuning the catalyst composition and synthesis procedure. The majority of this review has discussed the role of various promoters to achieve improved activity and selectivity due to the improved adsorption ability of the modified catalysts. In most cases, it was observed that the use of promoters is necessary for initial activation of $\mathrm{CO}_{2}$, which cannot otherwise be possible over simple active metal components without promotion. Integrated cascade pathways have been developed for the direct transformation of $\mathrm{CO}_{2}$ into hydrocarbon fuels and/or useful aromatics/olefins and the associated catalysts were designed accordingly. However, the main challenge of these processes is associated with the low $\mathrm{CO}_{2}$ conversion, poor product selectivity and dependence on cheap, renewable $\mathrm{H}_{2}$, which is still an obstacle in $\mathrm{CO}_{2}$-based refineries. Moreover, since $\mathrm{CO}_{2}$ conversion mainly deals with reduction by $\mathrm{H}_{2}$, water is always formed as an unavoidable byproduct. Thus, water removal becomes an important process design parameter because on the one hand, its removal allows the enhanced single pass conversion of $\mathrm{CO}_{2}$ due to the shift in the reaction equilibrium but on the other hand, if a methanol/ $\mathrm{CO}_{2}$-FTS catalyst is paired with a zeolite for the production of chemicals or fuels, then the water generated in the first step might play a potentially helpful role in maintaining the overall composite catalyst stability.

Looking forward, there are many possibilities for $\mathrm{CO}_{2}$ valorization in terms of deriving new renewable fine chemicals and fuels, but further attention needs to be paid to both catalyst design and process engineering. Nevertheless, despite all the difficulties, the state of the art is rapidly catching up and we foresee that the practical application of $\mathrm{CO}_{2}$ derived products will undoubtedly take place in the near future. 


\section{REFERENCES}

1. $\quad$ Petroleum, B., BP Statistical Review of World Energy Report. BP: London, UK 2019.

2. Mac Dowell, N.; Fennell, P. S.; Shah, N.; Maitland, G. C., The role of $\mathrm{CO}_{2}$ capture and utilization in mitigating climate change. Nat. Clim. Change 2017, 7, 243.

3. Letcher, T. M., 1 - Introduction With a Focus on Atmospheric Carbon Dioxide and Climate Change. In Future Energy (Third Edition), Letcher, T. M., Ed. Elsevier 2020; pp 3-17.

4. $\quad$ von der Assen, N.; Müller, L. J.; Steingrube, A.; Voll, P.; Bardow, A., Selecting CO2 Sources for CO2 Utilization by Environmental-Merit-Order Curves. Environ. Sci. Technol. 2016, 50, 1093-1101.

5. $\quad$ Rodrigue, J.-P., The Geography of Transport Systems. Taylor \& Francis 2016.

6. Gao, P.; Li, S.; Bu, X.; Dang, S.; Liu, Z.; Wang, H.; Zhong, L.; Qiu, M.; Yang, C.; Cai, J.; Wei, W.; Sun, Y., Direct Conversion of $\mathrm{CO}_{2}$ into Liquid Fuels with High Selectivity over a Bifunctional Catalyst. Nat. Chem. 2017, 9, 1019.

7. Wei, J.; Ge, Q.; Yao, R.; Wen, Z.; Fang, C.; Guo, L.; Xu, H.; Sun, J., Directly Converting $\mathrm{CO}_{2}$ into a Gasoline Fuel. Nat. Commun. 2017, 8, 15174.

8. Sreedhar, I.; Varun, Y.; Singh, S. A.; Venugopal, A.; Reddy, B. M., Developmental trends in CO2 methanation using various catalysts. Catal. Sci. Technol. 2019, 9, 4478-4504.

9. Fuel, B. What's In A Crude Oil Barrel? A Breakdown of Crude Oil Refined Products. https://www.breakthroughfuel.com/blog/crude-oil-barrel/ (31st of March, 2020),

10. IEA, The Future of Petrochemicals. IEA, Paris 2018.

11. Eskew, B., US Petrochemicals: The Growing Importance of Export Markets. In EIA Energy Conference 2018.

12. EPA, U. S. Greenhouse Gases Equivalencies Calculator - Calculations and References. https://www.epa.gov/energy/greenhouse-gases-equivalencies-calculator-calculations-and-references (31st of March, 2020),

13. IEA, Putting $\mathrm{CO}_{2}$ to Use. IEA, Paris 2019.

14. Le Quéré, C.; Andres, R. J.; Boden, T.; Conway, T.; Houghton, R. A.; House, J. I.; Marland, G.; Peters, G. P.; van der Werf, G. R.; Ahlström, A.; Andrew, R. M.; Bopp, L.; Canadell, J. G.; Ciais, P.; Doney, S. C.; Enright, C.; Friedlingstein, P.; Huntingford, C.; Jain, A. K.; Jourdain, C.; Kato, E.; Keeling, R. F.; Klein Goldewijk, K.; Levis, S.; Levy, P.; Lomas, M.; Poulter, B.; Raupach, M. R.; Schwinger, J.; Sitch, S.; Stocker, B. D.; Viovy, N.; Zaehle, S.; Zeng, N., The global carbon budget 1959-2011. Earth Syst. Sci. Data 2013, 5, 165-185.

15. Lovelock, C. E.; Duarte, C. M., Dimensions of Blue Carbon and emerging perspectives. Biol. Lett. 2019, 15, 20180781.

16. Kayfeci, M.; Keçebaş, A.; Bayat, M., Chapter 3 - Hydrogen production. In Solar Hydrogen Production, Calise, F.; D’Accadia, M. D.; Santarelli, M.; Lanzini, A.; Ferrero, D., Eds. Academic Press 2019; pp 45-83.

17. Dittmeyer, R.; Klumpp, M.; Kant, P.; Ozin, G., Crowd oil not crude oil. Nat. Commun. 2019, 10, 1818.

18. Sordakis, K.; Tang, C.; Vogt, L. K.; Junge, H.; Dyson, P. J.; Beller, M.; Laurenczy, G., Homogeneous Catalysis for Sustainable Hydrogen Storage in Formic Acid and Alcohols. Chem. Rev. 2018, 118, 372-433.

19. Artz, J.; Müller, T. E.; Thenert, K.; Kleinekorte, J.; Meys, R.; Sternberg, A.; Bardow, A.; Leitner, W., Sustainable Conversion of Carbon Dioxide: An Integrated Review of Catalysis and Life Cycle Assessment. Chem. Rev. 2018, 118, 434-504.

20. Grice, K. A., Carbon dioxide reduction with homogenous early transition metal complexes: Opportunities and challenges for developing CO2 catalysis. Coord. Chem. Rev. 2017, 336, 78-95.

21. Onishi, N.; Laurenczy, G.; Beller, M.; Himeda, Y., Recent progress for reversible homogeneous catalytic hydrogen storage in formic acid and in methanol. Coord. Chem. Rev. 2018, 373, 317-332.

22. Kar, S.; Kothandaraman, J.; Goeppert, A.; Prakash, G. K. S., Advances in catalytic homogeneous hydrogenation of carbon dioxide to methanol. J. CO2 Util. 2018, 23, 212-218. 
23. Wang, W.-H.; Himeda, Y.; Muckerman, J. T.; Manbeck, G. F.; Fujita, E., CO2 hydrogenation to formate and methanol as an alternative to photo-and electrochemical $\mathrm{CO} 2$ reduction. Chem. Rev. 2015, $115,12936-12973$.

24. Álvarez, A.; Bansode, A.; Urakawa, A.; Bavykina, A. V.; Wezendonk, T. A.; Makkee, M.; Gascon, J.; Kapteijn, F., Challenges in the Greener Production of Formates/Formic Acid, Methanol, and DME by Heterogeneously Catalyzed $\mathrm{CO}_{2}$ Hydrogenation Processes. Chem. Rev. 2017, 117, 9804-9838.

25. Jia, J.; Qian, C.; Dong, Y.; Li, Y. F.; Wang, H.; Ghoussoub, M.; Butler, K. T.; Walsh, A.; Ozin, G. A., Heterogeneous catalytic hydrogenation of $\mathrm{CO} 2$ by metal oxides: defect engineering - perfecting imperfection. Chem. Soc. Rev. 2017, 46, 4631-4644.

26. Jiang, X.; Nie, X.; Guo, X.; Song, C.; Chen, J. G., Recent Advances in Carbon Dioxide Hydrogenation to Methanol via Heterogeneous Catalysis. Chem. Rev. 2020, 120, 7984-8034.

27. Zhong, J.; Yang, X.; Wu, Z.; Liang, B.; Huang, Y.; Zhang, T., State of the art and perspectives in heterogeneous catalysis of CO2 hydrogenation to methanol. Chem. Soc. Rev. 2020, 49, 1385-1413.

28. Ye, R.-P.; Ding, J.; Gong, W.; Argyle, M. D.; Zhong, Q.; Wang, Y.; Russell, C. K.; Xu, Z.; Russell, A. G.; Li, Q.; Fan, M.; Yao, Y.-G., CO2 hydrogenation to high-value products via heterogeneous catalysis. Nat. Commun. 2019, 10, 5698.

29. Goeppert, A.; Czaun, M.; Jones, J.-P.; Prakash, G. S.; Olah, G. A., Recycling of carbon dioxide to methanol and derived products-closing the loop. Chem. Soc. Rev. 2014, 43, 7995-8048.

30. Bao, J.; Yang, G.; Yoneyama, Y.; Tsubaki, N., Significant advances in C1 catalysis: highly efficient catalysts and catalytic reactions. ACS Catal. 2019, 9, 3026-3053.

31. Roy, S.; Cherevotan, A.; Peter, S. C., Thermochemical CO2 Hydrogenation to Single Carbon Products: Scientific and Technological Challenges. ACS Energy Lett. 2018, 3, 1938-1966.

32. Zhao, G.; Huang, X.; Wang, X.; Wang, X., Progress in catalyst exploration for heterogeneous CO2 reduction and utilization: a critical review. J. Mater. Chem. A 2017, 5, 21625-21649.

33. Yu, S.; Wilson, A. J.; Kumari, G.; Zhang, X.; Jain, P. K., Opportunities and Challenges of SolarEnergy-Driven Carbon Dioxide to Fuel Conversion with Plasmonic Catalysts. ACS Energy Lett. 2017, 2, 2058-2070.

34. Li, D.; Kassymova, M.; Cai, X.; Zang, S.-Q.; Jiang, H.-L., Photocatalytic CO2 reduction over metal-organic framework-based materials. Coord. Chem. Rev. 2020, 412, 213262.

35. Zheng, T.; Jiang, K.; Wang, H., Recent Advances in Electrochemical CO2-to-CO Conversion on Heterogeneous Catalysts. Adv. Mater. 2018, 30, 1802066.

36. Nielsen, D. U.; Hu, X.-M.; Daasbjerg, K.; Skrydstrup, T., Chemically and electrochemically catalysed conversion of $\mathrm{CO} 2$ to $\mathrm{CO}$ with follow-up utilization to value-added chemicals. Nat. Catal. 2018, 1, 244-254.

37. $\mathrm{Xu}, \mathrm{S}$;; Carter, E. A., Theoretical Insights into Heterogeneous (Photo)electrochemical CO2 Reduction. Chem. Rev. 2019, 119, 6631-6669.

38. Jia, C.; Gao, J.; Dai, Y.; Zhang, J.; Yang, Y., The thermodynamics analysis and experimental validation for complicated systems in CO2 hydrogenation process. J. Energy Chem. 2016, 25, 1027-1037.

39. Yang, Y.; Evans, J.; Rodriguez, J. A.; White, M. G.; Liu, P., Fundamental studies of methanol synthesis from $\mathrm{CO} 2$ hydrogenation on $\mathrm{Cu}(111), \mathrm{Cu}$ clusters, and $\mathrm{Cu} / \mathrm{ZnO}(0001)$. Phys. Chem. Chem. Phys. 2010, 12, 9909-9917.

40. Porosoff, M. D.; Yan, B.; Chen, J. G., Catalytic reduction of $\mathrm{CO} 2$ by $\mathrm{H} 2$ for synthesis of CO, methanol and hydrocarbons: challenges and opportunities. Energy Environ. Sci. 2016, 9, 62-73.

41. Kattel, S.; Liu, P.; Chen, J. G., Tuning Selectivity of CO2 Hydrogenation Reactions at the Metal/Oxide Interface. J. Am. Chem. Soc. 2017, 139, 9739-9754.

42. Su, X.; Yang, X.; Zhao, B.; Huang, Y., Designing of highly selective and high-temperature endurable RWGS heterogeneous catalysts: recent advances and the future directions. J. Energy Chem. 2017, 26, 854-867.

43. Porosoff, M. D.; Chen, J. G., Trends in the catalytic reduction of $\mathrm{CO} 2$ by hydrogen over supported monometallic and bimetallic catalysts. J. Catal. 2013, 301, 30-37. 
44. Li, S.; Xu, Y.; Chen, Y.; Li, W.; Lin, L.; Li, M.; Deng, Y.; Wang, X.; Ge, B.; Yang, C.; Yao, S.; Xie, J.; Li, Y.; Liu, X.; Ma, D., Tuning the Selectivity of Catalytic Carbon Dioxide Hydrogenation over Iridium/Cerium Oxide Catalysts with a Strong Metal-Support Interaction. Angew. Chem. Int. Ed. 2017, 56, 10761-10765.

45. Yang, S.-C.; Pang, S. H.; Sulmonetti, T. P.; Su, W.-N.; Lee, J.-F.; Hwang, B.-J.; Jones, C. W., Synergy between Ceria Oxygen Vacancies and $\mathrm{Cu}$ Nanoparticles Facilitates the Catalytic Conversion of CO2 to CO under Mild Conditions. ACS Catal. 2018, 8, 12056-12066.

46. Panaritis, C.; Edake, M.; Couillard, M.; Einakchi, R.; Baranova, E. A., Insight towards the role of ceria-based supports for reverse water gas shift reaction over RuFe nanoparticles. J. CO2 Util. 2018, 26, 350-358.

47. Shan, W.; Feng, Z.; Li, Z.; Zhang, J.; Shen, W.; Li, C., Oxidative steam reforming of methanol on $\mathrm{Ce} 0.9 \mathrm{Cu} 0.1 \mathrm{OY}$ catalysts prepared by deposition-precipitation, coprecipitation, and complexationcombustion methods. J. Catal. 2004, 228, 206-217.

48. Bueno-López, A.; Krishna, K.; Makkee, M., Oxygen exchange mechanism between isotopic CO2 and Pt/CeO2. Appl. Catal. A: Gen. 2008, 342, 144-149.

49. Staudt, T.; Lykhach, Y.; Tsud, N.; Skála, T.; Prince, K. C.; Matolín, V.; Libuda, J., Ceria reoxidation by CO2: A model study. J. Catal. 2010, 275, 181-185.

50. Kim, S. S.; Lee, H. H.; Hong, S. C., A study on the effect of support's reducibility on the reverse water-gas shift reaction over Pt catalysts. Appl. Catal. A: Gen. 2012, 423-424, 100-107.

51. Kattel, S.; Yu, W.; Yang, X.; Yan, B.; Huang, Y.; Wan, W.; Liu, P.; Chen, J. G., CO2 Hydrogenation over Oxide-Supported PtCo Catalysts: The Role of the Oxide Support in Determining the Product Selectivity. Angew. Chem. Int. Ed. 2016, 55, 7968-7973.

52. Bobadilla, L. F.; Santos, J. L.; Ivanova, S.; Odriozola, J. A.; Urakawa, A., Unravelling the Role of Oxygen Vacancies in the Mechanism of the Reverse Water-Gas Shift Reaction by Operando DRIFTS and Ultraviolet-Visible Spectroscopy. ACS Catal. 2018, 8, 7455-7467.

53. Li, W.; Zhang, G.; Jiang, X.; Liu, Y.; Zhu, J.; Ding, F.; Liu, Z.; Guo, X.; Song, C., CO2 Hydrogenation on Unpromoted and M-Promoted $\mathrm{Co} / \mathrm{TiO} 2$ Catalysts $(\mathrm{M}=\mathrm{Zr}, \mathrm{K}, \mathrm{Cs})$ : Effects of Crystal Phase of Supports and Metal-Support Interaction on Tuning Product Distribution. ACS Catal. 2019, 9, 2739-2751.

54. Zhang, P.; Chi, M.; Sharma, S.; McFarland, E., Silica encapsulated heterostructure catalyst of Pt nanoclusters on hematite nanocubes: synthesis and reactivity. J. Mater. Chem. 2010, 20, 2013-2017.

55. Ro, I.; Sener, C.; Stadelman, T. M.; Ball, M. R.; Venegas, J. M.; Burt, S. P.; Hermans, I.; Dumesic, J. A.; Huber, G. W., Measurement of intrinsic catalytic activity of Pt monometallic and Pt$\mathrm{MoOx}$ interfacial sites over visible light enhanced $\mathrm{PtMoOx} / \mathrm{SiO} 2$ catalyst in reverse water gas shift reaction. J. Catal. 2016, 344, 784-794.

56. Kitamura Bando, K.; Soga, K.; Kunimori, K.; Arakawa, H., Effect of Li additive on CO2 hydrogenation reactivity of zeolite supported Rh catalysts. Appl. Catal. A: Gen. 1998, 175, 67-81.

57. Heyl, D.; Rodemerck, U.; Bentrup, U., Mechanistic Study of Low-Temperature CO2 Hydrogenation over Modified Rh/Al2O3 Catalysts. ACS Catal. 2016, 6, 6275-6284.

58. Liang, B.; Duan, H.; Su, X.; Chen, X.; Huang, Y.; Chen, X.; Delgado, J. J.; Zhang, T., Promoting role of potassium in the reverse water gas shift reaction on $\mathrm{Pt} /$ mullite catalyst. Catal. Today 2017, 281, 319-326.

59. $\quad$ Yang, X.; Su, X.; Chen, X.; Duan, H.; Liang, B.; Liu, Q.; Liu, X.; Ren, Y.; Huang, Y.; Zhang, T., Promotion effects of potassium on the activity and selectivity of Pt/zeolite catalysts for reverse water gas shift reaction. Appl. Catal. B: Environ. 2017, 216, 95-105.

60. Yan, B.; Wu, Q.; Cen, J.; Timoshenko, J.; Frenkel, A. I.; Su, D.; Chen, X.; Parise, J. B.; Stach, E.; Orlov, A.; Chen, J. G., Highly active subnanometer Rh clusters derived from Rh-doped SrTiO3 for CO2 reduction. Appl. Catal. B: Environ. 2018, 237, 1003-1011.

61. Dou, J.; Sheng, Y.; Choong, C.; Chen, L.; Zeng, H. C., Silica nanowires encapsulated Ru nanoparticles as stable nanocatalysts for selective hydrogenation of $\mathrm{CO} 2$ to CO. Appl. Catal. B: Environ. 2017, 219, 580-591. 
62. Yan, Y.; Wang, Q.; Jiang, C.; Yao, Y.; Lu, D.; Zheng, J.; Dai, Y.; Wang, H.; Yang, Y., Ru/A12O3 catalyzed CO2 hydrogenation: Oxygen-exchange on metal-support interfaces. J. Catal. 2018, 367, 194205.

63. Ishito, N.; Hara, K.; Nakajima, K.; Fukuoka, A., Selective synthesis of carbon monoxide via formates in reverse water-gas shift reaction over alumina-supported gold catalyst. J. Energy Chem. 2016, 25, 306-310.

64. Sikora, E.; Prekob, Á.; Halasi, G.; Vanyorek, L.; Pekker, P.; Kristály, F.; Varga, T.; Kiss, J.; Kónya, Z.; Viskolcz, B., Development and Application of Carbon-Layer-Stabilized, Nitrogen-Doped, Bamboo-Like Carbon Nanotube Catalysts in CO2 Hydrogenation. ChemistryOpen 2018, 7, 789-796.

65. Gonçalves, R. V.; Vono, L. L. R.; Wojcieszak, R.; Dias, C. S. B.; Wender, H.; Teixeira-Neto, E.; Rossi, L. M., Selective hydrogenation of $\mathrm{CO} 2$ into $\mathrm{CO}$ on a highly dispersed nickel catalyst obtained by magnetron sputtering deposition: A step towards liquid fuels. Appl. Catal. B: Environ. 2017, 209, 240246.

66. Li, Y.; Cai, X.; Chen, S.; Zhang, H.; Zhang, K. H. L.; Hong, J.; Chen, B.; Kuo, D.-H.; Wang, W., Highly Dispersed Metal Carbide on ZIF-Derived Pyridinic-N-Doped Carbon for CO2 Enrichment and Selective Hydrogenation. ChemSusChem 2018, 11, 1040-1047.

67. Zhao, B.; Yan, B.; Jiang, Z.; Yao, S.; Liu, Z.; Wu, Q.; Ran, R.; Senanayake, S. D.; Weng, D.; Chen, J. G., High selectivity of $\mathrm{CO} 2$ hydrogenation to $\mathrm{CO}$ by controlling the valence state of nickel using perovskite. Chem. Commun. 2018, 54, 7354-7357.

68. Winter, L. R.; Gomez, E.; Yan, B.; Yao, S.; Chen, J. G., Tuning Ni-catalyzed CO2 hydrogenation selectivity via Ni-ceria support interactions and Ni-Fe bimetallic formation. Appl. Catal. B: Environ. 2018, 224, 442-450.

69. Dai, B.; Zhou, G.; Ge, S.; Xie, H.; Jiao, Z.; Zhang, G.; Xiong, K., CO2 reverse water-gas shift reaction on mesoporous M-CeO2 catalysts. Can. J. Chem. Eng. 2017, 95, 634-642.

70. Zhang, X.; Zhu, X.; Lin, L.; Yao, S.; Zhang, M.; Liu, X.; Wang, X.; Li, Y.-W.; Shi, C.; Ma, D., Highly Dispersed Copper over $\beta$-Mo2C as an Efficient and Stable Catalyst for the Reverse Water Gas Shift (RWGS) Reaction. ACS Catal. 2017, 7, 912-918.

71. Álvarez Galván, C.; Schumann, J.; Behrens, M.; Fierro, J. L. G.; Schlögl, R.; Frei, E., Reverse water-gas shift reaction at the $\mathrm{Cu} / \mathrm{ZnO}$ interface: Influence of the $\mathrm{Cu} / \mathrm{Zn}$ ratio on structure-activity correlations. Appl. Catal. B: Environ. 2016, 195, 104-111.

72. Lin, L.; Yao, S.; Rui, N.; Han, L.; Zhang, F.; Gerlak, C. A.; Liu, Z.; Cen, J.; Song, L.; Senanayake, S. D.; Xin, H. L.; Chen, J. G.; Rodriguez, J. A., Conversion of CO2 on a highly active and stable $\mathrm{Cu} / \mathrm{FeOx} / \mathrm{CeO} 2$ catalyst: tuning catalytic performance by oxide-oxide interactions. Catal. Sci. Technol. 2019, 9, 3735-3742.

73. Zhang, Q.; Yang, Z.; Chen, B.; Liang, X., Phase-competition-driven formation of hierarchical FeNiZn-MIL-88B-on-MOF-5 octapods displaying high selectivity for the RWGS reaction. Chem. Commun. 2019, 55, 8450-8453.

74. He, Y.; Yang, K. R.; Yu, Z.; Fishman, Z. S.; Achola, L. A.; Tobin, Z. M.; Heinlein, J. A.; Hu, S.; Suib, S. L.; Batista, V. S.; Pfefferle, L. D., Catalytic manganese oxide nanostructures for the reverse water gas shift reaction. Nanoscale 2019, 11, 16677-16688.

75. Lin, L.; Yao, S.; Liu, Z.; Zhang, F.; Li, N.; Vovchok, D.; Martínez-Arias, A.; Castañeda, R.; Lin, J.; Senanayake, S. D.; Su, D.; Ma, D.; Rodriguez, J. A., In Situ Characterization of $\mathrm{Cu} / \mathrm{CeO} 2$ Nanocatalysts for CO2 Hydrogenation: Morphological Effects of Nanostructured Ceria on the Catalytic Activity. J. Phys. Chem. C 2018, 122, 12934-12943.

76. Yang, L.; Pastor-Pérez, L.; Villora-Pico, J. J.; Gu, S.; Sepúlveda-Escribano, A.; Reina, T. R., $\mathrm{CO} 2$ valorisation via reverse water-gas shift reaction using promoted $\mathrm{Fe} / \mathrm{CeO} 2-\mathrm{Al} 2 \mathrm{O} 3$ catalysts: Showcasing the potential of advanced catalysts to explore new processes design. Appl. Catal. A: Gen. 2020, 593, 117442.

77. Fishman, Z. S.; He, Y.; Yang, K. R.; Lounsbury, A. W.; Zhu, J.; Tran, T. M.; Zimmerman, J. B.; Batista, V. S.; Pfefferle, L. D., Hard templating ultrathin polycrystalline hematite nanosheets: effect of 
nano-dimension on $\mathrm{CO} 2$ to $\mathrm{CO}$ conversion via the reverse water-gas shift reaction. Nanoscale 2017, 9 , 12984-12995.

78. Loiland, J. A.; Wulfers, M. J.; Marinkovic, N. S.; Lobo, R. F., Fe/ $\gamma-\mathrm{Al} 2 \mathrm{O} 3$ and Fe-K/ $\gamma-\mathrm{Al} 2 \mathrm{O} 3$ as reverse water-gas shift catalysts. Catal. Sci. Technol. 2016, 6, 5267-5279.

79. Utsis, N.; Landau, M. V.; Erenburg, A.; Nehemya, R. V.; Herskowitz, M., Performance of Reverse Water Gas Shift on Coprecipitated and C-Templated BaFe-Hexaaluminate: The Effect of Fe Loading, Texture, and Promotion with K. ChemCatChem 2018, 10, 3795-3805.

80. Weatherbee, G. D.; Bartholomew, C. H., Hydrogenation of $\mathrm{CO} 2$ on group VIII metals: IV. Specific activities and selectivities of silica-supported Co, Fe, and Ru. J. Catal. 1984, 87, 352-362.

81. Millet, M.-M.; Algara-Siller, G.; Wrabetz, S.; Mazheika, A.; Girgsdies, F.; Teschner, D.; Seitz, F.; Tarasov, A.; Levchenko, S. V.; Schlögl, R.; Frei, E., Ni Single Atom Catalysts for CO2 Activation. $J$. Am. Chem. Soc. 2019, 141, 2451-2461.

82. Kwak, J. H.; Kovarik, L.; Szanyi, J., Heterogeneous Catalysis on Atomically Dispersed Supported Metals: CO2 Reduction on Multifunctional Pd Catalysts. ACS Catal. 2013, 3, 2094-2100.

83. Kwak, J. H.; Kovarik, L.; Szanyi, J., CO2 Reduction on Supported Ru/A12O3 Catalysts: Cluster Size Dependence of Product Selectivity. ACS Catal. 2013, 3, 2449-2455.

84. Matsubu, J. C.; Yang, V. N.; Christopher, P., Isolated Metal Active Site Concentration and Stability Control Catalytic CO2 Reduction Selectivity. J. Am. Chem. Soc. 2015, 137, 3076-3084.

85. Matsubu, J. C.; Zhang, S.; DeRita, L.; Marinkovic, N. S.; Chen, J. G.; Graham, G. W.; Pan, X.; Christopher, P., Adsorbate-mediated strong metal-support interactions in oxide-supported Rh catalysts. Nat. Chem. 2017, 9, 120.

86. Wang, Y.; Arandiyan, H.; Scott, J.; Aguey-Zinsou, K.-F.; Amal, R., Single Atom and Nanoclustered Pt Catalysts for Selective CO2 Reduction. ACS Appl. Energy Mater. 2018, 1, 6781-6789.

87. Chen, J.; Iyemperumal, S. K.; Fenton, T.; Carl, A.; Grimm, R.; Li, G.; Deskins, N. A., Synergy between Defects, Photoexcited Electrons, and Supported Single Atom Catalysts for CO2 Reduction. ACS Catal. 2018, 8, 10464-10478.

88. Aitbekova, A.; Wu, L.; Wrasman, C. J.; Boubnov, A.; Hoffman, A. S.; Goodman, E. D.; Bare, S. R.; Cargnello, M., Low-Temperature Restructuring of CeO2-Supported Ru Nanoparticles Determines Selectivity in CO2 Catalytic Reduction. J. Am. Chem. Soc. 2018, 140, 13736-13745.

89. Iyemperumal, S. K.; Pham, T. D.; Bauer, J.; Deskins, N. A., Quantifying Support Interactions and Reactivity Trends of Single Metal Atom Catalysts over TiO2. J. Phys. Chem. C 2018, 122, 25274-25289.

90. Lucci, F. R.; Liu, J.; Marcinkowski, M. D.; Yang, M.; Allard, L. F.; Flytzani-Stephanopoulos, M.; Sykes, E. C. H., Selective hydrogenation of 1,3-butadiene on platinum-copper alloys at the single-atom limit. Nat. Commun. 2015, 6, 8550.

91. Su, X.; Yang, X.-F.; Huang, Y.; Liu, B.; Zhang, T., Single-Atom Catalysis toward Efficient CO2 Conversion to $\mathrm{CO}$ and Formate Products. Acc. Chem. Res. 2019, 52, 656-664.

92. Ginés, M. J. L.; Marchi, A. J.; Apesteguía, C. R., Kinetic study of the reverse water-gas shift reaction over $\mathrm{CuO} / \mathrm{ZnO} / \mathrm{Al} 2 \mathrm{O} 3$ catalysts. Appl. Catal. A: Gen. 1997, 154, 155-171.

93. Kattel, S.; Yan, B.; Yang, Y.; Chen, J. G.; Liu, P., Optimizing Binding Energies of Key Intermediates for $\mathrm{CO} 2$ Hydrogenation to Methanol over Oxide-Supported Copper. J. Am. Chem. Soc. 2016, $138,12440-12450$.

94. Kattel, S.; Ramírez, P. J.; Chen, J. G.; Rodriguez, J. A.; Liu, P., Active sites for CO2 hydrogenation to methanol on $\mathrm{Cu} / \mathrm{ZnO}$ catalysts. Science 2017, 355, 1296-1299.

95. Arunajatesan, V.; Subramaniam, B.; Hutchenson, K. W.; Herkes, F. E., In situ FTIR investigations of reverse water gas shift reaction activity at supercritical conditions. Chem. Eng. Sci. 2007, 62, 5062-5069.

96. Wang, X.; Shi, H.; Kwak, J. H.; Szanyi, J., Mechanism of CO2 Hydrogenation on Pd/Al2O3 Catalysts: Kinetics and Transient DRIFTS-MS Studies. ACS Catal. 2015, 5, 6337-6349.

97. Wang, X.; Shi, H.; Szanyi, J., Controlling selectivities in CO2 reduction through mechanistic understanding. Nat. Commun. 2017, 8, 513. 
98. Wang, X.; Hong, Y.; Shi, H.; Szanyi, J., Kinetic modeling and transient DRIFTS-MS studies of CO2 methanation over Ru/A12O3 catalysts. J. Catal. 2016, 343, 185-195.

99. Wu, H. C.; Chang, Y. C.; Wu, J. H.; Lin, J. H.; Lin, I. K.; Chen, C. S., Methanation of CO2 and reverse water gas shift reactions on $\mathrm{Ni} / \mathrm{SiO} 2$ catalysts: the influence of particle size on selectivity and reaction pathway. Catal. Sci. Technol. 2015, 5, 4154-4163.

100. Zhao, X.; Xu, H.; Wang, X.; Zheng, Z.; Xu, Z.; Ge, J., Monodisperse Metal-Organic Framework Nanospheres with Encapsulated Core-Shell Nanoparticles Pt/Au@Pd@\{Co2(oba)4(3-bpdh)2\}4H2O for the Highly Selective Conversion of CO2 to CO. ACS Appl. Mater. Interfaces 2018, 10, 15096-15103.

101. Zheng, Z.; Xu, H.; Xu, Z.; Ge, J., A Monodispersed Spherical Zr-Based Metal-Organic Framework Catalyst, Pt/Au@Pd@UIO-66, Comprising an Au@Pd Core-Shell Encapsulated in a UIO-66 Center and Its Highly Selective CO2 Hydrogenation to Produce CO. Small 2018, 14, 1702812.

102. Gao, J.; Wu, Y.; Jia, C.; Zhong, Z.; Gao, F.; Yang, Y.; Liu, B., Controllable synthesis of $\alpha-$ MoC1-x and $\beta-M o 2 C$ nanowires for highly selective CO2 reduction to CO. Catal. Commun. 2016, 84, 147-150.

103. Graciani, J.; Mudiyanselage, K.; Xu, F.; Baber, A. E.; Evans, J.; Senanayake, S. D.; Stacchiola, D. J.; Liu, P.; Hrbek, J.; Sanz, J. F.; Rodriguez, J. A., Highly active copper-ceria and copper-ceria-titania catalysts for methanol synthesis from CO2. Science 2014, 345, 546-550.

104. Waugh, K. C., Methanol Synthesis. Catal. Today 1992, 15, 51-75.

105. Großmann, D.; Klementiev, K.; Sinev, I.; Grünert, W., Surface Alloy or Metal-Cation Interaction-The State of $\mathrm{Zn}$ Promoting the Active $\mathrm{Cu}$ Sites in Methanol Synthesis Catalysts. ChemCatChem 2017, 9, 365-372.

106. Huš, M.; Dasireddy, V. D. B. C.; Strah Štefančič, N.; Likozar, B., Mechanism, kinetics and thermodynamics of carbon dioxide hydrogenation to methanol on $\mathrm{Cu} / \mathrm{ZnAl} 2 \mathrm{O} 4$ spinel-type heterogeneous catalysts. Appl. Catal. B: Environ. 2017, 207, 267-278.

107. Du, S.; Tang, W.; Lu, X.; Wang, S.; Guo, Y.; Gao, P.-X., Cu-Decorated ZnO Nanorod Array Integrated Structured Catalysts for Low-Pressure CO2 Hydrogenation to Methanol. Adv. Mater. Interfaces 2018, 5, 1700730.

108. Xu, J.; Su, X.; Liu, X.; Pan, X.; Pei, G.; Huang, Y.; Wang, X.; Zhang, T.; Geng, H., Methanol synthesis from $\mathrm{CO} 2$ and $\mathrm{H} 2$ over $\mathrm{Pd} / \mathrm{ZnO} / \mathrm{Al} 2 \mathrm{O} 3$ : Catalyst structure dependence of methanol selectivity. Appl. Catal. A: Gen. 2016, 514, 51-59.

109. Guo, Y.; Guo, X.; Song, C.; Han, X.; Liu, H.; Zhao, Z., Capsule-Structured Copper-Zinc Catalyst for Highly Efficient Hydrogenation of Carbon Dioxide to Methanol. ChemSusChem 2019, 12, 4916-4926.

110. Lunkenbein, T.; Schumann, J.; Behrens, M.; Schlögl, R.; Willinger, M. G., Formation of a ZnO Overlayer in Industrial $\mathrm{Cu} / \mathrm{ZnO} / \mathrm{Al} 2 \mathrm{O} 3$ Catalysts Induced by Strong Metal-Support Interactions. Angew. Chem. Int. Ed. 2015, 54, 4544-4548.

111. Behrens, M.; Studt, F.; Kasatkin, I.; Kühl, S.; Hävecker, M.; Abild-Pedersen, F.; Zander, S.; Girgsdies, F.; Kurr, P.; Kniep, B.-L.; Tovar, M.; Fischer, R. W.; Nørskov, J. K.; Schlögl, R., The Active Site of Methanol Synthesis over Cu/ZnO/Al2O3 Industrial Catalysts. Science 2012, 336, 893-897.

112. Kuld, S.; Thorhauge, M.; Falsig, H.; Elkjær, C. F.; Helveg, S.; Chorkendorff, I.; Sehested, J., Quantifying the promotion of $\mathrm{Cu}$ catalysts by $\mathrm{ZnO}$ for methanol synthesis. Science 2016, 352, 969-974.

113. Kondrat, S. A.; Smith, P. J.; Wells, P. P.; Chater, P. A.; Carter, J. H.; Morgan, D. J.; Fiordaliso, E. M.; Wagner, J. B.; Davies, T. E.; Lu, L.; Bartley, J. K.; Taylor, S. H.; Spencer, M. S.; Kiely, C. J.; Kelly, G. J.; Park, C. W.; Rosseinsky, M. J.; Hutchings, G. J., Stable amorphous georgeite as a precursor to a high-activity catalyst. Nature 2016, 531, 83.

114. Liu, C.; Yang, B.; Tyo, E.; Seifert, S.; DeBartolo, J.; von Issendorff, B.; Zapol, P.; Vajda, S.; Curtiss, L. A., Carbon Dioxide Conversion to Methanol over Size-Selected Cu4 Clusters at Low Pressures. J. Am. Chem. Soc. 2015, 137, 8676-8679.

115. Yang, B.; Liu, C.; Halder, A.; Tyo, E. C.; Martinson, A. B. F.; Seifert, S.; Zapol, P.; Curtiss, L. A.; Vajda, S., Copper Cluster Size Effect in Methanol Synthesis from CO2. J. Phys. Chem. C 2017, 121, 10406-10412. 
116. Palomino, R. M.; Ramírez, P. J.; Liu, Z.; Hamlyn, R.; Waluyo, I.; Mahapatra, M.; Orozco, I.; Hunt, A.; Simonovis, J. P.; Senanayake, S. D.; Rodriguez, J. A., Hydrogenation of $\mathrm{CO} 2$ on $\mathrm{ZnO} / \mathrm{Cu}(100)$ and $\mathrm{ZnO} / \mathrm{Cu}(111)$ Catalysts: Role of Copper Structure and Metal-Oxide Interface in Methanol Synthesis. J. Phys. Chem. B 2018, 122, 794-800.

117. van den Berg, R.; Prieto, G.; Korpershoek, G.; van der Wal, L. I.; van Bunningen, A. J.; Lægsgaard-Jørgensen, S.; de Jongh, P. E.; de Jong, K. P., Structure sensitivity of $\mathrm{Cu}$ and CuZn catalysts relevant to industrial methanol synthesis. Nat. Commun. 2016, 7, 13057.

118. Karelovic, A.; Galdames, G.; Medina, J. C.; Yévenes, C.; Barra, Y.; Jiménez, R., Mechanism and structure sensitivity of methanol synthesis from $\mathrm{CO} 2$ over SiO2-supported $\mathrm{Cu}$ nanoparticles. J. Catal. 2019, 369, 415-426.

119. Kunkes, E. L.; Studt, F.; Abild-Pedersen, F.; Schlögl, R.; Behrens, M., Hydrogenation of CO2 to methanol and $\mathrm{CO}$ on $\mathrm{Cu} / \mathrm{ZnO} / \mathrm{Al} 2 \mathrm{O} 3$ : Is there a common intermediate or not? J. Catal. 2015, 328, 43-48.

120. Fichtl, M. B.; Schlereth, D.; Jacobsen, N.; Kasatkin, I.; Schumann, J.; Behrens, M.; Schlögl, R.; Hinrichsen, O., Kinetics of deactivation on $\mathrm{Cu} / \mathrm{ZnO} / \mathrm{Al} 2 \mathrm{O} 3$ methanol synthesis catalysts. Appl. Catal. A: Gen. 2015, 502, 262-270.

121. Tada, S.; Kayamori, S.; Honma, T.; Kamei, H.; Nariyuki, A.; Kon, K.; Toyao, T.; Shimizu, K.-i.; Satokawa, S., Design of Interfacial Sites between $\mathrm{Cu}$ and Amorphous $\mathrm{ZrO} 2$ Dedicated to CO2-toMethanol Hydrogenation. ACS Catal. 2018, 8, 7809-7819.

122. Bao, Y.; Huang, C.; Chen, L.; Zhang, Y. d.; Liang, L.; Wen, J.; Fu, M.; Wu, J.; Ye, D., Highly efficient $\mathrm{Cu}$ /anatase $\mathrm{TiO} 2\{001\}$-nanosheets catalysts for methanol synthesis from CO2. J. Energy Chem. 2018, 27, 381-388.

123. Fang, X.; Men, Y.; Wu, F.; Zhao, Q.; Singh, R.; Xiao, P.; Du, T.; Webley, P. A., Improved methanol yield and selectivity from $\mathrm{CO} 2$ hydrogenation using a novel $\mathrm{Cu}-\mathrm{ZnO}-\mathrm{ZrO} 2$ catalyst supported on Mg-Al layered double hydroxide (LDH). J. CO2 Util. 2019, 29, 57-64.

124. Wang, Z.-Q.; Xu, Z.-N.; Peng, S.-Y.; Zhang, M.-J.; Lu, G.; Chen, Q.-S.; Chen, Y.; Guo, G.-C., High-Performance and Long-Lived $\mathrm{Cu} / \mathrm{SiO} 2$ Nanocatalyst for $\mathrm{CO} 2$ Hydrogenation. ACS Catal. 2015, 5, 4255-4259.

125. Rodriguez, J. A.; Liu, P.; Stacchiola, D. J.; Senanayake, S. D.; White, M. G.; Chen, J. G., Hydrogenation of $\mathrm{CO} 2$ to Methanol: Importance of Metal-Oxide and Metal-Carbide Interfaces in the Activation of CO2. ACS Catal. 2015, 5, 6696-6706.

126. Larmier, K.; Liao, W.-C.; Tada, S.; Lam, E.; Verel, R.; Bansode, A.; Urakawa, A.; Comas-Vives, A.; Copéret, C., CO2-to-Methanol Hydrogenation on Zirconia-Supported Copper Nanoparticles: Reaction Intermediates and the Role of the Metal-Support Interface. Angew. Chem. Int. Ed. 2017, 56, 2318-2323.

127. Dong, X.; Li, F.; Zhao, N.; Xiao, F.; Wang, J.; Tan, Y., CO2 hydrogenation to methanol over $\mathrm{Cu} / \mathrm{ZnO} / \mathrm{ZrO} 2$ catalysts prepared by precipitation-reduction method. Appl. Catal. B: Environ. 2016, 191, $8-17$.

128. Chang, K.; Wang, T.; Chen, J. G., Hydrogenation of $\mathrm{CO} 2$ to methanol over CuCeTiOx catalysts. Appl. Catal. B: Environ. 2017, 206, 704-711.

129. Ren, S.; Shoemaker, W. R.; Wang, X.; Shang, Z.; Klinghoffer, N.; Li, S.; Yu, M.; He, X.; White, T. A.; Liang, X., Highly active and selective $\mathrm{Cu}-\mathrm{ZnO}$ based catalyst for methanol and dimethyl ether synthesis via CO2 hydrogenation. Fuel 2019, 239, 1125-1133.

130. Li, S.; Wang, Y.; Yang, B.; Guo, L., A highly active and selective mesostructured Cu/AlCeO catalyst for $\mathrm{CO} 2$ hydrogenation to methanol. Appl. Catal. A: Gen. 2019, 571, 51-60.

131. Li, K.; Chen, J. G., CO2 Hydrogenation to Methanol over ZrO2-Containing Catalysts: Insights into ZrO2 Induced Synergy. ACS Catal. 2019, 9, 7840-7861.

132. Hou, X.-X.; Xu, C.-H.; Liu, Y.-L.; Li, J.-J.; Hu, X.-D.; Liu, J.; Liu, J.-Y.; Xu, Q., Improved methanol synthesis from $\mathrm{CO} 2$ hydrogenation over $\mathrm{CuZnAlZr}$ catalysts with precursor pre-activation by formaldehyde. J. Catal. 2019, 379, 147-153.

133. Wang, W.; Qu, Z.; Song, L.; Fu, Q., Probing into the multifunctional role of copper species and reaction pathway on copper-cerium-zirconium catalysts for $\mathrm{CO} 2$ hydrogenation to methanol using high pressure in situ DRIFTS. J. Catal. 2020, 382, 129-140. 
134. Wu, W.; Xie, K.; Sun, D.; Li, X.; Fang, F., CuO/ZnO/Al2O3 Catalyst Prepared by MechanicalForce-Driven Solid-State Ion Exchange and Its Excellent Catalytic Activity under Internal Cooling Condition. Ind. Eng. Chem. Res. 2017, 56, 8216-8223.

135. Chen, S.; Zhang, J.; Wang, P.; Wang, X.; Song, F.; Bai, Y.; Zhang, M.; Wu, Y.; Xie, H.; Tan, Y., Effect of Vapor-phase-treatment to CuZnZr Catalyst on the Reaction Behaviors in CO2 Hydrogenation into Methanol. ChemCatChem 2019, 11, 1448-1457.

136. Wang, J.; Li, G.; Li, Z.; Tang, C.; Feng, Z.; An, H.; Liu, H.; Liu, T.; Li, C., A highly selective and stable $\mathrm{ZnO}-\mathrm{ZrO} 2$ solid solution catalyst for CO2 hydrogenation to methanol. Sci. Adv. 2017, 3, e1701290.

137. Wang, Y.; Kattel, S.; Gao, W.; Li, K.; Liu, P.; Chen, J. G.; Wang, H., Exploring the ternary interactions in $\mathrm{Cu}-\mathrm{ZnO}-\mathrm{ZrO} 2$ catalysts for efficient $\mathrm{CO} 2$ hydrogenation to methanol. Nat. Commun. 2019, 10, 1166.

138. Samson, K.; Śliwa, M.; Socha, R. P.; Góra-Marek, K.; Mucha, D.; Rutkowska-Zbik, D.; Paul, J. F.; Ruggiero-Mikołajczyk, M.; Grabowski, R.; Słoczyński, J., Influence of ZrO2 Structure and Copper Electronic State on Activity of $\mathrm{Cu} / \mathrm{ZrO} 2$ Catalysts in Methanol Synthesis from CO2. ACS Catal. 2014, 4, 3730-3741.

139. Lam, E.; Larmier, K.; Wolf, P.; Tada, S.; Safonova, O. V.; Copéret, C., Isolated Zr Surface Sites on Silica Promote Hydrogenation of $\mathrm{CO} 2$ to $\mathrm{CH} 3 \mathrm{OH}$ in Supported Cu Catalysts. J. Am. Chem. Soc. 2018, 140, 10530-10535.

140. Lam, E.; Noh, G.; Chan, K. W.; Larmier, K.; Lebedev, D.; Searles, K.; Wolf, P.; Safonova, O. V.; Copéret, C., Enhanced $\mathrm{CH} 3 \mathrm{OH}$ selectivity in $\mathrm{CO} 2$ hydrogenation using $\mathrm{Cu}$-based catalysts generated via SOMC from GaIII single-sites. Chem. Sci. 2020, 11, 7593-7598.

141. Li, M. M. J.; Chen, C.; Ayvalı, T.; Suo, H.; Zheng, J.; Teixeira, I. F.; Ye, L.; Zou, H.; O’Hare, D.; Tsang, S. C. E., CO2 Hydrogenation to Methanol over Catalysts Derived from Single Cationic Layer CuZnGa LDH Precursors. ACS Catal. 2018, 8, 4390-4401.

142. Jiang, Y.; Yang, H.; Gao, P.; Li, X.; Zhang, J.; Liu, H.; Wang, H.; Wei, W.; Sun, Y., Slurry methanol synthesis from $\mathrm{CO} 2$ hydrogenation over micro-spherical $\mathrm{SiO} 2$ support $\mathrm{Cu} / \mathrm{ZnO}$ catalysts. $J$. CO2 Util. 2018, 26, 642-651.

143. Chen, K.; Duan, X.; Fang, H.; Liang, X.; Yuan, Y., Selective hydrogenation of CO2 to methanol catalyzed by $\mathrm{Cu}$ supported on rod-like La2O2CO3. Catal. Sci. Technol. 2018, 8, 1062-1069.

144. Chen, K.; Fang, H.; Wu, S.; Liu, X.; Zheng, J.; Zhou, S.; Duan, X.; Zhuang, Y.; Chi Edman Tsang, S.; Yuan, Y., CO2 hydrogenation to methanol over Cu catalysts supported on La-modified SBA15: The crucial role of $\mathrm{Cu}-\mathrm{LaOx}$ interfaces. Appl. Catal. B: Environ. 2019, 251, 119-129.

145. Rungtaweevoranit, B.; Baek, J.; Araujo, J. R.; Archanjo, B. S.; Choi, K. M.; Yaghi, O. M.; Somorjai, G. A., Copper Nanocrystals Encapsulated in Zr-based Metal-Organic Frameworks for Highly Selective CO2 Hydrogenation to Methanol. Nano Lett. 2016, 16, 7645-7649.

146. An, B.; Zhang, J.; Cheng, K.; Ji, P.; Wang, C.; Lin, W., Confinement of Ultrasmall Cu/ZnOx Nanoparticles in Metal-Organic Frameworks for Selective Methanol Synthesis from Catalytic Hydrogenation of CO2. J. Am. Chem. Soc. 2017, 139, 3834-3840.

147. Kobayashi, H.; Taylor, J. M.; Mitsuka, Y.; Ogiwara, N.; Yamamoto, T.; Toriyama, T.; Matsumura, S.; Kitagawa, H., Charge transfer dependence on CO2 hydrogenation activity to methanol in $\mathrm{Cu}$ nanoparticles covered with metal-organic framework systems. Chem. Sci. 2019, 10, 3289-3294.

148. Liu, T.; Hong, X.; Liu, G., In Situ Generation of the Cu@3D-ZrOx Framework Catalyst for Selective Methanol Synthesis from CO2/H2. ACS Catal. 2020, 10, 93-102.

149. Studt, F.; Sharafutdinov, I.; Abild-Pedersen, F.; Elkjær, C. F.; Hummelshøj, J. S.; Dahl, S.; Chorkendorff, I.; Nørskov, J. K., Discovery of a Ni-Ga catalyst for carbon dioxide reduction to methanol. Nat. Chem. 2014, 6, 320.

150. Rui, N.; Wang, Z.; Sun, K.; Ye, J.; Ge, Q.; Liu, C.-j., CO2 hydrogenation to methanol over Pd/In2O3: effects of Pd and oxygen vacancy. Appl. Catal. B: Environ. 2017, 218, 488-497.

151. García-Trenco, A.; Regoutz, A.; White, E. R.; Payne, D. J.; Shaffer, M. S. P.; Williams, C. K., PdIn intermetallic nanoparticles for the Hydrogenation of $\mathrm{CO} 2$ to Methanol. Appl. Catal. B: Environ. 2018, 220, 9-18. 
152. Malik, A. S.; Zaman, S. F.; Al-Zahrani, A. A.; Daous, M. A.; Driss, H.; Petrov, L. A., Development of highly selective $\mathrm{PdZn} / \mathrm{CeO} 2$ and $\mathrm{Ca}$-doped $\mathrm{PdZn} / \mathrm{CeO} 2$ catalysts for methanol synthesis from $\mathrm{CO} 2$ hydrogenation. Appl. Catal. A: Gen. 2018, 560, $42-53$.

153. Hengne, A. M.; Samal, A. K.; Enakonda, L. R.; Harb, M.; Gevers, L. E.; Anjum, D. H.; Hedhili, M. N.; Saih, Y.; Huang, K.-W.; Basset, J.-M., Ni-Sn-Supported ZrO2 Catalysts Modified by Indium for Selective CO2 Hydrogenation to Methanol. ACS Omega 2018, 3, 3688-3701.

154. Tan, Q.; Shi, Z.; Wu, D., CO2 Hydrogenation to Methanol over a Highly Active $\mathrm{Cu}-\mathrm{Ni} / \mathrm{CeO} 2-$ Nanotube Catalyst. Ind. Eng. Chem. Res. 2018, 57, 10148-10158.

155. Richard, A. R.; Fan, M., Low-Pressure Hydrogenation of $\mathrm{CO} 2$ to $\mathrm{CH} 3 \mathrm{OH}$ Using Ni-In-Al/SiO2 Catalyst Synthesized via a Phyllosilicate Precursor. ACS Catal. 2017, 7, 5679-5692.

156. García-Trenco, A.; White, E. R.; Regoutz, A.; Payne, D. J.; Shaffer, M. S. P.; Williams, C. K., Pd2Ga-Based Colloids as Highly Active Catalysts for the Hydrogenation of $\mathrm{CO} 2$ to Methanol. ACS Catal. 2017, 7, 1186-1196.

157. Zhao, F.; Gong, M.; Cao, K.; Zhang, Y.; Li, J.; Chen, R., Atomic Layer Deposition of Ni on Cu Nanoparticles for Methanol Synthesis from CO2 Hydrogenation. ChemCatChem 2017, 9, 3772-3778.

158. Smitshuysen, T. E. L.; Nielsen, M. R.; Pruessmann, T.; Zimina, A.; Sheppard, T. L.; Grunwaldt, J.-D.; Chorkendorff, I.; Damsgaard, C. D., Optimizing $\mathrm{Ni}-\mathrm{Fe}-\mathrm{Ga}$ alloys into Ni2FeGa for the Hydrogenation of CO2 into Methanol. ChemCatChem 2020, 12, 3265-3273.

159. Ojelade, O. A.; Zaman, S. F.; Daous, M. A.; Al-Zahrani, A. A.; Malik, A. S.; Driss, H.; Shterk, G.; Gascon, J., Optimizing Pd:Zn molar ratio in $\mathrm{PdZn} / \mathrm{CeO} 2$ for $\mathrm{CO} 2$ hydrogenation to methanol. Appl. Catal. A: Gen. 2019, 584, 117185.

160. Song, J.; Liu, S.; Yang, C.; Wang, G.; Tian, H.; Zhao, Z.-j.; Mu, R.; Gong, J., The role of Al doping in $\mathrm{Pd} / \mathrm{ZnO}$ catalyst for $\mathrm{CO} 2$ hydrogenation to methanol. Appl. Catal. B: Environ. 2020, 263, 118367.

161. Martin, O.; Martín, A. J.; Mondelli, C.; Mitchell, S.; Segawa, T. F.; Hauert, R.; Drouilly, C.; Curulla-Ferré, D.; Pérez-Ramírez, J., Indium Oxide as a Superior Catalyst for Methanol Synthesis by CO2 Hydrogenation. Angew. Chem. Int. Ed. 2016, 55, 6261-6265.

162. Snider, J. L.; Streibel, V.; Hubert, M. A.; Choksi, T. S.; Valle, E.; Upham, D. C.; Schumann, J.; Duyar, M. S.; Gallo, A.; Abild-Pedersen, F.; Jaramillo, T. F., Revealing the Synergy between Oxide and Alloy Phases on the Performance of Bimetallic In-Pd Catalysts for CO2 Hydrogenation to Methanol. ACS Catal. 2019, 9, 3399-3412.

163. Chen, T.-y.; Cao, C.; Chen, T.-b.; Ding, X.; Huang, H.; Shen, L.; Cao, X.; Zhu, M.; Xu, J.; Gao, J.; Han, Y.-F., Unraveling Highly Tunable Selectivity in CO2 Hydrogenation over Bimetallic In-Zr Oxide Catalysts. ACS Catal. 2019, 9, 8785-8797.

164. Frei, M. S.; Mondelli, C.; García-Muelas, R.; Kley, K. S.; Puértolas, B.; López, N.; Safonova, O. V.; Stewart, J. A.; Curulla Ferré, D.; Pérez-Ramírez, J., Atomic-scale engineering of indium oxide promotion by palladium for methanol production via $\mathrm{CO} 2$ hydrogenation. Nat. Commun. 2019, 10, 3377.

165. Bavykina, A.; Yarulina, I.; Al Abdulghani, A. J.; Gevers, L.; Hedhili, M. N.; Miao, X.; Galilea, A. R.; Pustovarenko, A.; Dikhtiarenko, A.; Cadiau, A.; Aguilar-Tapia, A.; Hazemann, J.-L.; Kozlov, S. M.; Oud-Chikh, S.; Cavallo, L.; Gascon, J., Turning a Methanation Co Catalyst into an In-Co Methanol Producer. ACS Catal. 2019, 6910-6918.

166. Pustovarenko, A.; Dikhtiarenko, A.; Bavykina, A.; Gevers, L.; Ramírez, A.; Russkikh, A.; Telalovic, S.; Aguilar, A.; Hazemann, J.-L.; Ould-Chikh, S.; Gascon, J., Metal-Organic FrameworkDerived Synthesis of Cobalt Indium Catalysts for the Hydrogenation of $\mathrm{CO} 2$ to Methanol. ACS Catal. 2020, 10, 5064-5076.

167. Jia, X.; Sun, K.; Wang, J.; Shen, C.; Liu, C.-j., Selective hydrogenation of CO2 to methanol over $\mathrm{Ni} / \mathrm{In} 2 \mathrm{O} 3$ catalyst. J. Energy Chem. 2020, 50, 409-415.

168. Jiang, H.; Lin, J.; Wu, X.; Wang, W.; Chen, Y.; Zhang, M., Efficient hydrogenation of CO2 to methanol over Pd/In2O3/SBA-15 catalysts. J. CO2 Util. 2020, 36, 33-39.

169. Yao, L.; Shen, X.; Pan, Y.; Peng, Z., Synergy between active sites of Cu-In-Zr-O catalyst in CO2 hydrogenation to methanol. J. Catal. 2019, 372, 74-85. 
170. Frei, M. S.; Mondelli, C.; Cesarini, A.; Krumeich, F.; Hauert, R.; Stewart, J. A.; Curulla Ferré, D.; Pérez-Ramírez, J., Role of Zirconia in Indium Oxide-Catalyzed CO2 Hydrogenation to Methanol. ACS Catal. 2020, 10, 1133-1145.

171. Jiang, X.; Nie, X.; Gong, Y.; Moran, C. M.; Wang, J.; Zhu, J.; Chang, H.; Guo, X.; Walton, K. S.; Song, C., A combined experimental and DFT study of $\mathrm{H} 2 \mathrm{O}$ effect on In2O3/ZrO2 catalyst for CO2 hydrogenation to methanol. J. Catal. 2020, 383, 283-296.

172. Jiang, X.; Nie, X.; Wang, X.; Wang, H.; Koizumi, N.; Chen, Y.; Guo, X.; Song, C., Origin of Pd$\mathrm{Cu}$ bimetallic effect for synergetic promotion of methanol formation from $\mathrm{CO} 2$ hydrogenation. J. Catal. 2019, 369, 21-32.

173. Nie, X.; Jiang, X.; Wang, H.; Luo, W.; Janik, M. J.; Chen, Y.; Guo, X.; Song, C., Mechanistic Understanding of Alloy Effect and Water Promotion for $\mathrm{Pd}-\mathrm{Cu}$ Bimetallic Catalysts in $\mathrm{CO} 2$ Hydrogenation to Methanol. ACS Catal. 2018, 8, 4873-4892.

174. Yang, X.; Kattel, S.; Senanayake, S. D.; Boscoboinik, J. A.; Nie, X.; Graciani, J.; Rodriguez, J. A.; Liu, P.; Stacchiola, D. J.; Chen, J. G., Low Pressure CO2 Hydrogenation to Methanol over Gold Nanoparticles Activated on a CeOx/TiO2 Interface. J. Am. Chem. Soc. 2015, 137, 10104-10107.

175. Wang, L.; Zhang, W.; Zheng, X.; Chen, Y.; Wu, W.; Qiu, J.; Zhao, X.; Zhao, X.; Dai, Y.; Zeng, J., Incorporating nitrogen atoms into cobalt nanosheets as a strategy to boost catalytic activity toward CO2 hydrogenation. Nat. Energy 2017, 2, 869-876.

176. Li, H.; Wang, L.; Dai, Y.; Pu, Z.; Lao, Z.; Chen, Y.; Wang, M.; Zheng, X.; Zhu, J.; Zhang, W.; Si, R.; Ma, C.; Zeng, J., Synergetic interaction between neighbouring platinum monomers in CO2 hydrogenation. Nat. Nanotechnol. 2018, 13, 411-417.

177. Khan, M. U.; Wang, L.; Liu, Z.; Gao, Z.; Wang, S.; Li, H.; Zhang, W.; Wang, M.; Wang, Z.; Ma, C.; Zeng, J., Pt3Co Octapods as Superior Catalysts of CO2 Hydrogenation. Angew. Chem. Int. Ed. 2016, 55, 9548-9552.

178. Zhang, W.; Wang, L.; Liu, H.; Hao, Y.; Li, H.; Khan, M. U.; Zeng, J., Integration of Quantum Confinement and Alloy Effect to Modulate Electronic Properties of RhW Nanocrystals for Improved Catalytic Performance toward CO2 Hydrogenation. Nano Lett. 2017, 17, 788-793.

179. Makertiharta, I. G. B. N.; Dharmawijaya, P. T.; Wenten, I. G., Current progress on zeolite membrane reactor for $\mathrm{CO} 2$ hydrogenation. AIP Conf. Proc. 2017, 1788, 040001.

180. Ting, K. W.; Toyao, T.; Siddiki, S. M. A. H.; Shimizu, K.-i., Low-Temperature Hydrogenation of CO2 to Methanol over Heterogeneous TiO2-Supported Re Catalysts. ACS Catal. 2019, 9, 3685-3693.

181. Gothe, M. L.; Pérez-Sanz, F. J.; Braga, A. H.; Borges, L. R.; Abreu, T. F.; Bazito, R. C.; Gonçalves, R. V.; Rossi, L. M.; Vidinha, P., Selective CO2 hydrogenation into methanol in a supercritical flow process. J. CO2 Util. 2020, 40, 101195.

182. Yong, L.; Yi, Z.; Tiejun, W.; Noritatsu, T., Efficient Conversion of Carbon Dioxide to Methanol Using Copper Catalyst by a New Low-temperature Hydrogenation Process. Chem. Lett. 2007, 36, 11821183.

183. Shi, L.; Yang, G.; Tao, K.; Yoneyama, Y.; Tan, Y.; Tsubaki, N., An Introduction of CO2 Conversion by Dry Reforming with Methane and New Route of Low-Temperature Methanol Synthesis. Acc. Chem. Res. 2013, 46, 1838-1847.

184. Chen, F.; Zhang, P.; Zeng, Y.; Kosol, R.; Xiao, L.; Feng, X.; Li, J.; Liu, G.; Wu, J.; Yang, G.; Yoneyama, Y.; Tsubaki, N., Vapor-phase low-temperature methanol synthesis from CO2-containing syngas via self-catalysis of methanol and $\mathrm{Cu} / \mathrm{ZnO}$ catalysts prepared by solid-state method. Appl. Catal. B: Environ. 2020, 279, 119382.

185. Shi, Z.; Tan, Q.; Wu, D., A novel Core-Shell structured CuIn@SiO2 catalyst for CO2 hydrogenation to methanol. AIChE J. 2019, 65, 1047-1058.

186. Kurakata, H.; Izumi, Y.; Aika, K.-i., Ethanol synthesis from carbon dioxide on TiO2-supported [Rh10Se] catalyst. Chem. Commun. 1996, 389-390.

187. Inui, T.; Yamamoto, T.; Inoue, M.; Hara, H.; Takeguchi, T.; Kim, J.-B., Highly effective synthesis of ethanol by $\mathrm{CO} 2$-hydrogenation on well balanced multi-functional FT-type composite catalysts. Appl. Catal. A: Gen. 1999, 186, 395-406. 
188. Li, S.; Guo, H.; Luo, C.; Zhang, H.; Xiong, L.; Chen, X.; Ma, L., Effect of Iron Promoter on Structure and Performance of $\mathrm{K} / \mathrm{Cu}-\mathrm{Zn}$ Catalyst for Higher Alcohols Synthesis from CO2 Hydrogenation. Catal. Lett. 2013, 143, 345-355.

189. He, Z.; Qian, Q.; Ma, J.; Meng, Q.; Zhou, H.; Song, J.; Liu, Z.; Han, B., Water-Enhanced Synthesis of Higher Alcohols from CO2 Hydrogenation over a Pt/Co3O4 Catalyst under Milder Conditions. Angew. Chem. Int. Ed. 2016, 55, 737-741.

190. Liu, B.; Ouyang, B.; Zhang, Y.; Lv, K.; Li, Q.; Ding, Y.; Li, J., Effects of mesoporous structure and Pt promoter on the activity of Co-based catalysts in low-temperature $\mathrm{CO} 2$ hydrogenation for higher alcohol synthesis. J. Catal. 2018, 366, 91-97.

191. Ouyang, B.; Xiong, S.; Zhang, Y.; Liu, B.; Li, J., The study of morphology effect of Pt/Co3O4 catalysts for higher alcohol synthesis from CO2 hydrogenation. Appl. Catal. A: Gen. 2017, 543, 189-195.

192. Yang, C.; Mu, R.; Wang, G.; Song, J.; Tian, H.; Zhao, Z.-J.; Gong, J., Hydroxyl-mediated ethanol selectivity of CO2 hydrogenation. Chem. Sci. 2019, 10, 3161-3167.

193. Wang, G.; Luo, R.; Yang, C.; Song, J.; Xiong, C.; Tian, H.; Zhao, Z.-J.; Mu, R.; Gong, J., Active sites in CO2 hydrogenation over confined VOx-Rh catalysts. Sci. China Chem. 2019, 62, 1710-1719.

194. Bai, S.; Shao, Q.; Wang, P.; Dai, Q.; Wang, X.; Huang, X., Highly Active and Selective Hydrogenation of $\mathrm{CO} 2$ to Ethanol by Ordered Pd-Cu Nanoparticles. J. Am. Chem. Soc. 2017, 139, 68276830.

195. Caparrós, F. J.; Soler, L.; Rossell, M. D.; Angurell, I.; Piccolo, L.; Rossell, O.; Llorca, J., Remarkable Carbon Dioxide Hydrogenation to Ethanol on a Palladium/Iron Oxide Single-Atom Catalyst. ChemCatChem 2018, 10, 2365-2369.

196. Wang, D.; Bi, Q.; Yin, G.; Zhao, W.; Huang, F.; Xie, X.; Jiang, M., Direct synthesis of ethanol via CO2 hydrogenation using supported gold catalysts. Chem. Commun. 2016, 52, 14226-14229.

197. Wang, D.; Bi, Q.; Yin, G.; Wang, P.; Huang, F.; Xie, X.; Jiang, M., Photochemical Preparation of Anatase Titania Supported Gold Catalyst for Ethanol Synthesis from CO2 Hydrogenation. Catal. Lett. 2018, 148, 11-22.

198. Wang, L.; Wang, L.; Zhang, J.; Liu, X.; Wang, H.; Zhang, W.; Yang, Q.; Ma, J.; Dong, X.; Yoo, S. J.; Kim, J.-G.; Meng, X.; Xiao, F.-S., Selective Hydrogenation of CO2 to Ethanol over Cobalt Catalysts. Angew. Chem. Int. Ed. 2018, 57, 6104-6108.

199. Wang, L.; He, S.; Wang, L.; Lei, Y.; Meng, X.; Xiao, F.-S., Cobalt-Nickel Catalysts for Selective Hydrogenation of Carbon Dioxide into Ethanol. ACS Catal. 2019, 9, 11335-11340.

200. Zhang, S.; Liu, X.; Shao, Z.; Wang, H.; Sun, Y., Direct CO2 hydrogenation to ethanol over supported Co2C catalysts: Studies on support effects and mechanism. J. Catal. 2020, 382, 86-96.

201. An, B.; Li, Z.; Song, Y.; Zhang, J.; Zeng, L.; Wang, C.; Lin, W., Cooperative copper centres in a metal-organic framework for selective conversion of CO2 to ethanol. Nat. Catal. 2019, 2, 709-717.

202. Xu, D.; Ding, M.; Hong, X.; Liu, G.; Tsang, S. C. E., Selective C2+ Alcohol Synthesis from Direct CO2 Hydrogenation over a Cs-Promoted Cu-Fe-Zn Catalyst. ACS Catal. 2020, 10, 5250-5260.

203. Zhao, B.; Liu, Y.; Zhu, Z.; Guo, H.; Ma, X., Highly selective conversion of CO2 into ethanol on $\mathrm{Cu} / \mathrm{ZnO} / \mathrm{Al} 2 \mathrm{O} 3$ catalyst with the assistance of plasma. J. CO2 Util. 2018, 24, 34-39.

204. Yang, H.; Zhang, C.; Gao, P.; Wang, H.; Li, X.; Zhong, L.; Wei, W.; Sun, Y., A Review of the Catalytic Hydrogenation of Carbon Dioxide into Value-Added Hydrocarbons. Catal. Sci. Technol. 2017, 7, 4580-4598.

205. Guo, L.; Sun, J.; Ge, Q.; Tsubaki, N., Recent Advances in Direct Catalytic Hydrogenation of Carbon Dioxide to Valuable C2+ Hydrocarbons. J. Mater. Chem. A 2018, 6, 23244-23262.

206. Chang, Q.; Zhang, C.; Liu, C.; Wei, Y.; Cheruvathur, A. V.; Dugulan, A. I.; Niemantsverdriet, J. W.; Liu, X.; He, Y.; Qing, M.; Zheng, L.; Yun, Y.; Yang, Y.; Li, Y., Relationship between Iron Carbide Phases $(\varepsilon-\mathrm{Fe} 2 \mathrm{C}, \mathrm{Fe} 7 \mathrm{C} 3$, and $\chi$-Fe5C2) and Catalytic Performances of $\mathrm{Fe} / \mathrm{SiO} 2$ Fischer-Tropsch Catalysts. ACS Catal. 2018, 8, 3304-3316.

207. Marques Mota, F.; Kim, D. H., From CO2 methanation to ambitious long-chain hydrocarbons: alternative fuels paving the path to sustainability. Chem. Soc. Rev. 2019, 48, 205-259. 
208. Dokania, A.; Ramirez, A.; Bavykina, A.; Gascon, J., Heterogeneous Catalysis for the Valorization of $\mathrm{CO}_{2}$ : Role of Bifunctional Processes in the Production of Chemicals. ACS Energy Lett. 2019, 4, 167-176.

209. Ma, Z.; Porosoff, M. D., Development of Tandem Catalysts for CO2 Hydrogenation to Olefins. ACS Catal. 2019, 9, 2639-2656.

210. Gao, Y.; Liu, S.; Zhao, Z.; Tao, H.; Sun, Z., Heterogeneous Catalysis of CO2 Hydrogenation to C2+ Products. Acta Phys. -Chim. Sin. 2018, 34, 858-872.

211. Centi, G.; Perathoner, S., Green Carbon Dioxide: Advances in CO2 Utilization. John Wiley \& Sons: Hoboken, NJ, 2014; p 1-303.

212. You, Z.; Deng, W.; Zhang, Q.; Wang, Y., Hydrogenation of carbon dioxide to light olefins over non-supported iron catalyst. Chin. J. Catal. 2013, 34, 956-963.

213. Visconti, C. G.; Martinelli, M.; Falbo, L.; Infantes-Molina, A.; Lietti, L.; Forzatti, P.; Iaquaniello, G.; Palo, E.; Picutti, B.; Brignoli, F., CO2 hydrogenation to lower olefins on a high surface area Kpromoted bulk Fe-catalyst. Appl. Catal. B: Environ. 2017, 200, 530-542.

214. Wu, T.; Lin, J.; Cheng, Y.; Tian, J.; Wang, S.; Xie, S.; Pei, Y.; Yan, S.; Qiao, M.; Xu, H.; Zong, B., Porous Graphene-Confined Fe-K as Highly Efficient Catalyst for CO2 Direct Hydrogenation to Light Olefins. ACS Appl. Mater. Interfaces 2018, 10, 23439-23443.

215. Gnanamani, M. K.; Hamdeh, H. H.; Shafer, W. D.; Hopps, S. D.; Davis, B. H., Hydrogenation of carbon dioxide over iron carbide prepared from alkali metal promoted iron oxalate. Appl. Catal. A: Gen. 2018, 564, 243-249.

216. Ramirez, A.; Ould-Chikh, S.; Gevers, L.; Dutta Chowdhury, A.; Abou Hamad, E.; Aguilar, A.; Hazemann, J.-L.; Wehbe, N.; Al Abdulghani, A. J.; Kozlov, S.; Cavallo, L.; Gascon, J., Tandem conversion of $\mathrm{CO} 2$ to valuable hydrocarbons in highly concentrated potassium iron catalysts. ChemCatChem 2019, 11, 2879-2886.

217. Wang, S.; Wu, T.; Lin, J.; Ji, Y.; Yan, S.; Pei, Y.; Xie, S.; Zong, B.; Qiao, M., Iron-Potassium on Single-Walled Carbon Nanotubes as Efficient Catalyst for CO2 Hydrogenation to Heavy Olefins. ACS Catal. 2020, 6389-6401.

218. Wang, X.; Wu, D.; Zhang, J.; Gao, X.; Ma, Q.; Fan, S.; Zhao, T.-S., Highly selective conversion of $\mathrm{CO} 2$ to light olefins via Fischer-Tropsch synthesis over stable layered $\mathrm{K}-\mathrm{Fe}-\mathrm{Ti}$ catalysts. Appl. Catal. A: Gen. 2019, 573, 32-40.

219. Ramirez, A.; Gevers, L.; Bavykina, A.; Ould-Chikh, S.; Gascon, J., Metal Organic FrameworkDerived Iron Catalysts for the Direct Hydrogenation of CO2 to Short Chain Olefins. ACS Catal. 2018, 8, 9174-9182.

220. Shafer, W. D.; Jacobs, G.; Graham, U. M.; Hamdeh, H. H.; Davis, B. H., Increased CO2 hydrogenation to liquid products using promoted iron catalysts. J. Catal. 2019, 369, 239-248.

221. Russkikh, A.; Shterk, G.; Al-Solami, B. H.; Fadhel, B. A.; Ramirez, A.; Gascon, J., Turning Waste into Value: Potassium-Promoted Red Mud as an Effective Catalyst for the Hydrogenation of CO2. ChemSusChem 2020, 13, 2981-2987.

222. Wei, J.; Sun, J.; Wen, Z.; Fang, C.; Ge, Q.; Xu, H., New insights into the effect of sodium on Fe3O4- based nanocatalysts for CO2 hydrogenation to light olefins. Catal. Sci. Technol. 2016, 6, 47864793.

223. Cui, X.; Gao, P.; Li, S.; Yang, C.; Liu, Z.; Wang, H.; Zhong, L.; Sun, Y., Selective Production of Aromatics Directly from Carbon Dioxide Hydrogenation. ACS Catal. 2019, 9, 3866-3876.

224. Liang, B.; Duan, H.; Sun, T.; Ma, J.; Liu, X.; Xu, J.; Su, X.; Huang, Y.; Zhang, T., Effect of Na Promoter on Fe-Based Catalyst for CO2 Hydrogenation to Alkenes. ACS Sustainable Chem. Eng. 2019, 7, 925-932.

225. Liang, B.; Sun, T.; Ma, J.; Duan, H.; Li, L.; Yang, X.; Zhang, Y.; Su, X.; Huang, Y.; Zhang, T., Mn decorated $\mathrm{Na} / \mathrm{Fe}$ catalysts for $\mathrm{CO} 2$ hydrogenation to light olefins. Catal. Sci. Technol. 2019, 9, 456464. 
226. Liu, J.; Zhang, A.; Jiang, X.; Liu, M.; Sun, Y.; Song, C.; Guo, X., Selective CO2 Hydrogenation to Hydrocarbons on $\mathrm{Cu}$-Promoted Fe-Based Catalysts: Dependence on $\mathrm{Cu}-\mathrm{Fe}$ Interaction. ACS Sustainable Chem. Eng. 2018, 6, 10182-10190.

227. Gnanamani, M. K.; Jacobs, G.; Hamdeh, H. H.; Shafer, W. D.; Liu, F.; Hopps, S. D.; Thomas, G. A.; Davis, B. H., Hydrogenation of Carbon Dioxide over Co-Fe Bimetallic Catalysts. ACS Catal. 2016, 6, 913-927.

228. Gnanamani, M. K.; Hamdeh, H. H.; Jacobs, G.; Shafer, W. D.; Hopps, S. D.; Thomas, G. A.; Davis, B. H., Hydrogenation of Carbon Dioxide over K-Promoted FeCo Bimetallic Catalysts Prepared from Mixed Metal Oxalates. ChemCatChem 2017, 9, 1303-1312.

229. Boreriboon, N.; Jiang, X.; Song, C.; Prasassarakich, P., Fe-based bimetallic catalysts supported on $\mathrm{TiO} 2$ for selective $\mathrm{CO} 2$ hydrogenation to hydrocarbons. J. CO2 Util. 2018, 25, 330-337.

230. Guo, L.; Cui, Y.; Zhang, P.; Peng, X.; Yoneyama, Y.; Yang, G.; Tsubaki, N., Enhanced Liquid Fuel Production from CO2 Hydrogenation: Catalytic Performance of Bimetallic Catalysts over a TwoStage Reactor System. ChemistrySelect 2018, 3, 13705-13711.

231. Aitbekova, A.; Goodman, E. D.; Wu, L.; Boubnov, A.; Hoffman, A. S.; Genc, A.; Cheng, H.; Casalena, L.; Bare, S. R.; Cargnello, M., Engineering of Ruthenium-Iron Oxide Colloidal Heterostructures: Improved Yields in $\mathrm{CO} 2$ Hydrogenation to Hydrocarbons. Angew. Chem. Int. Ed. 2019, $58,17451-17457$.

232. Gnanamani, M. K.; Jacobs, G.; Keogh, R. A.; Shafer, W. D.; Sparks, D. E.; Hopps, S. D.; Thomas, G. A.; Davis, B. H., Fischer-Tropsch synthesis: Effect of pretreatment conditions of cobalt on activity and selectivity for hydrogenation of carbon dioxide. Appl. Catal. A: Gen. 2015, 499, 39-46.

233. Owen, R. E.; Plucinski, P.; Mattia, D.; Torrente-Murciano, L.; Ting, V. P.; Jones, M. D., Effect of support of Co-Na-Mo catalysts on the direct conversion of $\mathrm{CO} 2$ to hydrocarbons. J. CO2 Util. 2016, 16, 97-103.

234. Xie, C.; Chen, C.; Yu, Y.; Su, J.; Li, Y.; Somorjai, G. A.; Yang, P., Tandem Catalysis for CO2 Hydrogenation to C2-C4 Hydrocarbons. Nano Lett. 2017, 17, 3798-3802.

235. Wei, J.; Yao, R.; Ge, Q.; Wen, Z.; Ji, X.; Fang, C.; Zhang, J.; Xu, H.; Sun, J., Catalytic Hydrogenation of $\mathrm{CO}_{2}$ to Isoparaffins over Fe-Based Multifunctional Catalysts. ACS Catal. 2018, 8, 9958-9967.

236. Ramirez, A.; Dutta Chowdhury, A.; Dokania, A.; Cnudde, P.; Caglayan, M.; Yarulina, I.; AbouHamad, E.; Gevers, L.; Ould-Chikh, S.; De Wispelaere, K.; van Speybroeck, V.; Gascon, J., Effect of Zeolite Topology and Reactor Configuration on the Direct Conversion of $\mathrm{CO}_{2}$ to Light Olefins and Aromatics. ACS Catal. 2019, 9, 6320-6334.

237. Dokania, A.; Dutta Chowdhury, A.; Ramirez, A.; Telalovic, S.; Abou-Hamad, E.; Gevers, L.; Ruiz-Martinez, J.; Gascon, J., Acidity modification of ZSM-5 for enhanced production of light olefins from CO2. J. Catal. 2020, 381, 347-354.

238. Ramirez, A.; Dutta Chowdhury, A.; Caglayan, M.; Rodriguez-Gomez, A.; Wehbe, N.; AbouHamad, E.; Gevers, L.; Ould-Chikh, S.; Gascon, J., Coated sulfated zirconia/SAPO-34 for the direct conversion of CO2 to light olefins. Catal. Sci. Technol. 2020, 10, 1507-1517.

239. Xu, Y.; Shi, C.; Liu, B.; Wang, T.; Zheng, J.; Li, W.; Liu, D.; Liu, X., Selective production of aromatics from CO2. Catal. Sci. Technol. 2019, 9, 593-610.

240. Fujimoto, K.; Shikada, T., Selective Synthesis of $\mathrm{C}_{2}-\mathrm{C}_{5}$ Hydrocarbons from Carbon Dioxide Utilizing a Hybrid Catalyst Composed of a Methanol Synthesis Catalyst and Zeolite. Appl. Catal. 1987, 31, 13-23.

241. Chen, J.; Wang, X.; Wu, D.; Zhang, J.; Ma, Q.; Gao, X.; Lai, X.; Xia, H.; Fan, S.; Zhao, T.-S., Hydrogenation of $\mathrm{CO}_{2}$ to Light Olefins on CuZnZr@(Zn-)SAPO-34 Catalysts: Strategy for Product Distribution. Fuel 2019, 239, 44-52.

242. Li, Z.; Wang, J.; Qu, Y.; Liu, H.; Tang, C.; Miao, S.; Feng, Z.; An, H.; Li, C., Highly Selective Conversion of Carbon Dioxide to Lower Olefins. ACS Catal. 2017, 7, 8544-8548. 
243. Gao, P.; Dang, S.; Li, S.; Bu, X.; Liu, Z.; Qiu, M.; Yang, C.; Wang, H.; Zhong, L.; Han, Y.; Liu, Q.; Wei, W.; Sun, Y., Direct Production of Lower Olefins from $\mathrm{CO}_{2}$ Conversion via Bifunctional Catalysis. ACS Catal. 2018, 8, 571-578.

244. Dang, S.; Gao, P.; Liu, Z.; Chen, X.; Yang, C.; Wang, H.; Zhong, L.; Li, S.; Sun, Y., Role of Zirconium in Direct $\mathrm{CO}_{2}$ Hydrogenation to Lower Olefins on Oxide/Zeolite Bifunctional Catalysts. $J$. Catal. 2018, 364, 382-393.

245. Wang, J.; Zhang, A.; Jiang, X.; Song, C.; Guo, X., Highly Selective Conversion of $\mathrm{CO}_{2}$ to Lower Hydrocarbons $\left(\mathrm{C}_{2}-\mathrm{C}_{4}\right)$ over Bifunctional Catalysts Composed of $\mathrm{In}_{2} \mathrm{O}_{3}-\mathrm{ZrO}_{2}$ and Zeolite. J. CO2 Util. 2018, 27, 81-88.

246. Numpilai, T.; Wattanakit, C.; Chareonpanich, M.; Limtrakul, J.; Witoon, T., Optimization of Synthesis Condition for $\mathrm{CO}_{2}$ Hydrogenation to Light Olefins over $\operatorname{In}_{2} \mathrm{O}_{3}$ Admixed with SAPO-34. Energy Convers. Manag. 2019, 180, 511-523.

247. Liu, X.; Wang, M.; Zhou, C.; Zhou, W.; Cheng, K.; Kang, J.; Zhang, Q.; Deng, W.; Wang, Y., Selective Transformation of Carbon Dioxide into Lower Olefins with a Bifunctional Catalyst Composed of $\mathrm{ZnGa}_{2} \mathrm{O}_{4}$ and SAPO-34. Chem. Commun. 2018, 54, 140-143.

248. Jiao, F.; Li, J.; Pan, X.; Xiao, J.; Li, H.; Ma, H.; Wei, M.; Pan, Y.; Zhou, Z.; Li, M.; Miao, S.; Li, J.; Zhu, Y.; Xiao, D.; He, T.; Yang, J.; Qi, F.; Fu, Q.; Bao, X., Selective conversion of syngas to light olefins. Science 2016, 351, 1065-1068.

249. Wang, Y.; Tan, L.; Tan, M.; Zhang, P.; Fang, Y.; Yoneyama, Y.; Yang, G.; Tsubaki, N., Rationally Designing Bifunctional Catalysts as an Efficient Strategy To Boost $\mathrm{CO}_{2}$ Hydrogenation Producing Value-Added Aromatics. ACS Catal. 2019, 9, 895-901.

250. Ni, Y.; Chen, Z.; Fu, Y.; Liu, Y.; Zhu, W.; Liu, Z., Selective Conversion of $\mathrm{CO}_{2}$ and $\mathrm{H}_{2}$ into Aromatics. Nat. Commun. 2018, 9, 3457.

251. Zhang, J.; Zhang, M.; Chen, S.; Wang, X.; Zhou, Z.; Wu, Y.; Zhang, T.; Yang, G.; Han, Y.; Tan, Y., Hydrogenation of $\mathrm{CO}_{2}$ into Aromatics over a $\mathrm{ZnCrOx}-\mathrm{Zeolite}$ Composite Catalyst. Chem. Commun. 2019, 55, 973-976.

252. Zhang, X.; Zhang, A.; Jiang, X.; Zhu, J.; Liu, J.; Li, J.; Zhang, G.; Song, C.; Guo, X., Utilization of $\mathrm{CO}_{2}$ for Aromatics Production over $\mathrm{ZnO} / \mathrm{ZrO}_{2}-\mathrm{ZSM}-5$ Tandem Catalyst. J. CO2 Util. 2019, 29, 140145.

253. Yarulina, I.; Chowdhury, A. D.; Meirer, F.; Weckhuysen, B. M.; Gascon, J., Recent trends and fundamental insights in the methanol-to-hydrocarbons process. Nat. Catal. 2018, 1, 398-411.

254. Olsbye, U.; Svelle, S.; Bjørgen, M.; Beato, P.; Janssens, T. V. W.; Joensen, F.; Bordiga, S.; Lillerud, K. P., Conversion of Methanol to Hydrocarbons: How Zeolite Cavity and Pore Size Controls Product Selectivity. Angew. Chem. Int. Ed. 2012, 51, 5810-5831.

255. Ilias, S.; Bhan, A., Mechanism of the Catalytic Conversion of Methanol to Hydrocarbons. ACS Catal. 2013, 3, 18-31.

256. Sun, X.; Mueller, S.; Liu, Y.; Shi, H.; Haller, G. L.; Sanchez-Sanchez, M.; van Veen, A. C.; Lercher, J. A., On reaction pathways in the conversion of methanol to hydrocarbons on HZSM-5. $J$. Catal. 2014, 317, 185-197.

257. Dang, S.; Li, S.; Yang, C.; Chen, X.; Li, X.; Zhong, L.; Gao, P.; Sun, Y., Selective Transformation of $\mathrm{CO} 2$ and $\mathrm{H} 2$ into Lower Olefins over In2O3-ZnZrOx/SAPO-34 Bifunctional Catalysts. ChemSusChem 2019, 12, 3582-3591.

258. Liu, J.; Zhang, A.; Jiang, X.; Zhang, G.; Sun, Y.; Liu, M.; Ding, F.; Song, C.; Guo, X., Overcoating the Surface of Fe-Based Catalyst with $\mathrm{ZnO}$ and Nitrogen-Doped Carbon toward High Selectivity of Light Olefins in CO2 Hydrogenation. Ind. Eng. Chem. Res. 2019, 58, 4017-4023.

259. Wang, S.; Wu, T.; Lin, J.; Tian, J.; Ji, Y.; Pei, Y.; Yan, S.; Qiao, M.; Xu, H.; Zong, B., FeK-on3D Graphene-Zeolite Tandem Catalyst with High Efficiency and Versatility in Direct CO2 Conversion to Aromatics. ACS Sustainable Chem. Eng. 2019.

260. Zhou, C.; Shi, J.; Zhou, W.; Cheng, K.; Zhang, Q.; Kang, J.; Wang, Y., Highly Active ZnO-ZrO2 Aerogels Integrated with H-ZSM-5 for Aromatics Synthesis from Carbon Dioxide. ACS Catal. 2020, 10, 302-310. 
261. Ghasemi, M.; Mohammadi, M.; Sedighi, M., Sustainable production of light olefins from greenhouse gas $\mathrm{CO} 2$ over SAPO-34 supported modified cerium oxide. Microporous Mesoporous Mater. 2020, 297, 110029.

262. Wang, Y.; Kazumi, S.; Gao, W.; Gao, X.; Li, H.; Guo, X.; Yoneyama, Y.; Yang, G.; Tsubaki, N., Direct conversion of $\mathrm{CO} 2$ to aromatics with high yield via a modified Fischer-Tropsch synthesis pathway. Appl. Catal. B: Environ. 2020, 269, 118792.

263. Villa, P.; Forzatti, P.; Buzzi-Ferraris, G.; Garone, G.; Pasquon, I., Synthesis of alcohols from carbon oxides and hydrogen. 1. Kinetics of the low-pressure methanol synthesis. Ind. Eng. Chem. Process Des. Dev. 1985, 24, 12-19.

264. Bussche, K. M. V.; Froment, G. F., A Steady-State Kinetic Model for Methanol Synthesis and the Water Gas Shift Reaction on a Commercial Cu/ZnO/Al2O3Catalyst. J. Catal. 1996, 161, 1-10.

265. Seidel, C.; Jörke, A.; Vollbrecht, B.; Seidel-Morgenstern, A.; Kienle, A., Kinetic modeling of methanol synthesis from renewable resources. Chem. Eng. Sci. 2018, 175, 130-138.

266. Graaf, G. H.; Winkelman, J. G. M., Chemical Equilibria in Methanol Synthesis Including the Water-Gas Shift Reaction: A Critical Reassessment. Ind. Eng. Chem. Res. 2016, 55, 5854-5864.

267. Slotboom, Y.; Bos, M. J.; Pieper, J.; Vrieswijk, V.; Likozar, B.; Kersten, S. R. A.; Brilman, D. W. F., Critical assessment of steady-state kinetic models for the synthesis of methanol over an industrial $\mathrm{Cu} / \mathrm{ZnO} / \mathrm{Al} 2 \mathrm{O} 3$ catalyst. Chem. Eng. J. 2020, 389, 124181.

268. Chiavassa, D. L.; Collins, S. E.; Bonivardi, A. L.; Baltanás, M. A., Methanol synthesis from $\mathrm{CO} 2 / \mathrm{H} 2$ using Ga2O3-Pd/silica catalysts: Kinetic modeling. Chem. Eng. J. 2009, 150, 204-212.

269. Ahmad, K.; Upadhyayula, S., Kinetics of CO2 hydrogenation to methanol over silica supported intermetallic Ga3Ni5 catalyst in a continuous differential fixed bed reactor. Int. J. Hydrogen Energy 2020, 45, 1140-1150.

270. Riedel, T.; Schaub, G.; Jun, K.-W.; Lee, K.-W., Kinetics of CO2 Hydrogenation on a KPromoted Fe Catalyst. Ind. Eng. Chem. Res. 2001, 40, 1355-1363.

271. Willauer, H. D.; Ananth, R.; Olsen, M. T.; Drab, D. M.; Hardy, D. R.; Williams, F. W., Modeling and kinetic analysis of $\mathrm{CO} 2$ hydrogenation using a $\mathrm{Mn}$ and K-promoted Fe catalyst in a fixed-bed reactor. J. CO2 Util. 2013, 3-4, 56-64.

272. Saeidi, S.; Najari, S.; Fazlollahi, F.; Nikoo, M. K.; Sefidkon, F.; Klemeš, J. J.; Baxter, L. L., Mechanisms and kinetics of $\mathrm{CO} 2$ hydrogenation to value-added products: A detailed review on current status and future trends. Renew. Sustain. Energy Rev. 2017, 80, 1292-1311.

273. Coronas, J.; Santamaría, J., Catalytic reactors based on porous ceramic membranes. Catal. Today 1999, 51, 377-389.

274. Li, H.; Qiu, C.; Ren, S.; Dong, Q.; Zhang, S.; Zhou, F.; Liang, X.; Wang, J.; Li, S.; Yu, M., Na+gated water-conducting nanochannels for boosting $\mathrm{CO}_{2}$ conversion to liquid fuels. Science 2020, 367, 667.

275. Gallucci, F.; Paturzo, L.; Basile, A., An experimental study of CO2 hydrogenation into methanol involving a zeolite membrane reactor. Chem. Eng. Process. 2004, 43, 1029-1036.

276. Chen, G.; Yuan, Q., Methanol synthesis from CO2 using a silicone rubber/ceramic composite membrane reactor. Sep. Purif. Technol. 2004, 34, 227-237.

277. Gallucci, F.; Basile, A., A theoretical analysis of methanol synthesis from $\mathrm{CO} 2$ and $\mathrm{H} 2$ in a ceramic membrane reactor. Int. J. Hydrogen Energy 2007, 32, 5050-5058.

278. Li, C.; Fujimoto, K., Efficient conversion of carbon dioxide to non-methane light hydrocarbons — Two stage process with intercooler. Fuel Process. Technol. 2015, 136, 50-55.

279. Kim, J.-S.; Lee, S.; Lee, S.-B.; Choi, M.-J.; Lee, K.-W., Performance of catalytic reactors for the hydrogenation of $\mathrm{CO} 2$ to hydrocarbons. Catal. Today 2006, 115, 228-234.

280. Cui, X.; Kær, S. K., A comparative study on three reactor types for methanol synthesis from syngas and CO2. Chem. Eng. J. 2020, 393, 124632.

281. Van-Dal, É. S.; Bouallou, C., Design and simulation of a methanol production plant from CO2 hydrogenation. J. Clean. Prod. 2013, 57, 38-45. 
282. Milani, D.; Khalilpour, R.; Zahedi, G.; Abbas, A., A model-based analysis of CO2 utilization in methanol synthesis plant. J. CO2 Util. 2015, 10, 12-22.

283. Pérez-Fortes, M.; Schöneberger, J. C.; Boulamanti, A.; Tzimas, E., Methanol synthesis using captured $\mathrm{CO} 2$ as raw material: Techno-economic and environmental assessment. Appl. Energy 2016, 161, 718-732.

284. Zhang, H.; Wang, L.; Maréchal, F.; Desideri, U., Techno-Economic Optimization of CO2-toMethanol with Solid-Oxide Electrolyzer. Energies 2019, 12, 3742.

285. Zhang, C.; Jun, K.-W.; Gao, R.; Kwak, G.; Park, H.-G., Efficient Way of Carbon Dioxide Utilization in a Gas-to-Methanol Process: From Fundamental Research to Industrial Demonstration. Top. Catal. 2018, 61, 1794-1809.

286. König, D. H.; Baucks, N.; Dietrich, R.-U.; Wörner, A., Simulation and evaluation of a process concept for the generation of synthetic fuel from CO2 and H2. Energy 2015, 91, 833-841.

287. Zhang, C.; Gao, R.; Jun, K.-W.; Kim, S. K.; Hwang, S.-M.; Park, H.-G.; Guan, G., Direct conversion of carbon dioxide to liquid fuels and synthetic natural gas using renewable power: Technoeconomic analysis. J. CO2 Util. 2019, 34, 293-302.

288. González-Garay, A.; Frei, M. S.; Al-Qahtani, A.; Mondelli, C.; Guillén-Gosálbez, G.; PérezRamírez, J., Plant-to-planet analysis of CO2-based methanol processes. Energy Environ. Sci. 2019, 12, 3425-3436.

289. Abanades, J. C.; Rubin, E. S.; Mazzotti, M.; Herzog, H. J., On the climate change mitigation potential of CO2 conversion to fuels. Energy Environ. Sci. 2017, 10, 2491-2499.

290. Glenk, G.; Reichelstein, S., Economics of converting renewable power to hydrogen. Nat. Energy 2019, 4, 216-222. 